OECD Health Working Papers No. 30

\title{
Improved Health System Performance through better Care Coordination
}

\section{Maria M. Hofmarcher,}

Howard Oxley,

Elena Rusticelli 


\section{IMPROVED HEALTH SYSTEM PERFORMANCE THROUGH BETTER CARE COORDINATION}

Maria M. Hofmarcher, Howard Oxley, and Elena Rusticelli

\section{0}


Organisation de Coopération et de Développement Economiques

Organisation for Economic Co-operation and Development

12-Dec-2007

DIRECTORATE FOR EMPLOYMENT, LABOUR AND SOCIAL AFFAIRS

English - Or. English HEALTH COMMITTEE

\section{Health Working Papers}

OECD HEALTH WORKING PAPER NO. 30

IMPROVED HEALTH SYSTEM PERFORMANCE THROUGH BETTER CARE COORDINATION

Maria M. Hofmarcher, Howard Oxley, and Elena Rusticelli 


\title{
DIRECTORATE FOR EMPLOYMENT, LABOUR AND SOCIAL AFFARIS
}

\section{OECD HEALTH WORKING PAPERS}

This series is designed to make available to a wider readership health studies prepared for use within the OECD. Authorship is usually collective, but principal writers are named. The papers are generally available only in their original language - English or French - with a summary in the other.

Comment on the series is welcome, and should be sent to the Directorate for Employment, Labour and Social Affairs, 2, rue André-Pascal, 75775 PARIS CEDEX 16, France.

The opinions expressed and arguments employed here are the responsibility of the author(s) and do not necessarily reflect those of the OECD

\section{Applications for permission to reproduce or translate \\ all or part of this material should be made to:}

\author{
Head of Publications Service \\ OECD \\ 2, rue André-Pascal \\ 75775 Paris, CEDEX 16 \\ France
}

Copyright OECD 2007 


\section{ACKNOWLEDGEMENTS}

This paper was prepared by Maria M. Hofmarcher-Holzhacker, Howard Oxley and Elena Rusticelli for the Health Division of the Directorate for Employment, Labour and Social Affairs. The authors would like to give particular thanks to countries who aided in the preparation of the questionnaire and those members of national administrations who took the time to fill it in. Within the OECD, support was received from Lihan Wei who helped designing the questionnaire and assured contact with the countries. Martin Strandberg-Larsen provided useful background work on a number of OECD countries. Helpful comments were received from John Martin, Martine Durand, Peter Scherer and Elizabeth Docteur as well as from many Delegates to the meeting. Marie-Christine Charlemagne, Gabrielle Luthy and Danna Pacheco provided technical support.

The basic funding for this project was received through general contributions from member countries of the OECD. In addition, voluntary contributions specifically in support of this project were received from Australia, Canada, Denmark, Finland, Hungary, Ireland, Japan, Korea, Mexico, The Netherlands, Norway and Spain.

The work was also supported by a grant provided by the Directorate General for Public Health and Consumer Affairs of the European Commission.

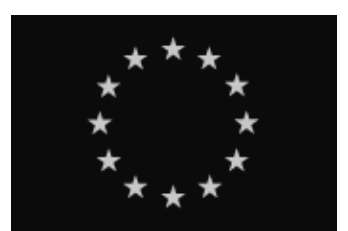




\section{TABLE OF CONTENTS}

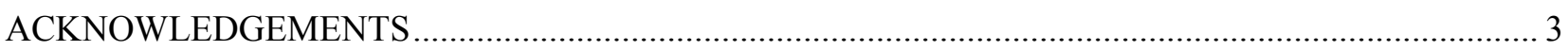

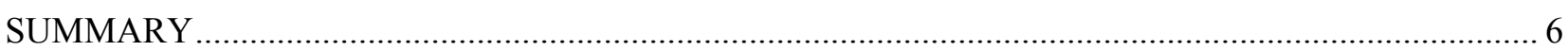

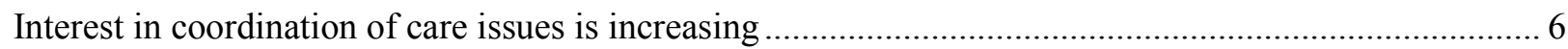

Targeted programmes appear to improve quality but evidence on cost-efficiency is inconclusive............ 6

Care coordination would be facilitated by better information transfer and wider use of ICT................... 7

The balance of resources going to ambulatory care may need to be reviewed ......................................... 7

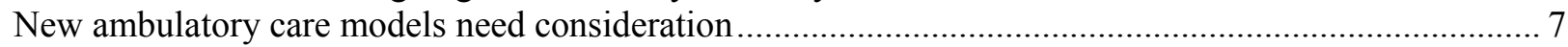

Care coordination may benefit from greater health-system integration ................................................... 7

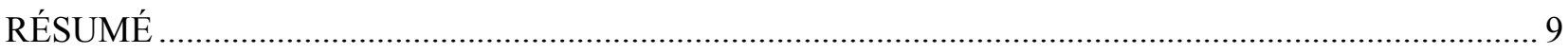

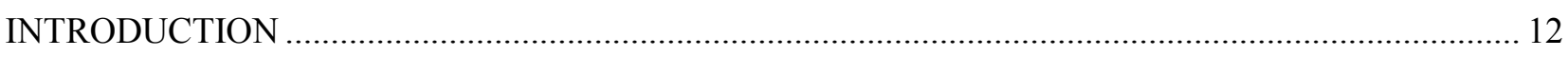

CHAPTER 1. COORDINATION OF CARE: ISSUES, OBJECTIVES AND PRACTICE .................. 15

1.1 Why care coordination issues are receiving greater attention ..................................................... 15

1.2 Which health-care goals might be better achieved from improved care coordination? ..................... 17

1.3 Evidence on current care-coordination practices in survey countries........................................... 19

CHAPTER 2. CONDITIONS FOR ACHIEVING BETTER CARE COORDINATION ..................... 26

2.1 More readily available information on patient health and on provider quality is needed .................. 26

2.2 The capacity of ambulatory care providers' to coordinate needs strengthening ................................ 31

2.3 Payment schemes need to be better aligned with system-wide objectives ....................................... 34

2.4 Regulatory and administrative barriers to cooperation across sectors need to be reduced .................. 40

CHAPTER 3. "TARGETED" CARE CO-ORDINATION PROGRAMMES AND POLICIES.............. 45

3.1 Experience with targeted programmes: a cross-country overview................................................... 45

3.2 The impact of disease/case management programmes: a review of recent literature ....................... 50

3.3 Some tentative conclusions: quality improvements may come at a cost........................................... 58

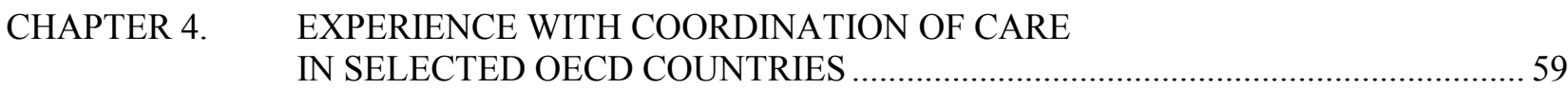

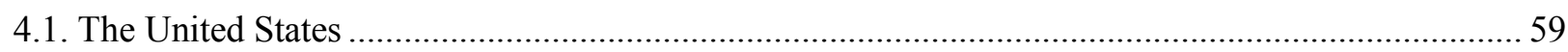

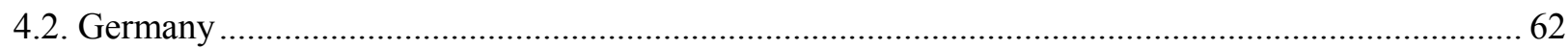

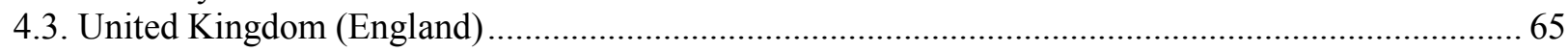

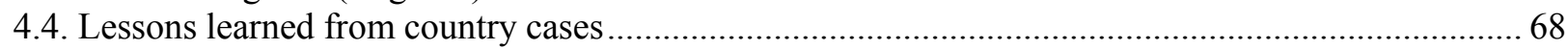

CHAPTER 5. SOME AREAS FOR POLICY CONSIDERATION ................................................... 69

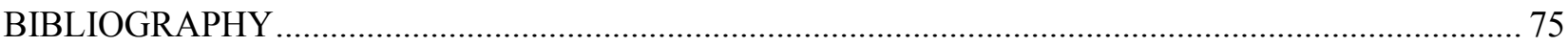




\section{Tables}

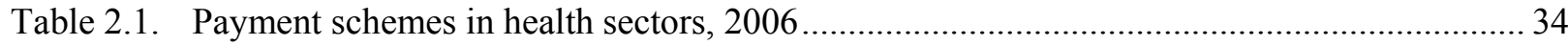

Box Table 1. The impact of payment schemes on the likelihood of reporting problems of care coordination... 36

Table 3.1. Share of countries reporting targeted programmes. 46

\section{Figures}

Figure 1.1 Population groups likely to benefit most from care coordination....................................... 17

Figure 1.2 Main goals of policies to improve care coordination ........................................................ 18

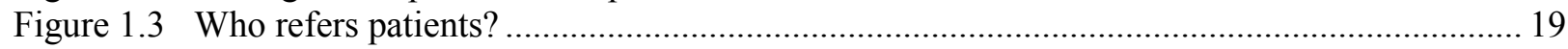

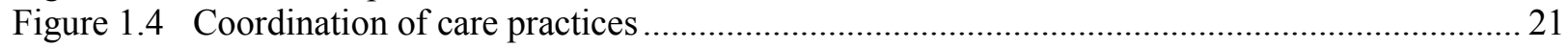

Figure 1.5 Where do problems of care coordination occur? ............................................................. 22

Figure 1.6 The role of primary-care providers at transition points between care settings ..................... 23

Figure 1.7 Patient management at the interface to long-term care...................................................... 24

Figure 1.8 Problems of care coordination and management of patients entering long-term care............ 25

Figure 2.1 Policy debates concerning care coordination at a national level ...................................... 27

Figure 2.2 Degree of information transfer between care settings .................................................... 28

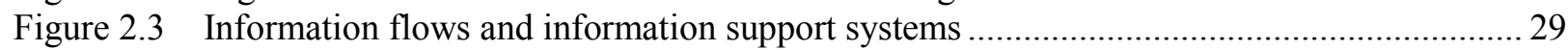

Figure 2.4 Expenditure by provider, in percent of total expenditure on health, 1995 and 2004 ............ 32

Figure 2.5 What are the incentives for care coordination? ............................................................... 38

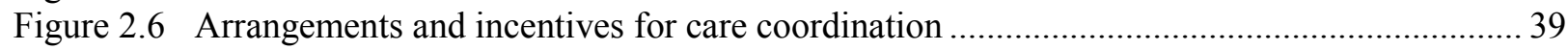

Figure 2.7 Do administrative barriers between sectors hamper coordination of care? .......................... 42

Figure 2.8 Regulations governing permitted activities on coordination of care ................................... 44

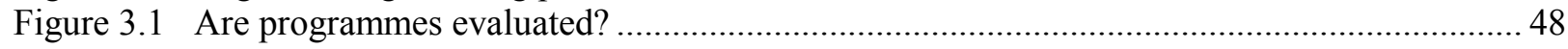

Figure 3.2 Have targeted programmes increased efficiency? ........................................................... 49

Figure 3.3 Have targeted programmes increased quality and patient responsiveness?..........................50

\section{Boxes}

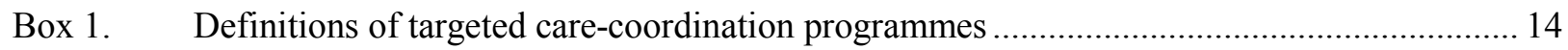

Box 2. Health-care costs and chronic disease: some evidence.................................................. 16

Box 3. Problems of care coordination and payment incentives ................................................. 36

Box 4. Targeted care coordination programmes in OECD countries............................................ 46

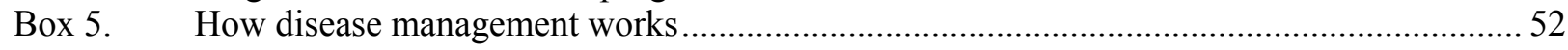




\section{SUMMARY}

This report attempts to assess whether -- and to what degree - better care coordination can improve health system performance in terms of quality and cost-efficiency. Coordination of care refers to policies that help create patient-centred care that is more coherent both within and across care settings and over time. Broadly speaking, it means making health-care systems more attentive to the needs of individual patients and ensuring they get the appropriate care for acute episodes as well as care aimed at stabilising their health over long periods in less costly environments. These issues are of particular interest to patients with chronic conditions and the elderly who may find it difficult to "navigate" fragmented health-care systems that are often found in OECD countries.

\section{Interest in coordination of care issues is increasing}

Growing interest in these issues has reflected a shift in the demands placed on health-care services. Chronic conditions have become progressively more important and are absorbing a growing share of health-care budgets. Since most of the chronically ill are elderly, this share can be expected to rise as populations age over coming decades. At the same time, many reports suggest that the quality of care that the chronically ill receive may need improvement. With these developments occurring in a context of tight public finance, some countries have been attempting to improve both the quality of care provided to the chronically ill and reduce cost pressures via changes to the architecture of health-care systems that encourage greater care coordination.

With consistent cross-country information on these issues largely absent, the Secretariat has used a questionnaire to canvass views and gather information on current care-coordination concerns, problems and practices in OECD and EU countries. Analysis of questionnaire results -- and of the literature more generally -- suggests that concern over care coordination issues is widespread among policy makers and health-care providers and the public at large. The recognition of this problem in combination with emerging care needs has stimulated a range of possible supply-side responses. Nonetheless, most policies appear to share the same broad intent of reducing the need for high-cost hospitalisation for the chronically ill by shifting the locus of policy attention and programmes towards ensuring high-quality, patient-centred care outside acute hospital settings.

\section{Targeted programmes appear to improve quality but evidence on cost-efficiency is inconclusive}

Much policy attention has been focused in recent years on "targeted" programmes (such as "disease and case management") aimed at specific illness or population groups. These programmes are intended to increase the quality of care through better follow-up of patients with chronic conditions. These programmes are expected to reduce overall demands on the health-care system by reducing unplanned hospital stays and the use of emergency services. Such arrangements were introduced first in the United States and, more recently, in Germany, United Kingdom and a few other countries. Numerous studies have attempted to evaluate these programmes, but they largely draw on the US experience. Current expert consensus suggests that such programmes appear to improve quality of care but are not always able to produce strong and consistent evidence of substantial financial savings. The latter could reflect the cost of set-up and operation of such programmes, difficulties in targeting those most likely to benefit and the fact that better follow-up often reveals unmet patient needs. To achieve consistently better performance of health-care systems, such targeted programmes may need to be developed within broader efforts to improve care coordination and to make care delivery more patient-centred. 
This study identifies four key areas where reforms could potentially enhance the capacity of healthcare systems to better coordinate care.

\section{Care coordination would be facilitated by better information transfer and wider use of ICT}

First, better collection and dissemination of information on patients and provider performance appear to be a cornerstone for building improved care coordination and system governance for quality. Organisation of referrals and the appropriateness of care are facilitated if patient information is recent, accurate and provided on a timely basis. System governance and improvement of the quality of care also depend on having up-to-date indicators of provider performance. While Information and Communications Technology (ICT) appears to hold promise as a vehicle for this purpose, the penetration of information technology has remained weak to date in many countries. According to the questionnaire, very few countries consider that providers are often equipped with ICT and only about one-third frequently have patient files in electronic format. Some countries have introduced or are considering the introduction of national systems allowing transfer of patient files. However, nation wide systems of information transfer are costly to introduce and the potential benefits need to be balanced against high start-up and operating costs. In this context, the achievement of adequate (social) returns on investment needs to be assured.

\section{The balance of resources going to ambulatory care may need to be reviewed}

Second, with the progressive shift in care from inpatient to ambulatory-care settings, governments may need to consider whether the relative share of overall resources allocated to the ambulatory sector is in line with the new patterns of demand. As mentioned, ambulatory care needs seem likely to grow accentuated as populations age over coming decades.

\section{New ambulatory care models need consideration}

Third, and possibly more important, policy makers need to adapt better their ambulatory-care models to the new demands placed on them by chronic disease While there is some presumption that professionals at the primary-care level are best placed to take on this role, multidisciplinary teams involving medical and non-medical professionals may be better placed to provide more coherent care, particularly for patients with multiple pathologies. Systems dominated by providers operating in solo practice and paid for on a fee-for-service basis may be less-well suited to meeting the care needs of the chronically ill. One specific avenue for consideration concerns scope-of-practice rules of non-medical practitioners. Questionnaire results suggest that most countries consider that these limit the capacity for care coordination. Widening the scope of their activities and, possibly, defining new classifications of medical workers specialising in care coordination tasks may improve the capacity to coordinate care while releasing medical professionals and consultants to concentrate on tasks of medical diagnosis and assessment.

\section{Care coordination may benefit from greater health-system integration}

Finally, the questionnaire results suggest that care coordination problems are most intense at the interfaces between health-care sectors and between providers. This suggests that coordination can be improved by bridging better the administrative and other barriers that impede easy transitions from one sector or provider to another. This issue may be particularly important for transitions into long-term care where problems appear to be the most intense. As noted, better systems for information transfer can aid the planning and organisation of services. Pooling resources between the health and social sectors for designated care coordinators who help patients and families at these transition points may be one model to bridge administrative barriers. But there may be also scope for integrated-care models that bring specialities and services under one roof and help make fragmented and complex systems more "userfriendly". 
This report has attempted to identify care coordination practices and to isolate problems that currently impede better coordination. It has also examined current knowledge about targeted care coordination problems. The results broadly suggest that targeted programmes can have positive effects on quality. The evidence on cost savings is less consistent. But cost effectiveness may be improved by making care delivery more patient-centred. The study suggests that there is scope for improving performance in coordination by "tweaking" existing health-care systems through a policy mix ranging from better organized ambulatory care to patient-centred integration of health and long-term care. While the suggested areas for policy reflection are not new, they may now be taking on greater policy relevance as the importance of chronic disease increases. 


\section{RÉSUMÉ}

L'objet de ce rapport est de tenter d'apprécier si - et, le cas échéant, dans quelle mesure - une meilleure coordination des soins est susceptible d'améliorer la performance des systèmes de santé en termes de qualité et d'efficience au regard du coût. Par coordination des soins on entend les mesures de nature à aider à instaurer une prise en charge centrée sur le patient qui soit plus cohérente aussi bien à l'intérieur d'un même cadre de soins qu'entre différents cadres de soins, et dans le temps. Plus généralement, il s'agit de faire en sorte que les systèmes de santé soient plus attentifs aux besoins individuels des patients et de faire en sorte que ceux-ci reçoivent les soins appropriés à l'occasion d'épisodes aigus, ainsi que des soins destinés à stabiliser leur état de santé, dans une perspective à long terme, dans un environnement moins coûteux. Ces questions revêtent une importance toute particulière pour les malades chroniques et pour les personnes âgées qui trouveront sans doute difficile de «naviguer » à l'intérieur de systèmes de santé fragmentés comme c'est souvent le cas dans les pays de l'OCDE.

\section{On s'intéresse de plus en plus à la problématique de la coordination des soins}

L'intérêt croissant pour cette question reflète un déplacement des attentes à l'égard des services de santé. Les maladies chroniques sont de plus en plus fréquentes et absorbent une part croissante des budgets de santé. Les maladies chroniques concernant, le plus souvent, les personnes âgées, on peut penser, la population vieillissant, que c'est un aspect des systèmes de santé qui prendra de plus en plus d'importance au cours des décennies à venir. Dans le même temps, de nombreux rapports signalent que la qualité des soins dispensés aux malades chroniques pourrait sans doute être améliorée. Ces évolutions intervenant dans un contexte difficile pour les finances publiques, certains pays s'efforcent d'améliorer la qualité des soins dispensés aux malades chroniques et de réduire la pression sur les coûts en repensant complètement l'architecture de leur système de santé, de façon à encourager une plus grande coordination des soins.

Faute d'informations homogènes, au niveau international, sur ces questions, le Secrétariat a eu recours à un questionnaire pour recueillir avis et informations sur les préoccupations, les difficultés et les pratiques actuelles, en matière de coordination des soins, dans les pays de l'OCDE et de l'UE. L'analyse des résultats du questionnaire - et de la littérature, de façon plus générale - tend à indiquer que le souci de la coordination des soins est général, chez les responsables publics et les prestataires de santé, et aussi dans le public, plus largement. La prise de conscience de ce problème, conjuguée à l'émergence de besoins nouveaux, a amené à imaginer différents types de réactions possibles du côté de l'offre. Néanmoins, la plupart des mesures semblent partager le même objectif général consistant à réduire le recours à une hospitalisation très coûteuse pour les malades chroniques en centrant l'attention et les programmes sur une prise en charge de grande qualité, axée sur le patient, en dehors d'un contexte d'hospitalisation aiguë.

Les programmes ciblés améliorent apparemment la qualité, mais les données disponibles ne permettent pas de dégager de conclusions définitives en ce qui concerne l'efficience au regard du coût

L'attention s'est largement focalisée, ces dernières années, sur les programmes « ciblés » (gestion par maladie et par cas, par exemple), axés spécifiquement sur certaines maladies ou sur un certain segment de la population. Ces programmes devraient permettre d'améliorer la qualité des soins en permettant un meilleur suivi des patients souffrant d'une maladie chronique. Ils devraient aussi permettre de réduire la demande globale en soins et services de santé en réduisant la fréquence des séjours non programmés à l'hôpital et en limitant le recours aux services d'urgence. Ce type de dispositif a d'abord été mis en œuvre 
aux États-Unis, puis, plus récemment, en Allemagne, au Royaume-Uni et dans quelques autres pays. De nombreuses études ont tenté d'évaluer ces dispositifs, mais elles reposent largement sur l'expérience des États-Unis. Actuellement, le consensus parmi les experts est que ces programmes semblent améliorer la qualité des soins mais qu'il n'est pas évident qu'ils permettent de réaliser d'importantes économies financières. Cela peut refléter le coût de la mise en place et du fonctionnement de ce type de programme et les difficultés qu'il y a à cibler les publics le plus susceptibles d'en tirer profit, outre qu'un meilleur suivi fait souvent apparaitre des besoins non satisfaits. Pour une amélioration constante de la performance des systèmes de santé, sans doute faudrait-il que ces programmes ciblés s'inscrivent dans le cadre d'efforts plus larges pour améliorer la coordination des soins et faire que la prestation de soins soit davantage centrée sur le patient.

Cette étude identifie quatre domaines clés dans lesquels des réformes pourraient certainement accroître la capacité des systèmes de santé de dispenser des soins mieux coordonnés.

\section{La coordination des soins serait facilitée par un meilleur transfert d'informations et une plus large utilisation des TIC}

Premièrement, améliorer la collecte et la diffusion des informations sur les patients et la performance des prestataires paraît être un élément fondamental pour améliorer la coordination des soins et la gouvernance des systèmes dans une optique de qualité. Il est plus facile d'orienter les patients et de leur dispenser les soins appropriés si l'information les concernant est récente et précise et communiquée en temps utile. La gouvernance des systèmes et l'amélioration de la qualité des soins supposent, aussi, qu'on dispose d'indicateurs à jour de la performance des prestataires. Bien que les technologies de l'information et des communications (TIC) semblent un outil très prometteur dans cette perspective, le taux de pénétration de ces technologies reste faible, à ce jour, dans de nombreux pays. D'après les résultats du questionnaire, très peu de pays pensent que les prestataires soient couramment équipés en TIC, et un tiers seulement environ auraient couramment les dossiers de leurs patients sous forme électronique. Certains pays ont introduit ou envisagent d'introduire des systèmes nationaux de transfert des dossiers des patients. Cependant, des systèmes de transfert d'informations au niveau national sont coûteux à mettre en place et les avantages à en attendre doivent s'apprécier au regard de coûts de démarrage et de fonctionnement élevés. Dans ce contexte, il faut avoir l'assurance d'un retour suffisant sur investissement pour la collectivité.

\section{Sans doute faudrait-il revoir la part de ressources consacrée aux soins ambulatoires}

Deuxièmement, au vu du déplacement progressif des soins d'un contexte d'hospitalisation à un contexte ambulatoire, sans doute faudrait-il que les gouvernements se demandent si la part de ressources consacrée au secteur ambulatoire est conforme à la nouvelle configuration de la demande. Comme cela a été signalé, on peut penser que ces tendances vont s'accentuer à mesure que la population vieillira, au cours des décennies à venir.

\section{Il convient d'envisager de nouveaux modèles de soins ambulatoires}

Troisièmement, et c'est peut-être l'aspect le plus important, les responsables publics doivent mieux adapter leurs systèmes de soins ambulatoires aux demandes nouvelles liées aux maladies chroniques. Si l'on peut penser, à certains égards, que les professionnels au niveau des soins primaires sont les mieux placés pour assumer ce rôle, on peut aussi penser que des équipes pluridisciplinaires, associant des personnels médicaux et des personnels non médicaux, sont peut-être mieux à même d'apporter des soins plus cohérents, en particulier s'agissant de patients présentant des pathologies multiples. Les systèmes organisés autour de prestataires exerçant en solo et rémunérés à l'acte sont sans doute moins performants pour répondre aux besoins en soins des malades chroniques. L'une des voies à explorer concerne les règles 
encadrant la pratique des praticiens non médicaux. Les résultats du questionnaire tendent à indiquer que, dans la plupart des pays, on considère que ces règles limitent les possibilités de coordonner les soins. En élargissant le champ des activités de ces praticiens et en définissant, peut-être, de nouvelles catégories de travailleurs médicaux spécialistes des tâches de coordination, sans doute pourrait-on améliorer la capacité de coordonner les soins tout en libérant les professionnels et consultants médicaux qui pourraient alors se concentrer sur les tâches de diagnostic et d'évaluation médicale.

\section{La coordination des soins aurait à gagner à un renforcement de l'intégration des systèmes de santé}

Enfin, les résultats du questionnaire indiquent que les problèmes de coordination se posent avec une acuité toute particulière à l'interface entre les différents secteurs de soins et entre prestataires. On peut donc penser que la coordination s'en trouverait améliorée si on parvenait à lever les obstacles, administratifs et autres, qui empêchent les transitions aisées d'un secteur à l'autre ou d'un prestataire à l'autre. La question se pose, en particulier, pour les transitions vers une prise en charge de longue durée, qui semble être le secteur où les problèmes se posent avec le plus d'acuité. Comme cela a été noté précédemment, une amélioration des systèmes de transfert d'information peut faciliter la planification et l'organisation des services. Une mise en commun des ressources du secteur de la santé et du secteur social au profit de coordonnateurs de soins désignés, chargés d'aider les patients et les familles aux points de transition, peut être un modèle à suivre pour lever les obstacles administratifs. Mais on peut aussi envisager des modèles de soins intégrés qui rassemblent les spécialités et les services sous un même toit et contribuent à faire que des systèmes complexes, fragmentés, répondent mieux aux besoins des utilisateurs.

Ce rapport a tenté d'identifier les pratiques en matière de coordination des soins et de repérer les problèmes qui, actuellement, empêchent une meilleure coordination. On s'est aussi intéressé aux problèmes de coordination des soins ciblés. Les résultats donnent largement à penser que des programmes ciblés peuvent avoir des effets positifs sur la qualité. Les données en ce qui concerne les économies en termes de coûts sont moins concluantes. Mais l'efficacité au regard du coût peut sans doute être améliorée si la prestation de soins est davantage axée sur le patient. L'étude incite à conclure qu'il est possible d'améliorer les performances en matière de coordination en "infléchissant» les systèmes de soins existants, par tout un ensemble de mesures, allant d'une meilleure organisation des soins ambulatoires à une intégration des soins de santé et d'une prise en charge de longue durée axée sur le patient. Les domaines dans lesquels il est suggéré d'approfondir la réflexion ne sont pas nouveaux, mais on peut penser que la problématique est d'autant plus d'actualité que l'importance des maladies chroniques va grandissant. 


\section{INTRODUCTION}

1. This report concerns ways to make health-care systems respond better to emerging health-care needs through enhanced "coordination of care". In this report, this term is used to encompass system-wide efforts and/or specific policies to ensure that patients -- particularly those with chronic conditions -receive services that are appropriate to their needs and coherent across care settings and over time. Some examples of problems that these policies address include:

- Chronically-ill patients tend to have multiple contacts with the health-care system and see a number of different specialists in different care settings. But they may lack one provider who can oversee and bring together clinical results and follow patients in the course of their disease.

- Alternatively, patients may also face special difficulties at transitions between care settings. For example, elderly patients leaving hospitals may require ambulatory-care follow-up to ensure that treatment and medication regimes are respected, thus reducing the risk of re-hospitalisation.

- Some patients, for example those with severe diabetes and heart disease, may need continuous follow-up from a health-care professional to ensure that medication protocols are being followed and that necessary medical tests are programmed in a timely manner so as to reduce the risk of unplanned hospital episodes.

2. Several features of existing health-care systems have contributed to such problems. First, for most countries, health-care delivery has evolved on the basis of a series of separate care settings -sometimes referred to as "silos". These can be institutionally independent and most often operate under different budgetary regimes, particularly where they are under the responsibility of different levels of government. Second, at a clinical level, there has been growing specialisation of medical knowledge. Both of these factors may make it more difficult for the chronically ill to find their way through the system. Thus, policies to improve coordination of care are intended, amongst other things, to offset this fragmentation of care systems, to help bridge the gap between various care settings and to provide greater coherence in the process of care.

3. In addressing the scope of the study, the OECD has been confronted with:

- Limited information on care-coordination policies for most countries;

- Differences in the intended goals of such programmes;

- Variability in the approaches used to address care-coordination issues ; and,

- Variation in degree of progress across countries in introducing such policies.

4. In practice, all countries have some arrangements for coordinating care between providers and across care settings. However, institutional boundaries between care settings vary across countries, e.g. specialist care provided in hospitals (e.g. England) rather than in private practice (e.g. France). A questionnaire, which was sent to all OECD and EU countries, included a series of definitions of specific programme types shown in Box 1. These largely concern programmes targeted on specific disease or population groups with special needs. The responses to the questionnaire -- and reviews of the situation in a few selected countries -- reveal that a range of other policies are increasingly being employed to foster 
improved care coordination, including changes in the way care is organised and provided. Thus, this report defines care coordination broadly in recognition of the fact that care coordination tasks are not necessarily confined to one group of providers and programmes, but can involve various medical and non-medical professionals within an individual care environment and at the interfaces between them (see also Table A 2.4 in Annex 2).

5. The report aims at providing a broad overview of care coordination issues and approaches in OECD and European Union non-OECD members and has the following main objectives:

- Examine how health-care systems respond to the challenges of increasing chronic disease and to assess whether (and how) OECD and EU countries can promote better performance of their health systems by improved coordination of care;

- Identify specific problem areas likely to impede care coordination and policies that could help address these issues, largely drawing on the more detailed experiences of 26 countries responding to the questionnaire and;

- Assess evidence as to whether "targeted" programmes - primarily of a disease management nature - can improve the quality and cost-efficiency (or cost-effectiveness) of health-care systems.

6. In addressing care coordination issues, this report

- Draws on the results of a questionnaire sent to 38 countries in 2006 with replies from 26 (see Table A 2.2, Annex 2 for a complete list);

- Supplements questionnaire findings by a comprehensive literature review; and,

- Portrays a number of recent policy approaches to care coordination in selected OECD countries

7. The main subject areas covered in the questionnaire concerned: i) debates or key issues under discussion in the context of care coordination; ii) how care is normally coordinated in countries today, who undertakes the coordination and impediments to care coordination within existing health-care systems; and, iii) information on the experience with "targeted" policies or programmes (e.g. disease management) and their impact on health-care system performance. In preparing their replies to the questionnaire, countries were encouraged to enlist the help of a range of stakeholders at different governmental and professional levels. The Secretariat recommended that the central or federal authorities respond to the questionnaire, drawing on expertise at the sub-national and expert level where available. ${ }^{1}$

8. The remainder of this report is divided into 5 chapters. Chapter 1 addresses some of the reasons for increasing prominence of care coordination issues in recent years and indicates which specific issues are of particular importance to policy makers in the countries surveyed. Chapter 2 examines specific impediments to care coordination within existing health-care systems on the basis of the questionnaire replies and provides support for broad policy measures that could enhance coordination of care. Chapter 3 reviews the experience with "targeted" care coordination programmes in OECD and EU countries, also drawing on the questionnaire. It briefly summarises what is known about the impact of targeted

1 The results of this statistical analysis of the questionnaire need to be treated with some caution. While most questionnaire respondents appear to have attempted to reply to the questionnaire as accurately as possible, the information remains subjective rather than representing "hard" data. Statistical techniques used focus on providing probabilities of events instead of point estimates. In this environment assessments of causality can be difficult. Where the Secretariat has advanced what it considers to be plausible reasons for the results, it has attempted to back these up with evidence from the literature. 
programmes from the literature. In order to enhance understanding of the importance of institutional context in the introduction of care-coordination programmes, Chapter 4 takes a more detailed look at developments in the United States, Germany and the United Kingdom (England). These three countries have been chosen because they have been front runners in policies in this area and they present contrasting institutional environments. Chapter 5 summarizes key messages and presents areas for further policy consideration.

9. Background material has been presented in four Annexes. Annex 1 provides supplementary figures and tables, including the main results of the questionnaire for individual countries in Tables A1.1 to A1.23. Further details concerning the main characteristics of the questionnaire, their interpretation and the methods of analysing the results are presented in Annex A 2. The text of the original questionnaire is found in Annex 3.

\section{Box 1. Definitions of targeted care-coordination programmes}

Care management refers to a system of coordinated health care for the population that is not disease-specific but covers the range of care that individuals are entitled to under the insurance package of included goods and services. This term, which is often used in social care and involves a set of activities which assures that every person served by the system has a single approved care (service) plan that is coordinated, not duplicative, and designed to ensure cost-efficient and effective care outcomes (Hutt et al., 2004). Initial and continuing authorizations are generated by care coordinators.

Case management: refers to the service system coordinating the various system components in order to achieve a successful outcome. It entails the assessment of a person's longer-term care needs and is followed by appropriate recommendations for care, monitoring and follow-up. Five core case management activities are: (1) assessment; (2) planning; (3) linking; (4) monitoring, and (5) advocacy. Case management's primary goal is service provision for the consumer, not management of the system or its resources. This includes responsibility for referral, consultation, prescription of therapy, admission to hospitals, follow-up care, and (where necessary) prepayment approval of referred services. It includes responsibility for relocating, coordinating, and monitoring all medical care on behalf of a patient. Case management has essentially aimed at limiting health costs by reducing the need for hospitalization and the use of emergency services of high risk individuals. It is normally organised by case management doctors or nurses, often in consultation with an insurer.

Continuing Care generally describes a system of service delivery which includes all of the services provided by long-term care, home care and home support. This term encompasses two complementary concepts: that care may "continue" over a long period of time; and, that an integrated programme of care "continues" across service components. This is not a specific medical service. Rather it concerns a continuum of care within a context of a complex "system" of service delivery that can include a variety of providers (doctors, hospitals, nursing homes etc.). The care coordination can be carried out by health-care professionals - either doctors or nurses - sometimes in the context of multi-disciplinary teams.

Disease management: concerns a continuous, coordinated health-care process that seeks to manage and improve the health status of a defined patient population over the entire course of a disease, instead of viewing each physician visit as a separate event. The patient populations targeted are high-risk, high-cost patients with chronic conditions (long-term illnesses or recurring conditions) that often depend on appropriate pharmaceutical care and patient self-care for proper maintenance. Disease management services include disease prevention efforts as well as patient management once the medical condition has been diagnosed.

Episodes of care is a treatment period that begins with initial assessment and includes follow-up interventions and reassessment necessary to provide reasonable medical services related to a specific condition. It produces a grouping of services (initial and follow-up services, ancillary services...) that is reasonably expected or anticipated for a given diagnosis and clinical condition.

Patient pathways: This is the route that a patient with a given pathology can be expected to take from her or his first contact with the health system (for instance, the GP in gate-keeper systems), through referral, to the completion of his or her treatment. It also covers the period from entry into a hospital or a Treatment Centre, until the patient leaves. This can be thought as a timeline or decision tree, on which every event relating to treatment can be entered. Events such as consultations, diagnosis, treatment, medication, diet, assessment, patient education and preparation for discharge from the hospital can all be mapped on this timeline. The pathway can be used both for patient information and for planning services, e.g. as a template pathway created to illustrate common services and operations. 


\section{CHAPTER 1. COORDINATION OF CARE: ISSUES, OBJECTIVES AND PRACTICE}

10. This chapter first examines key reasons for the growing interest in care-coordination issues. It then presents questionnaire results regarding which issues policy makers see as being most relevant in this area. Views of questionnaire respondents as to which health-care goals are likely to be most affected by improved coordination of care are considered subsequently. Finally, it reviews information, aimed at throwing light on current practices of care coordination in respondent countries and where countries see problems of poor care coordination as being most intense. This largely draws on questionnaire replies contained in the Annexes.

\subsection{Why care coordination issues are receiving greater attention}

\section{Fragmentation in health, long-term care and other social support systems impedes patient-centred care}

11. On the supply side, there is considerable fragmentation of health-care provision in OECD countries. In part, this reflects the increasing specialisation of medical practice whereby an individual patient can see a number of different providers during any single care episode. It also results from weak linkages between different care "silos" (ambulatory care, acute hospital care and long-term care). These problems are widespread and exist to some degree in all countries. There is a growing perception of inadequate oversight of the care process of individual patients and the need for medical professionals who take on a coordinating role (Wagner et al., 2001). It is widely believed that the achievement of both efficiency and quality goals may be hampered in the absence of improved co-operation and collaboration among the various parts of the health and social support systems. (Schmidt, 2006, Kohn et al., 2000)

\section{Health-care costs are highly concentrated in a small share of the population often with chronic conditions}

12. The need for better coordination of care is closely linked to the growing prevalence of chronic disease. Scattered data from a number of countries indicate that a large and growing share of contacts with the health-care system is for health problems of a chronic nature (Box 2). Individuals with chronic conditions tend to be high users of health-care services and have numerous contacts with the health-care system. Thus, efforts to control costs would do well to ensure that these high-cost groups are obtaining the most cost-efficient care. Better care coordination may have an important role to play in that context. 


\section{Box 2. Health-care costs and chronic disease: some evidence}

Chronic conditions are concentrated among the elderly and are an important determinant of care costs. An eleven country survey on the health status of people 50 years and older in Europe shows that more than two thirds of survey respondents have had at least one chronic disease diagnosed during their life-time, and around $40 \%$ report two or more (Mackenbach, 2005). Canada has found that 50 per cent of Canadian adults and 81 per cent of seniors $(65+)$ have at least one chronic condition (Statistics Canada, 1999). For the United States Medicare population, 82 percent have at least one chronic condition and 65 percent have multiple chronic conditions. Data for Wales indicate that $1 / 3$ of the Welsh population has at least one chronic condition compared with two-thirds of the population over 65 and three quarters of the population over 85 (National Public Health Service for Wales, 2005).

These individuals absorb a high share of health-care costs. For Canada in 2003, the direct costs of all chronic conditions are estimated to be $67 \%$ of the total direct cost of health care and 60 per cent of indirect costs through loss of productivity and income (Broemeling et al, 2005). Similar data for the United States put direct health-care costs from chronic disease at three quarters of total direct spending on health care. It is estimated that diabetes and complications arising from the disease are the largest single contributor to direct health-care costs (International Diabetes Federation, 2006).

Those with chronic disease contribute to the concentration of health-care spending among a small share of the population which often has some degree of preventable hospitalization (Wolff J.L. et al., 2002). Thorpe and Howard (2006) find that, in 1987, 31 percent of Medicare beneficiaries received treatment for five or more conditions. This same group accounted for about half of total Medicare spending. Ten years later, nearly 40 percent of beneficiaries were treated for five or more conditions accounting for 65 percent of overall Medicare spending. The US Congressional Budget Office also reports a significant degree of concentration in the spending of Medicare beneficiaries, both in a given year and over time. For example, the top 25 percent of beneficiaries in terms of their care costs accounted for 85 percent of annual expenditures in 2001 and for 68 percent of five-year cumulative expenditures from 1997 to 2001 (CBO, 2005).

\section{New chronic-care needs are emerging}

13. The importance of chronic conditions appears likely to increase as populations age over the next three decades (Lafortune and Balestat, 2007) ${ }^{2}$, the outcome partly depending on the development of future health-risk factors. Even though healthy lifetimes may lengthen over the coming years, increased health spending may be necessary both to delay the onset of disease and to palliate its eventual chronic effects. In this context, tobacco and alcohol consumption has declined and this is possibly contributing to slower growth or declines in certain chronic diseases (circulatory and respiratory problems and selected cancers). However, there are important forces working in the opposite direction. The increase in overweight and obese individuals in most OECD countries is notable and is leading to significantly higher risks of impaired health and chronic health conditions (Andreyeva et al., 2007). This group is at much greater risk of circulatory problems, kidney failure, heart disease and, above all, of diabetes. ${ }^{3}$ The increase in diseases related to rising obesity is also found among youth and disability rates and chronic diseases are increasing rapidly among lower age groups (International Diabetes Federation, 2006; American Academy of Pediatrics, 2005) implying subsequently higher rates of chronic conditions during adulthood (Perrin et al., 2007). ${ }^{4}$ depend on a range of factors, e.g. improvements in the quality and, effectiveness of care (Oliveira, M. J. and C. De La Maisonneuve 2006), Joyce et al., 2005, Goldman et al, 2005).

3 By 2025 , the number of people with diabetes is expected to rise by $21 \%$ in Europe, $53 \%$ in North America. (International Diabetes Federation, 2006). These projections only take into account the effects of expected changes in age/sex patterns and in the degree of urbanisation. Since the prevalence of the disease is expected to increase over the period as well these numbers are underestimates.

In addition, the share of chronic conditions in total morbidity is increasing even among the very young, partly reflecting improved survival rates of young children with special needs - for example after 


\section{The chronically ill are the group most likely to be affected by weak coordination}

14. Consistent with the literature, almost 80 percent of questionnaire respondents see patients with chronic conditions and the elderly as being the population groups likely to be most affected by inadequate coordination of care (Figure 1.1). ${ }^{5}$ As discussed in Box 2, these groups most often have illnesses that require multiple contacts with the health-care system and often see a range of specialists in the course of a care episode.

\section{Figure 1.1 Population groups likely to benefit most from care coordination}

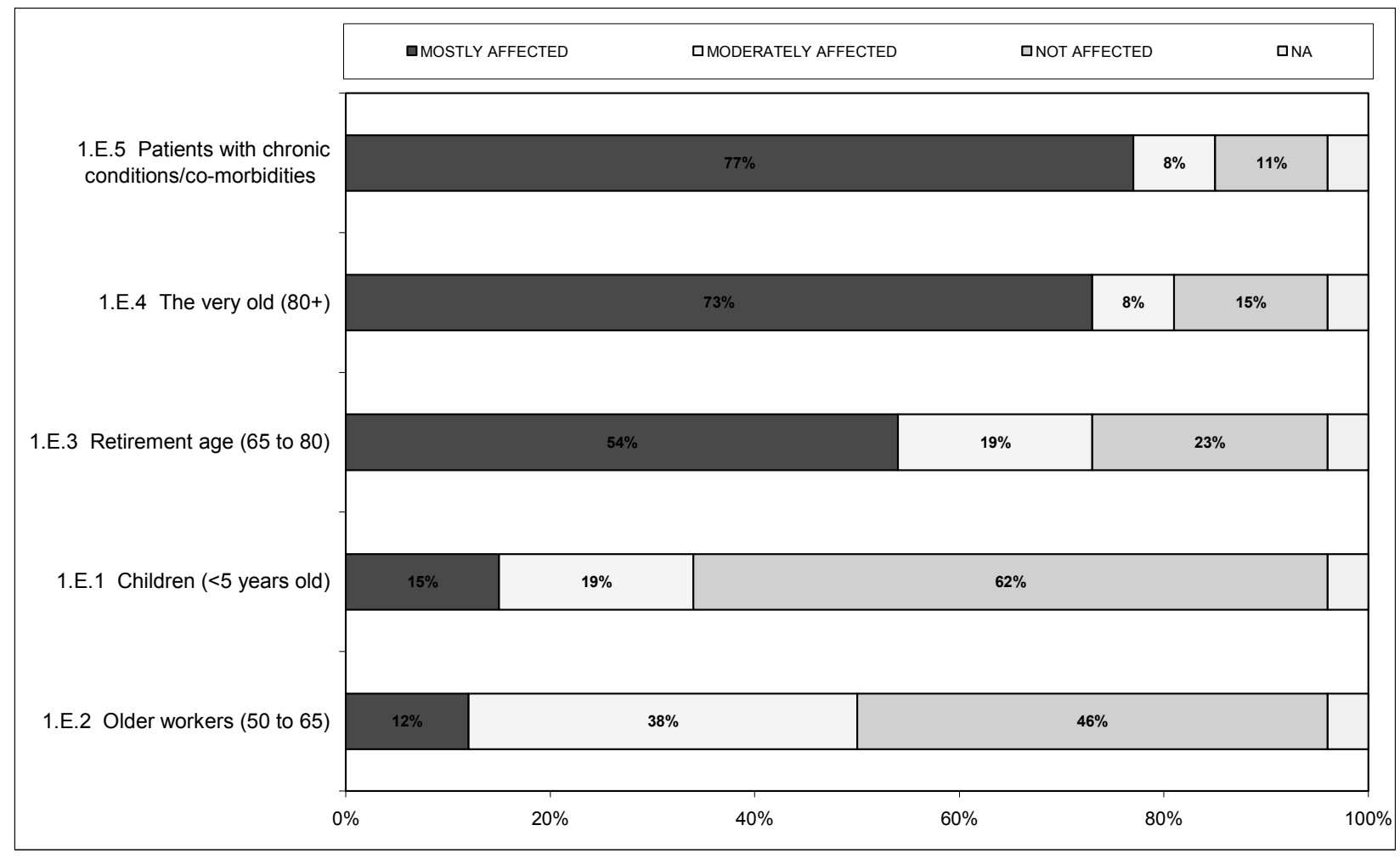

Source: OECD questionnaire on coordination of care 2006, N=26. (Annex 1, Table A1.4).

\subsection{Which health-care goals might be better achieved from improved care coordination?}

\section{Quality and cost efficiency issues are the key reasons for focusing on care coordination}

15. Questionnaire respondents overwhelmingly agree that policy discussions about care coordination are most closely linked to goals of quality of care (i.e. impact on health outcomes and responsiveness to patient needs), on cost efficiency and, to a lesser degree, on ensuring access to care (Figure 1.2). All countries indicated that quality issues were important, possibly reflecting growing concern about the quality of care. In this context, there is a wide body of research pointing to care that does not meet bestpractice standards. For example, Asch et al.,(2006) estimates that half of patients in the United States do not receive the care they should, a result that echoes the report "Crossing the Quality chasm" (Kohn et al.,

premature birth. (American Academy of Pediatrics, 2005). In this context, Lafortune and Balestat (2007) find no clear downward trends in disability in recent years in a survey of 12 OECD countries.

5 See Annex 2 for details on the figures and how to interpret them. 
(2000)). ${ }^{6}$ A large number of studies also indicate that there are important differences in practice patterns and new data suggest that there are high levels of medical error in other countries as well. ${ }^{7}$ Studies based on information from "root-cause" analysis of specific incidents suggest that poor design of health-care delivery processes, rather than technical incompetence of professionals, underlay the majority of problems (Docteur and Oxley, 2003). Coordination of care is one possible way to improve the delivery of quality health care through greater coherence between contacts in the care process and ensuring that there is greater adherence to "best-practice" medicine.

Figure 1.2 Main goals of policies to improve care coordination

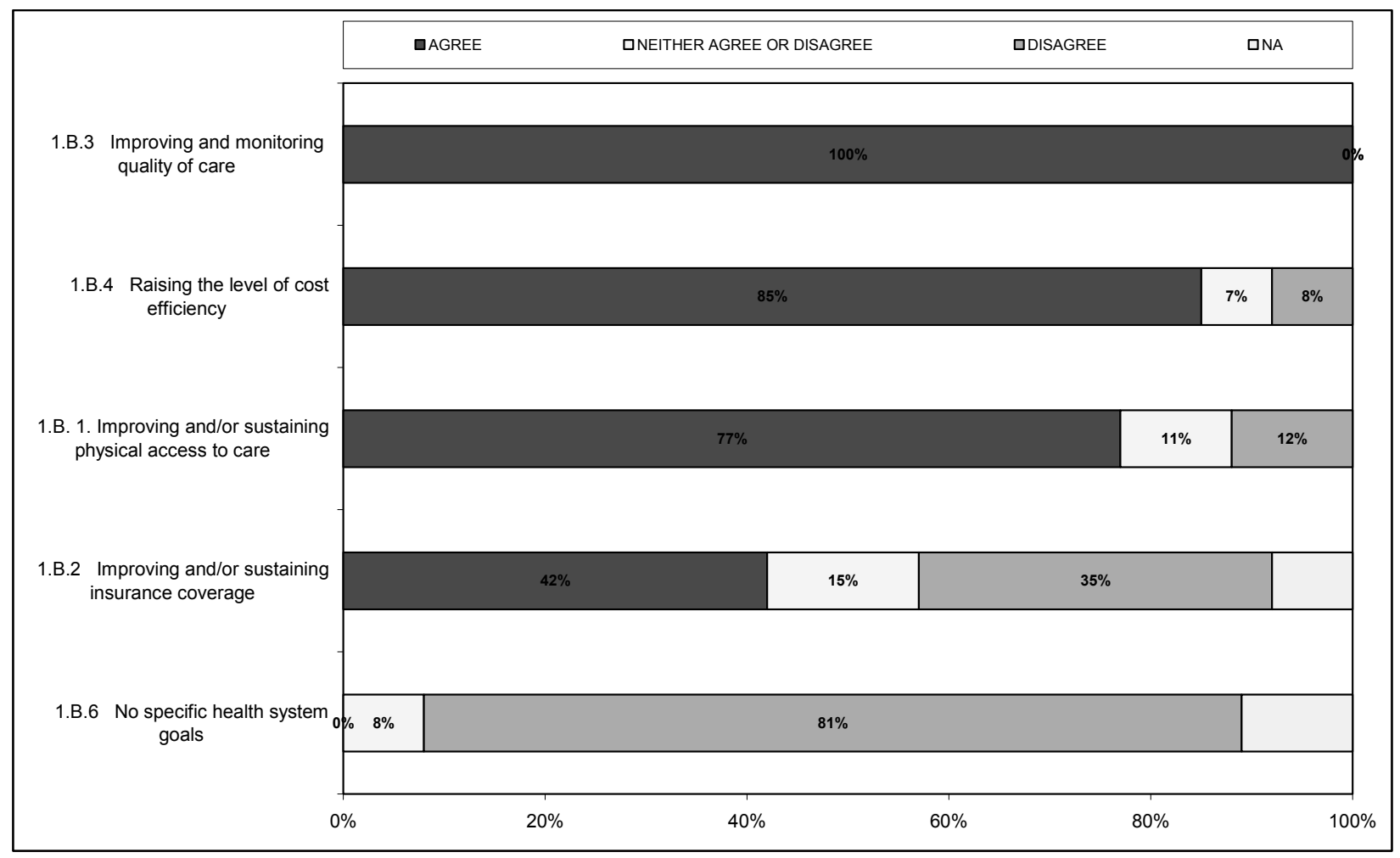

Source: OECD questionnaire on coordination of care 2006, N=26 (Annex 1, Table A1.1).

\section{Concern about the impact of poor care coordination on health-care systems varies with the level of health spending}

16. Problems of care coordination appear are widespread (see Figure 1.5) and seem linked to the level of health-care spending in two different ways:

6 This report noted that medical errors were responsible for more annual deaths than motor vehicle accidents in the United States. Comparable error rates have been reported in Australia Denmark and the United Kingdom (Docteur and Oxley, 2004 and references therein).

7 A 2005 survey of sick adults in Australia, Canada, Germany, New Zealand, the United Kingdom and the United States indicates that sizeable shares of patients in all six countries report safety risks, poor care coordination, and deficiencies in care for chronic conditions (Schoen et al., 2005). 
- Countries with higher levels of health care spending are also those that are most concerned about improving efficiency, i.e. higher levels of spending may be associated with greater consciousness about the need for efficiency gains ${ }^{8}$, for example, through. a reduction in the duplication of tests;

- At the same time, countries with a higher share of health-care spending in GDP are less likely to report care-coordination problems, possibly because the greater availability of financial resources may ease some of the more general supply-side issues, such as lengthy waiting lists and the resulting low level of patient satisfaction (Siciliani and Hurst, 2004).

\subsection{Evidence on current care-coordination practices in survey countries.}

17. Some form of patient coordination is present in all health-care systems covered by the questionnaire. The referral patterns of patients as they progress through the health-care system (see Figure 1.3) and the types of care-coordination activities (see Figure 1.4) provide some information on current practices. Particular attention has been given to identifying which health-care provider takes responsibility at each change in health-care setting.

\subsubsection{Referral patterns}

Figure 1.3 Who refers patients?

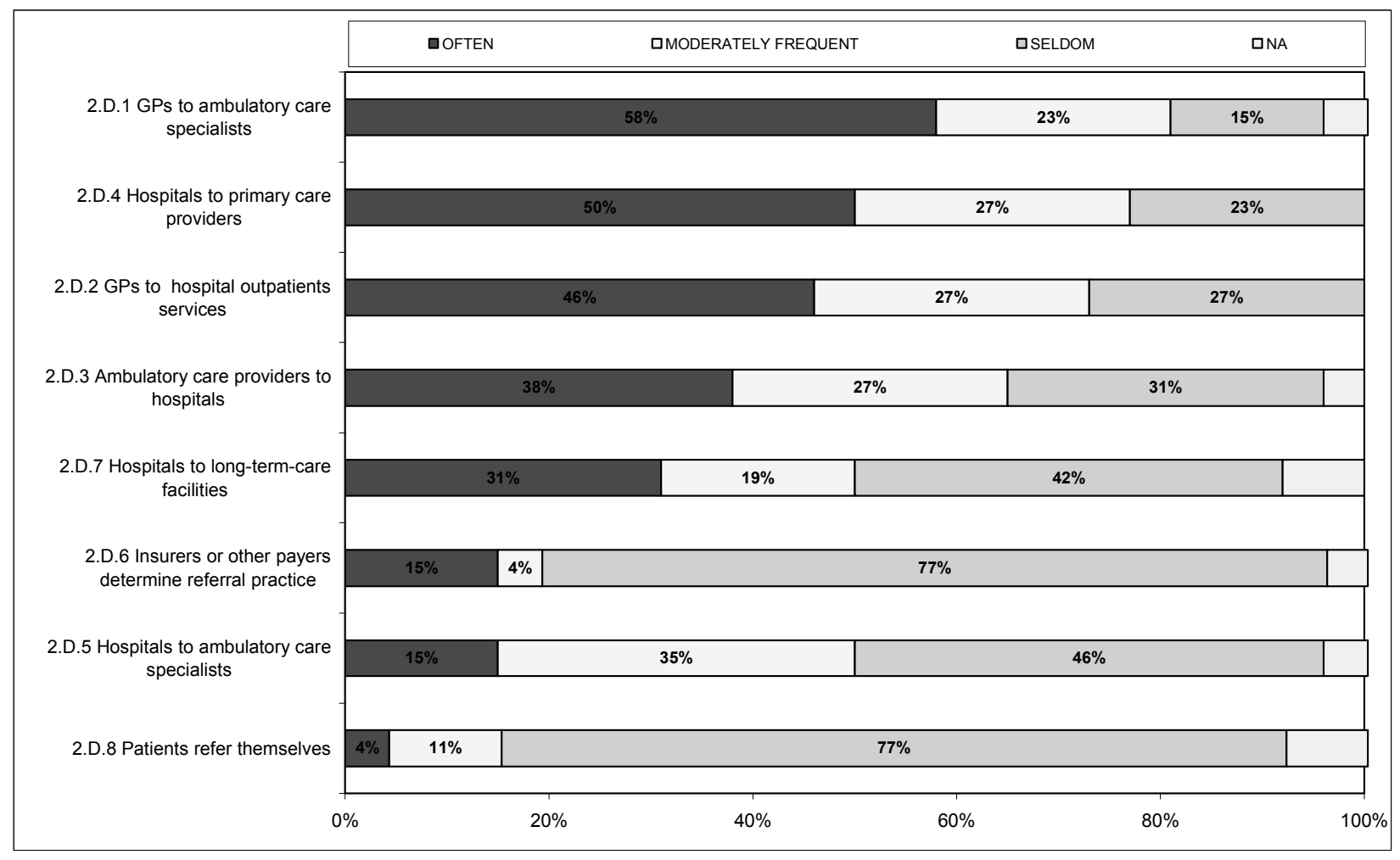

Source: OECD questionnaire on coordination of care 2006, N=26 (Annex 1, Table A1.13).

Odds Ratio (OR), 1.76; p-value, 0.042 in a regression where questionnaire replies concerning inefficient transfer of information between providers (question 1C4 in Annex 3) is regressed on the share of health expenditures in GDP using a univariate logistic model. For further information on the statistical methods used and the interpretation of statistics see Annex 2) 
18. Questionnaire results suggest that the vast majority of patients enter the health-care system at the level of primary care and rarely see providers at other levels of care without a referral (Annex 1, Figure A.1.1). Thus, it would appear that countries, generally speaking, have some form of legal or behavioral constraint concerning the initial contact with the health-care system. ${ }^{9}$ From there, patients are typically referred to ambulatory care specialists (Figure 1.3) who, in turn, refer them on to hospitals.

19. Referrals back to ambulatory care providers appear widespread. ${ }^{10}$ However, referrals from hospitals back to ambulatory care specialists are less frequent. This may reflect the importance countries give to primary-care providers in ensuring patient follow-up and care coordination. As suggested in Chapter 2 (sections 2.2 and 2.3), this pattern of referrals and the resulting provider behavior seem to be a key source of concern with respect to coordination of care.

\subsubsection{Care coordination practices}

20. As with referrals, information on existing patterns of coordination has been derived from detailed questions on the use of selected coordination practices and on which actor plays the strongest role in guiding the patients through each of five interfaces. Answers were requested at the system-wide level (see Figure 1.4) and at the different transition points between institutional levels of the health-care system (Figures A1.2 to A1.6 in Annex 1):

- Between ambulatory care and specialist ambulatory care;

- Between primary or specialist ambulatory care and outpatient specialist care;

- Between ambulatory care and acute inpatient care;

- Between ambulatory and long-term care;

- Between acute-inpatient and long-term care.

21. Key problems in coordination appear to be found at these interfaces, especially at cross-over points to long-term care (Figure 1.5). In comparison, problems within care settings seem less important. For example, care coordination within hospitals is carried out most of the time at the specialist level (Figure 1.4). Nonetheless, 30 per cent of countries indicate problems of care coordination within this setting ${ }^{11}$ (Figure 1.5) suggesting that there is also potential to improve the organisation of care delivery in hospitals.

$9 \quad$ As would be expected, patients also enter via hospital accident and emergency services without consulting a primary care provider. Some questionnaire respondents indicated concerns over overuse of emergency care services. Although a majority of countries indicate that outpatients' emergency wards are being visited "often", replies suggested that differences in the use of emergency services across countries may be related to high prices in ambulatory care relative to the price paid for care provided in emergency wards and, possibly, to limited supply or lack of flexibility in the availability of primary-care providers.

However, 30 per cent of countries indicate that they infrequently refer hospital patients back to primary care providers, suggesting, for example, that problems of information transmission may be important in many countries.

Survey countries also show a strong association between care coordination within care sectors and cost efficiency problems, a result that appears to be more widespread in tax-funded countries. (Correlation between 1B4 and 3A3 in Annex 3; correlation 0.506, p-value =0.094). In general, this may be related to differences in the supply of available capacity: social health insurance countries had on balance 7 inpatient care beds per 1000 while tax-based countries have only 4 beds per 1000 (OECD Health Data 2006). 
Figure 1.4 Coordination-of-care practices

DELSA/HEA/WD/HWP(2007)6

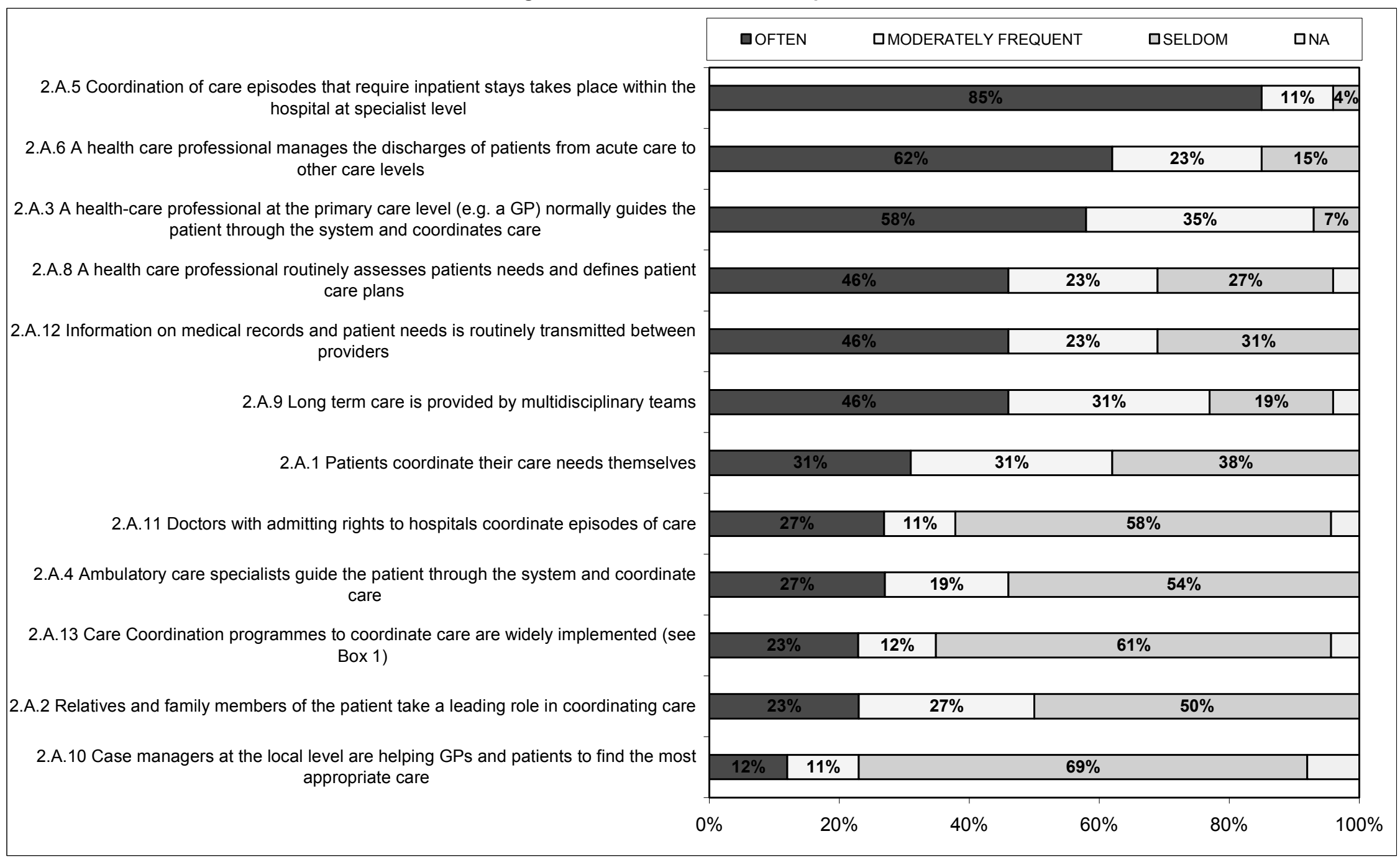

Source: OECD questionnaire on coordination of care 2006, N=26 (Annex 1, Table A1.6). 
Figure 1.5 Where do problems of care coordination occur?

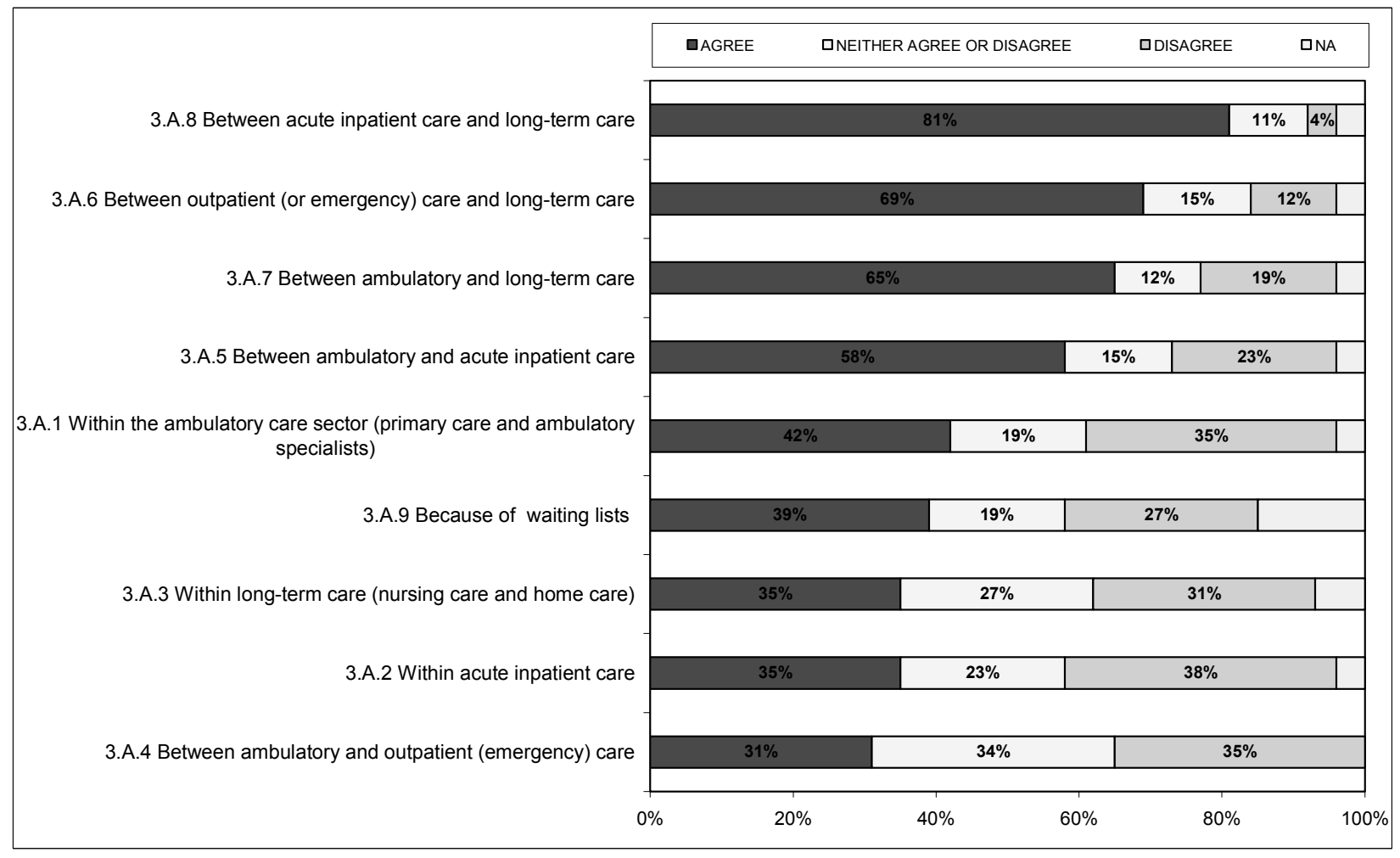

Source: OECD questionnaire on coordination of care 2006, N=26 (Annex 1, Table A1.14).

\section{The role of the primary-care physician declines as patients move towards hospital and institutional care}

22. Figure 1.6 collates information on the role of the primary-care physician as care coordinator for the system as a whole and for each of the five interfaces. More than half of countries see primary-care providers as "often" giving patients guidance as they move through the health-care system. However, the role of the primary-care physicians appears to decline in many countries as patients move towards hospital and institutional care. While almost three countries out of four see a GP managing patients at the interface between primary-care and ambulatory specialists, the likelihood of guidance from the primary-care level declines at successive interfaces such that only one in five countries judged that guidance to patients is given "often" by a primary-care provider. Mirroring this pattern, there is an increase in the share of countries indicating that guidance from a primary-care provider is "seldom" given. At the interface between acute inpatient care and long-term care, two thirds of countries indicate that a primary-care provider "seldom" takes part in guiding patients even though primary carers most often play a key role in overseeing care needs. 
Figure 1.6 The role of primary-care providers at transition points between care settings

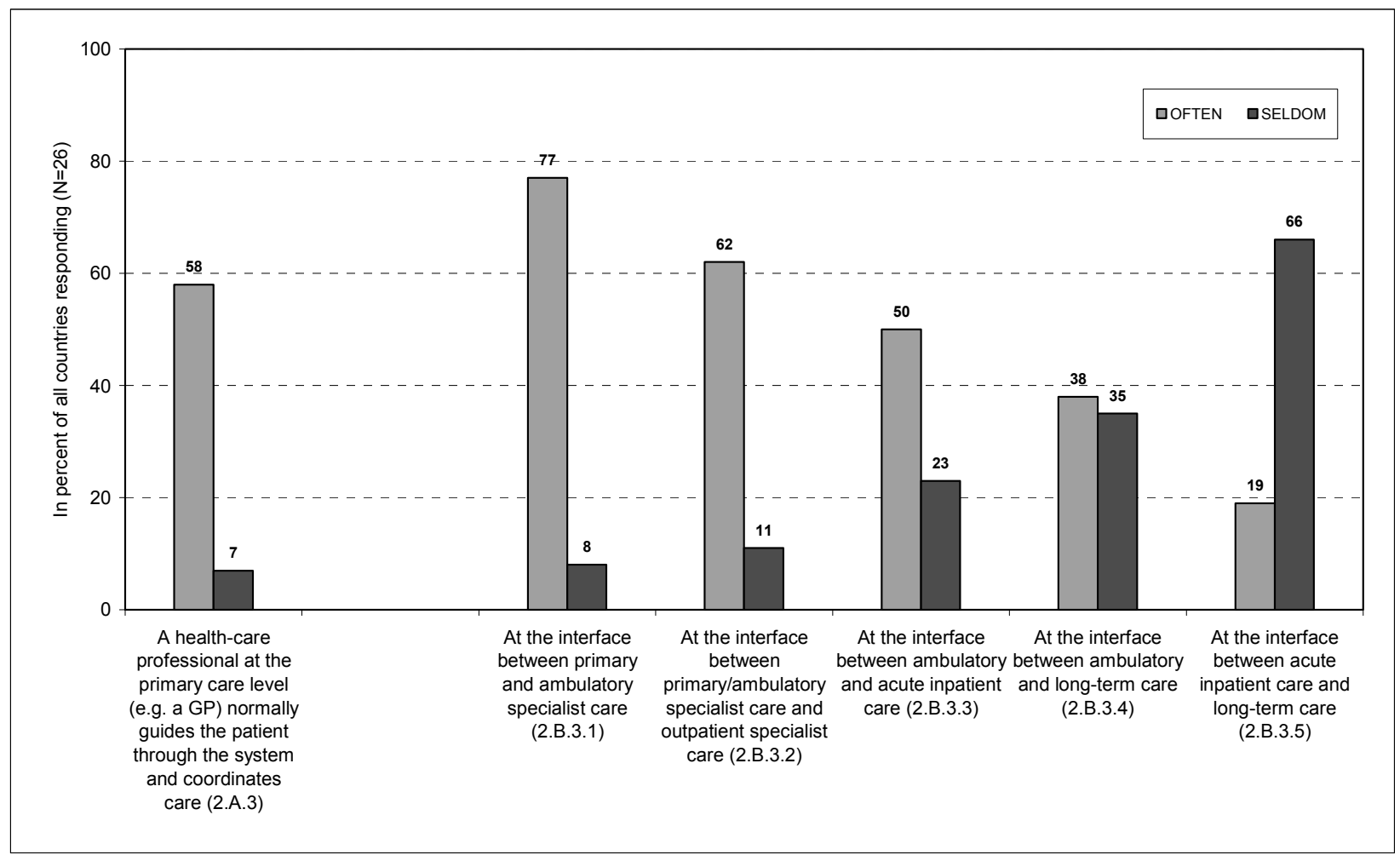

Source: OECD questionnaire on coordination of care $2006, \mathrm{~N}=26$.

\section{Once within hospitals, coordination of care is handled by hospital specialists}

23. Within hospitals, care coordination is almost entirely carried out at the level of hospital specialists (Figure 1.4). In a quarter of countries, ambulatory care doctors "often" have admitting rights, possibly increasing their scope for care coordination between the ambulatory and the acute care sectors.

\section{Health-care professionals other than GPs give guidance at transition points to long-term care}

24. Patterns of coordination change as patients move from acute to long-term care. Discharges by a medical professional - which is likely to occur before transfer to long-term care -- are widespread: around three quarters of the countries suggest that this occurred "often" at the transition between acute and longterm care (Figure 1.7). A similar share of countries also agreed that a health-care professional "often" routinely assesses patient needs and defines patient care plans at this transition. At transitions from ambulatory care into long-term care, neither GPs (Figure 1.6) nor ambulatory specialists appear to take on a leading role. This pattern suggests that other health professionals are compensating to some degree for the weaker role of GPs at these interfaces and some form of care coordination may be present in many countries in this sector as well. 
Figure 1.7 Patient management at the interface to long-term care

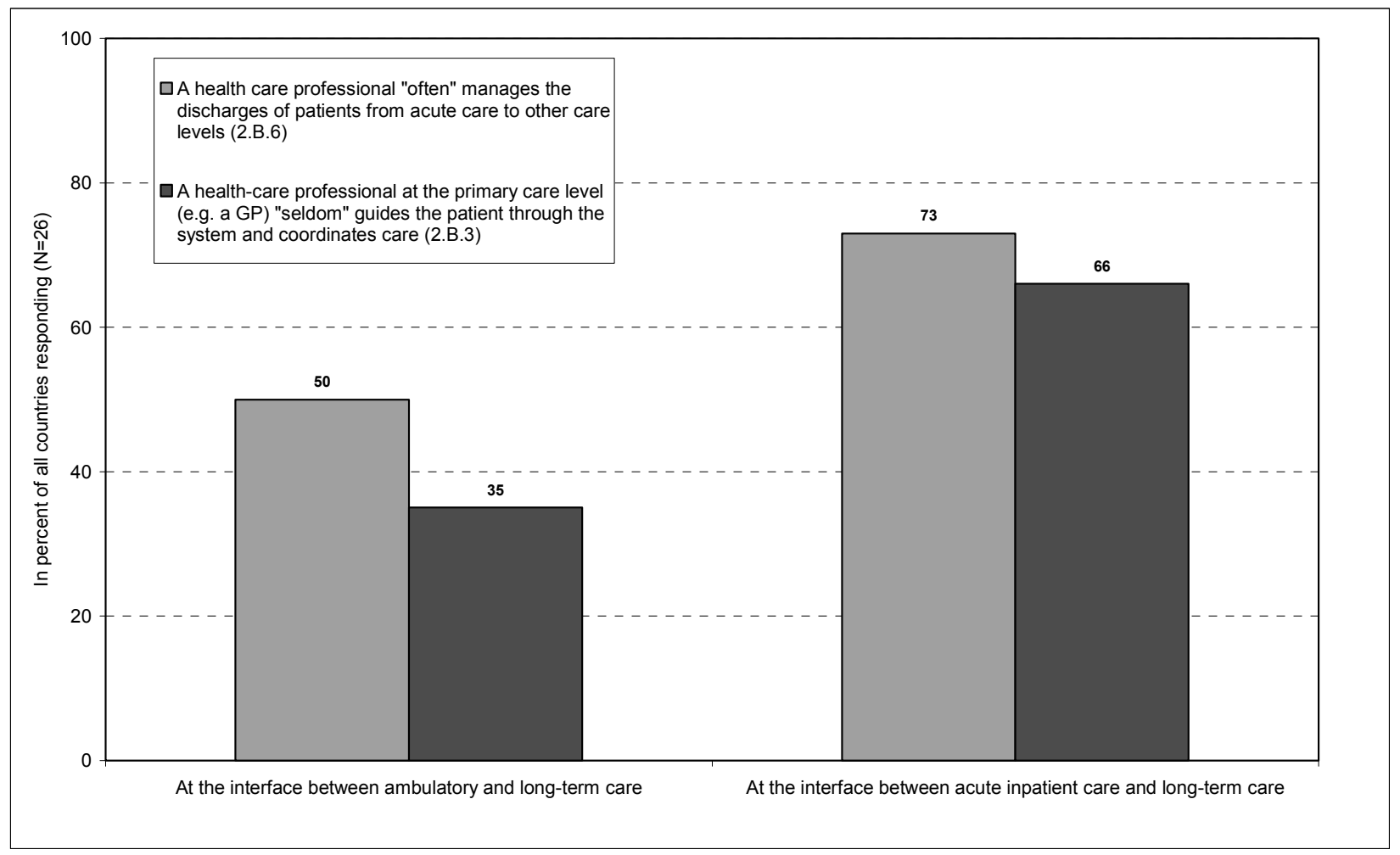

Source: OECD questionnaire on coordination of care $2006, \mathrm{~N}=26$.

\section{But countries still report significant difficulties at all of the interfaces with long-term care}

25. Nonetheless, countries indicate widespread difficulties at all of the transitions to long-term care: around two thirds of countries agree that difficulties exist at transitions from ambulatory care and four fifths at the level of transitions from acute care (Figures 1.5 and 1.8). In addition, countries that are particularly concerned with problems at these interfaces are also those that are highly concerned about efficiency issues more generally (See Figure 1.2). ${ }^{12}$ Despite health-care professionals managing transitions into long-term care, these services do not appear adequate or appropriately formulated to meet the challenge of care coordination (Figure 1.7 and Figure 1.8). These problems seem to prevail in spite of widespread efforts in many countries to improve continuity between hospital and community care (Leichsenring et al., 2004).

\section{Health-care systems do provide some form of guidance/coordination but it is not necessarily coherent across settings}

26. In sum, replies to the questionnaire provide a fairly consistent picture across countries of some form of care coordination in which health professionals help guide patients across institutional transitions and within individual sectors. However, country responses suggest that the health-care "coordinator" can, and often does, differ at each transition. In such cases, appropriate care coordination during any single episode of care may not be ensured. Problems of care coordination persist, particularly at the interfaces

12 This specifically concerns countries with tax-funded health-care systems. (Correlation between item 1B4 and $3 \mathrm{~A} 7$ in Annex 3; correlation $=0.757$, p-value: 0.004). 
with long-term care. The latter is possibly linked to administrative barriers: health-care systems are under the responsibility of Health Ministries, while long-term care systems are often run by Social Affairs Ministries or at other levels of government (OECD 2005b, Godfrey et al., 2003, Leichsenring et al., 2004).

Figure 1.8 Problems of care coordination and management of patients entering long-term care

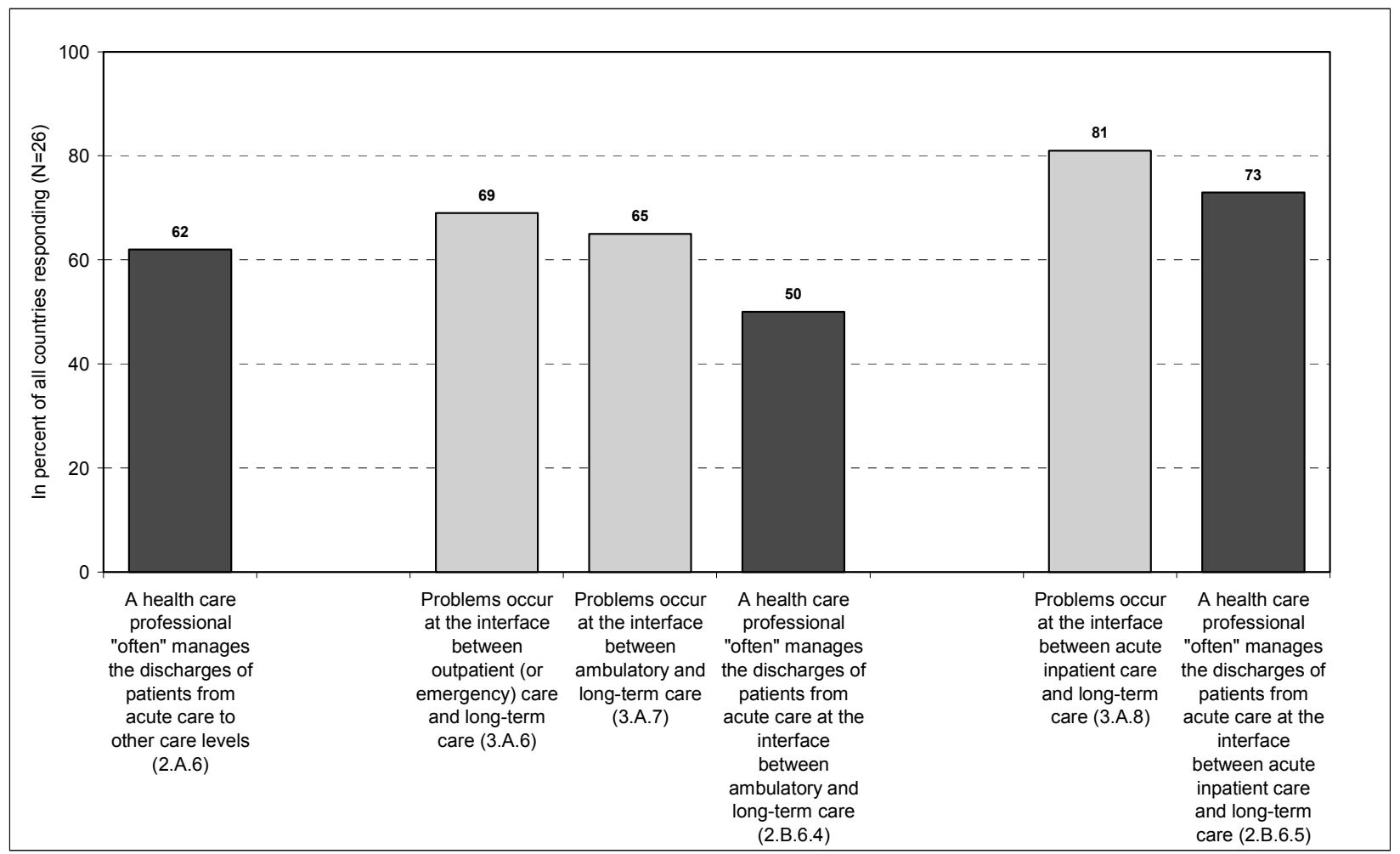

Note: dark bars: frequency in percent, light bars: degree of agreement

Source: OECD questionnaire on coordination of care $2006, \mathrm{~N}=26$. 


\section{CHAPTER 2. CONDITIONS FOR ACHIEVING BETTER CARE COORDINATION}

27. As discussed in Chapter 1, a majority of the countries surveyed consider that they have problems of care coordination, particularly at the interfaces with long-term care (see Figure 1.5 and Figure 1.8). The objective of this chapter is to provide a more detailed analysis of care-coordination problems and impediments and to identify policies that could lead to improved performance in terms of greater system efficiency and quality of care. Results derived from the analysis suggest that coordination of care and system performance may be improved by: increasing the availability of information on patient health and on the quality of providers; ensuring the adequacy of resources in ambulatory-care; paying greater attention to the incentives embodied in provider payment arrangements; reducing fragmentation of governance and supply; and, improving the capacity of the workforce to respond through new forms of care. These four subject areas are dealt with in succession.

\subsection{More readily available information on patient health and on provider quality is needed}

\section{Poor transmission of information between providers is seen as a key cause of weak coordination}

28. Information dissemination and transfer is a key (Arrow, 1963) and pervasive issue in many survey countries. The availability of medical records of individual patients helps providers make appropriate medical decisions for their clients and organise referrals were necessary. It can also help reduce some of the information asymmetries associated with health-care markets: information on provider performance embodied in patient records may help improve system governance, for example, by encouraging the provision of better quality care.

29. Questionnaire replies indicate that this is an important issue across responding countries. Almost all countries "frequently" or "regularly" debate the issue of poor transfer of information between providers (Figure 2.1). Medical records of individual patients help health professionals provide more coordinated care. Nonetheless they were "frequently" used in under half of the countries and "seldom" used in almost one third (see Figure 2.2). This is consistent with findings in the US where, for example, only 48 percent of patients with congestive heart failure leave the hospital with written instructions and follow-up care (Gauthier et al., 2006).

30. Transmissions of patient information is strongest at the interface with long-term care (see Figure 2.2) even though respondents indicated that care-coordination problems tended to be most intense at this transition (see Figure 1.5). This, in turn, suggests that policies other than information transfer may be needed at these cross-over points. 
DELSA/HEA/WD/HWP(2007)6

Figure 2.1 Policy debates concerning care coordination at a national level

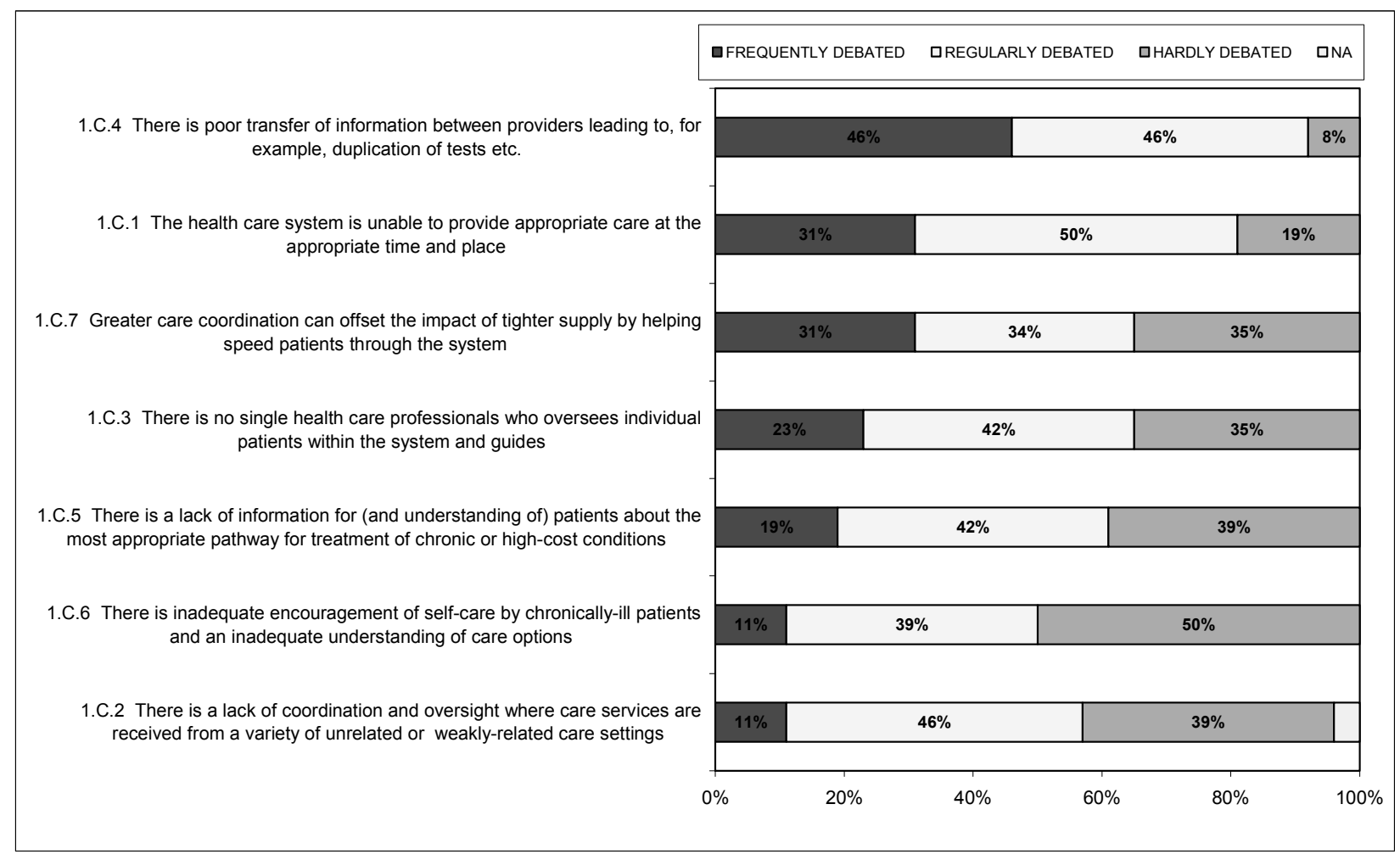

Source: OECD questionnaire on coordination of care 2006, N=26 (Annex 1, Table A1.2). 
Figure 2.2 Degree of information transfer between care settings

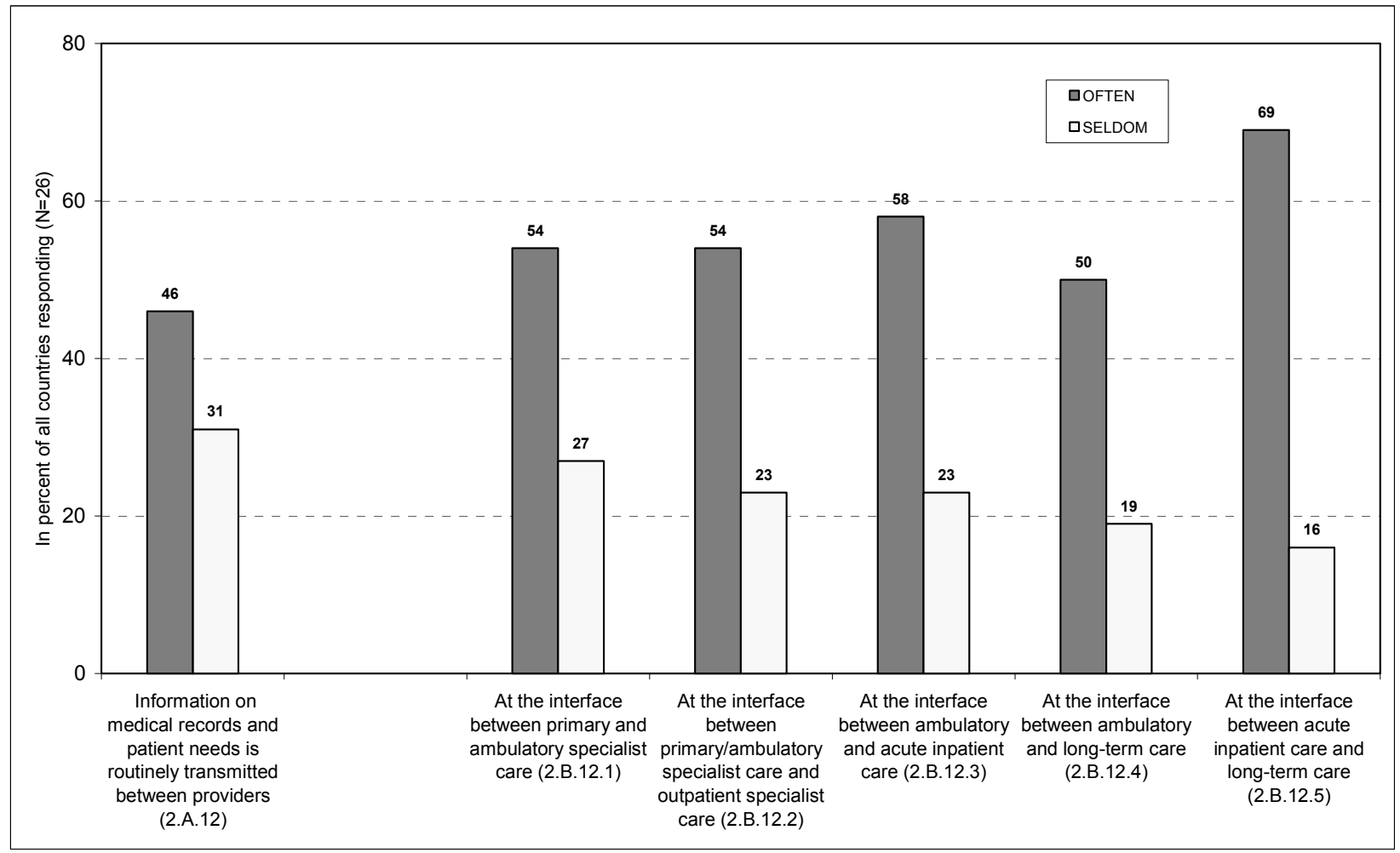

Note: The two left hand columns of Figure 2.2 represent the views of the responding countries for the overall system. The remaining columns reflect separate answers concerning information transfer at each one of the transitions. Since countries answered separately to questions at each one of the interfaces, it is possible that the share of countries indicated for the overall level is not entirely consistent with the share of countries at each one of the interfaces.

Source: OECD questionnaire on coordination of care $2006, \mathrm{~N}=26$.

31. The analysis of questionnaire replies provides some support for the role of improved information in enhancing care coordination:

- Countries with better information flows also have higher rates of referrals from hospitals back to ambulatory care - i.e. ease of transfer of medical records may facilitate referrals back to the primary-care level; ${ }^{13}$

- Countries that indicate that they have weak exchange of information across providers tend to be those where concerns about poor coordination at the interface with long-term care are the most intense; $;^{14}$

- Countries recognize that governance of the health-care sector is improved by better information exchange between providers. About half of responding countries indicate that lack of information about provider performance is a limiting factor in introducing more coordinated care (Figure 2.7).

\footnotetext{
13 Correlation between questions 2D4 and 1C4 in Annex 3; correlation 0.57, p-value $=0.04$ for social health insurance countries.

Correlation between questions $3 \mathrm{~A} 8$ and $1 \mathrm{C} 4$ in Annex 3; correlation $=0.44$, p-value $=0.03$. Correlation between questions $3 \mathrm{~A} 7$ and $1 \mathrm{C} 4$ in Annex 3; correlation $=0.51 \mathrm{p}$-value $=0.076$.
} 
Figure 2.3 Information flows and information support systems

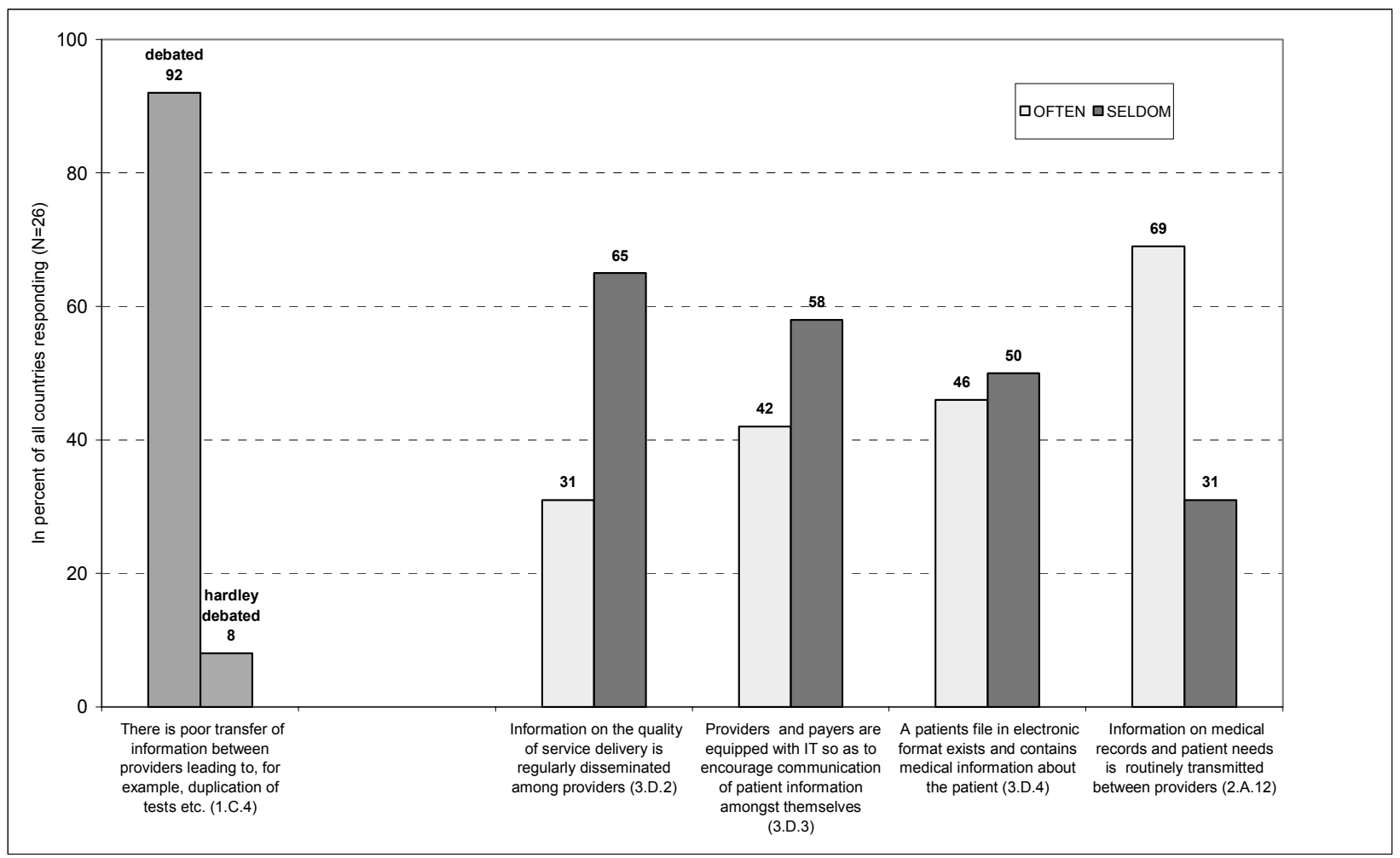

Source: OECD questionnaire on coordination of care $2006, \mathrm{~N}=26$.

\section{Information about the dissemination and the use of information technology (ICT) is limited}

32. Information technology provides scope for quality and efficiency gains (OECD 2006a and OECD 2006b), Anderson et al, 2006, McInnes et al., 2006). For example, Feachem et al., (2002) attribute a part of the purported difference in efficiency in service provision between the English NHS and Kaiser Permanente (a large staff-model HMO in California) to the continuous investment in ICT of the latter organisation. Questionnaire replies suggest that, despite the perceived benefits of these technologies, relatively few countries have so far put policies in place to enhance information collection and transfer.

33. Figure 2.3, for example, shows that the use of information technology is not very widespread, e.g. only 15 percent of countries say that providers are "often" equipped with IT. These subjective assessments contrast somewhat with other studies. For example, an EU Eurobarometer study (April 2003) finds that an average of 48 per cent of primary care practices in the Europe 15 group were computerised with substantially higher rates in northern European countries. Similarly, a survey of seven countries (Schoen et al. (2006a) finds high rates of introduction in Australia and most European countries and lower rates in North America. These different findings on diffusion rates suggest that information at the level of policy makers about the use of ICT in the health system may be incomplete and that these knowledge gaps are likely to be a source of concern as regards weak coordination practice. For example, Shekelle et al., (2006) indicate that widespread implementation of ICT has been limited by a lack of sufficient knowledge about what types of ICT and which methods of implementation will improve care and help manage costs for specific health organizations. 
34. Even though some countries reported frequent use of electronic health records, dissemination of exchange of information on the quality of service delivery is very infrequent (see Figure 2.3). This suggests that information systems may not have matured and/or that concerns about information security remain strong. Shekelle et al., (2006) also find that ICT in health have the potential to enable transformation in the delivery of health care, making it safer, more effective, and more efficient. Some organizations have already realized major gains through the implementation of multifunctional, interoperable ICT systems built around an electronic health records. For example, an electronic health record in the US Veterans Health Administration was largely developed around the needs of doctors. This is considered central to performance management and improvements (Oliver 2007a).

35. In practice, the intensity of use of ICT may be related to the degree of fragmentation of healthcare provision. For example, Audet et al., (2004) find marked differences in the use of information technologies between physicians in large group organisations and those in solo and small group practices. Furthermore, survey countries do not consider that information transfer between providers within "targeted" programmes was more rapid or complete than those not in such arrangements (see Figure 3.3), suggesting inadequate introduction or use of information systems.

\section{Interest in ICT is increasing}

36. Attitudes towards using ICT appear to be evolving. For example, about two thirds of Germans had already heard about electronic health records and more than 60 percent support the introduction of electronic information exchange (Amhof, 2006). This growing interest is also reflected in the programme of work on ICT in the health sector currently underway in the OECD Health Committee. Countries that are concerned about ICT are also those that are actively debating the need for a single health professional to act as a coordinator, providing guidance and overseeing patient needs. ${ }^{15}$ This could suggest that questionnaire respondents see a link between easy transmission of information and improved care coordination. Casalino et al., (2003), for example, find that organized care management in US physician organisations was more common when those groups used clinical information technologies and received incentives to improve quality of provision.

37. While concern has been expressed over privacy and information security, patients generally see ICT as a tool for improving the quality of health care ${ }^{16}$. Resistance to the introduction of ICT, which has come from many patient and citizen groups, may be declining. A recent survey in the United States suggests that patients appreciate both the easy access to their medical records and the benefits of having this information available to all doctors (Schoen, et al., 2005). ${ }^{17}$ This may reflect increased attention by policy makers to privacy issues. A cross-country study found that countries engaged in health information technology are developing standards that govern how patient data are collected and used. In Germany, for example, the collection of administrative data (e.g., co-payment status) is required, but patients can decide how clinical information - such as diagnoses and drug usage-is used and disclosed (Anderson et al., 2006). In this context, policies to ensure greater transparency for users may well be more important than the speed of introduction of ICT systems (Amhof, 2006).

15 Correlation between questions 3D3 and 1C3 in Annex 3; correlation 0.493, p-value 0.010.

16 The role of the Internet in the change in citizens' attitudes has probably been important. In 1999, it was estimated that more than $40 \%$ of searches on the Internet were health-related (Gruen, 1999) and a recent Eurobarometer study (EB Flash 135, April 2003) confirms that 40\% of Europeans use the Internet to find health-related information.

Almost 80 percent of respondents of the survey said that easy access to medical records is very important; a similarly high share said that it is very also important that all doctors have easy access to this information. 


\section{Countries need to evaluate the cost effectiveness of such systems with care}

38. Efforts to improve coordination of care and to raise the level of efficiency should aim at improving the flows of information through the system. A significant improvement in the capacity of the system to transmit patient information to other providers on a timely basis would appear to provide scope for important efficiency gains through better collaboration between providers and better informed medical decisions. In this context, a significant number of countries are putting national programmes in place to this end (or are considering doing so). These include Canada, Denmark, Finland and the United Kingdom (OECD 2006a). Nonetheless, introducing such systems is not an easy task. Investments in ICT that permit easy communication of such data are costly and countries that have embarked on such policies have most often faced high costs and programme delays. ${ }^{18}$ Careful balancing of potential costs and benefits is needed to ensure that such programmes are cost-effective. ${ }^{19}$

39. Increased flows of patient information will enhance capacity of providers to collaborate more closely. This is particularly important because more and more care is being provided outside hospitals, making the transmission of information between providers more difficult. Intensified efforts are needed to build capacity, particularly in ambulatory-care settings.

\subsection{The capacity of ambulatory care providers to coordinate needs strengthening}

\section{Problems in ambulatory care may be the result of changing patterns of demand}

40. Over recent decades, there has been a trend to shift patients from hospital care towards other care settings and, in particular, ambulatory care (OECD 2005a), where much care coordination reportedly takes place (Boerma, 2006). These shifts have been significantly aided by the development of new medication that has permitted better control of chronic disease. However, ambulatory care providers have traditionally focused on easily treatable disease with specialist referrals for more complex cases. In addition, this sector has often been organised around independent self-employed contractors operating in solo practice, although there is a significant subset of countries with other provider arrangements such as primary care clinics.

41. Increased chronic disease is also leading to growing needs for care provision in an ambulatory environment as care delivery is increasingly associated with a shift from "cure" towards "care" and "follow-up". Problems resulting from these changes are most important for the elderly, particularly those afflicted by multiple pathologies (see Figure 1.1 and Box 2). These new patterns of demand may now be placing greater pressure on resources in the ambulatory care sectors and this can be expected to increase as a result of population ageing (see Chapter 1).

42. Expenditure data (for a sample of 10 countries for which disaggregated spending data are available) indicate that there has been little shift in the patterns of spending despite changing patterns of demand associated with chronic disease. Spending in real terms has been growing most rapidly for medical goods (which are largely made up of drugs) over the last decade, leading to a small increase in its overall share of spending (Figure 2.4). At the same time, the share spent on hospital and ambulatory care services

18 For example, Protti, (2007) reports investment costs per capita that range from an estimated 133 Canadian dollars in Canada to 570 Canadian dollars per enrolee in Kaiser Permanente with the level depending also on the degree of sophistication of the system.

In a review of 10 European countries, Stroetmann (2006) finds that on average it could take as long as 4 years for ICT investments in health to show a positive annual return and five years for a positive cumulative return. There was a wide range around this mean across countries. 
-- taken together - has fallen. While the fall in the expenditure share for hospitals is more marked than for ambulatory care, there has been no significant shift of total spending towards ambulatory care. ${ }^{20}$

Figure 2.4 Expenditure by provider, in percent of total expenditure on health, 1995 and 2004

(and changes in percentage points)

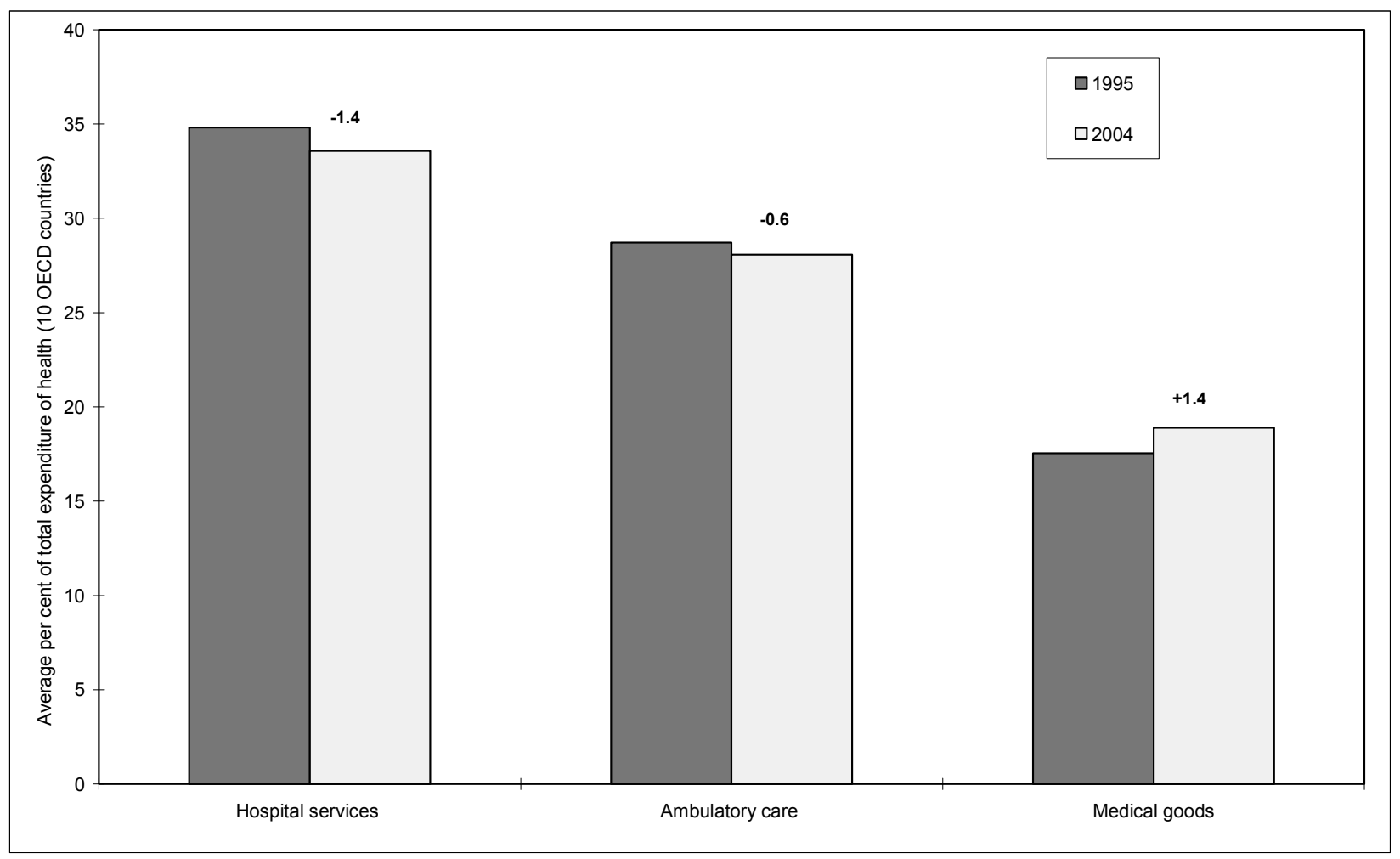

Source: OECD Health Data 2006. Note: Includes Australia, Canada, France, Germany, Korea, Luxembourg, Mexico, the Netherlands, Portugal and the United States. The shares of the components in the figure do not sum to 100 because expenditure on services of nursing and residential care facilities, on services of public health organisations, on services of public health administration and on health services of other industries have not been included.

Capacity problems in ambulatory care may be reflected in flows of referrals of patients.

43. Earlier results show that patients normally enter the health-care system at the primary-care level and then proceed -- mostly via referrals -- to progressively higher levels of care as required by their medical condition (Figure 1.3). An analysis of referral patterns - after controlling for spending levels -indicate two features of interest in this context (see also Figure A1.8 in Annex 1):

- First, countries that frequently refer patients from primary to higher levels of care (either ambulatory or hospital specialists) express less concern about care coordination than those that do not; ${ }^{21}$ the components. 
- Second - and in contrast - countries that indicate a greater frequency of referrals from higher levels of care back to primary care are more likely to indicate that they have problems with care coordination. ${ }^{22}$

44. These two effects are widespread across interfaces but are particularly notable for long-term care (Table A2.5 in Annex 2). This pattern could suggest that primary or ambulatory care providers may be easing capacity constraints by referring more difficult cases to specialist care as quickly as possible but may be overburdened, at the same time, by demands from difficult cases discharged from hospitals. Further statistical tests provide some support for this view:

- Countries with higher densities of hospital beds tend to make fewer referrals back to ambulatory care. ${ }^{23}$ More beds may allow for longer hospital stays (albeit with some extra cost) and may be associated with better follow-up at the hospital level, thereby reducing the need for referrals back to the ambulatory sector.

- Countries indicating frequent use of high-cost emergency wards in hospitals because of inadequate or inconvenient ambulatory-care supply are more likely to state that they have carecoordination problems. ${ }^{24}$

45. These features suggest that countries may need to review policies in two areas: first, whether the balance of resources going to ambulatory care relative to inpatient care is appropriate; and, second, whether current models of ambulatory-care provision are adapted to the emerging chronic care needs (see Chapter 1). In practice, these two dimensions are likely to be closely linked.

46. As noted, policy makers may need to consider increasing the level of available resources in outpatient care. However, if this is not to lead to increased overall spending, economies will need to be found within the broader health-care system. Any additional payments to ambulatory care should be conditional on the ability and willingness of medical practitioners to eliminate existing regulatory barriers that prevent new and more efficient care models from emerging. This could include, for example, permitting providers to share practices (and practice personnel and facilities), to contract with third parties or to cooperate more closely with inpatient care. It should also be linked with measures to better align incentives with system objectives through a review of remuneration arrangements (see next section). It will also be important that the increased emphasis on out-patient care lead to lower demand for higher cost hospital inpatient services and, where this is the case, that hospital services be wound back.

47. Finally, policy makers should attempt to break down the barriers between different care silos thereby helping systems to become more patient centred. For example, Light and Dixon (2004) - in commenting on recent English reforms (see section 4.3) -- argue that shared budget responsibility between primary and secondary care providers at Kaiser Permanente -- where most patients are diagnosed and treated by multidisciplinary teams -- is a key lesson in the search for greater control of costs. This would argue in favour of broader contracting arrangement that cross institutional boundaries and encourage system-wide integration in the approach to care.

\section{New models of ambulatory care are emerging}

48. As described in Chapter 4 for England, Germany and the United States, new ways of organising and contracting for ambulatory care are being considered and implemented and have been accompanied, in some cases, by regulatory changes that permit other health-care professionals to take on a wider range of

\footnotetext{
22 Odds Ratio 1.10: p-value, 0.038 (see model 1, Table A2.5 in Annex 2).

$23 \mathrm{t}$-test on the difference of the means ( $\mathrm{p}$-value $=0.05$ ).

24 Odds Ratio, 1.18: p-value, 0.090 (see model 3, Table A2.5 in Annex 2).
} 
tasks under the control and supervision of doctors. Patient-centred care delivered by a coordinator outside hospitals or at interfaces between sectors will be increasingly necessary, especially in the light of rapidly emerging chronic care needs. For example, a recent study surveying primary-care physicians in seven countries found that primary-care doctors share many common challenges, including improving coordination of care for patients with chronic disease. Despite these similarities, the survey indicates sharp differences in the incentives facing providers, in the availability IT capacity, in the use of care teams, and in patient access to care (Schoen et al., 2006a). The development of more appropriate and efficient ambulatory care models will require paying greater attention to incentives arising from payments systems and to new and more effective ways of providing services.

\subsection{Payment schemes need to be better aligned with system-wide objectives}

\section{There is a wide range of different payment models in use}

49. Capitation and mixed payment schemes are the most prominent forms of payment in primary care (Table 2.1). ${ }^{25}$ Specialist ambulatory care is most frequently paid for on a fee-for-service basis, while specialist care provided in a hospital outpatient environment is mostly salaried with relatively fewer copayments when compared with ambulatory specialists. Prospective case rates, such as DRGs, are now the most common payment scheme in acute hospital care. But they are often combined with budget envelopes, partly reflecting the incentive of case rates to increase supply. Long-term care is predominantly paid for on a per-diem basis with case rates infrequent. Out-of-pocket payment seems relatively more widespread in long-term care than in other sub-sectors. (See Box 4 for indications of specific incentives associated with each of these payment methods.).

Table 2.1 Payment schemes in health sectors, 2006

(share of countries replying "yes"; $\mathrm{N}=26$ )

\begin{tabular}{|c||c|c|c|c|c|c|c|c|}
\hline & $\begin{array}{c}\text { Fee-for- } \\
\text { service }\end{array}$ & Capitation & Salary & Mixed & $\begin{array}{c}\text { Budget } \\
\text { payments }\end{array}$ & $\begin{array}{c}\text { Case } \\
\text { rates }\end{array}$ & $\begin{array}{c}\text { Per } \\
\text { diem } \\
\text { rates }\end{array}$ & $\begin{array}{c}\text { Out-of- } \\
\text { pocket } \\
\text { payments }\end{array}$ \\
\hline \hline PRIMARY CARE & $42 \%$ & $35 \%$ & $23 \%$ & $54 \%$ & $9 \%$ & $4 \%$ & $0 \%$ & $31 \%$ \\
\hline $\begin{array}{c}\text { SPECIALIST CARE } \\
\text { (ambulatory) }\end{array}$ & $65 \%$ & $0 \%$ & $38 \%$ & $15 \%$ & $9 \%$ & $12 \%$ & $0 \%$ & $46 \%$ \\
\hline $\begin{array}{c}\text { SPECIALIST CARE } \\
\text { (hospital outpatient) }\end{array}$ & $54 \%$ & $4 \%$ & $54 \%$ & $19 \%$ & $27 \%$ & $27 \%$ & $4 \%$ & $39 \%$ \\
\hline $\begin{array}{c}\text { ACUTE INPATIENT } \\
\text { CARE }\end{array}$ & $33 \%$ & $4 \%$ & $54 \%$ & $19 \%$ & $38 \%$ & $69 \%$ & $19 \%$ & $42 \%$ \\
\hline \begin{tabular}{c} 
LONG-TERM CARE \\
\hline
\end{tabular} & $23 \%$ & $8 \%$ & $42 \%$ & $19 \%$ & $23 \%$ & $8 \%$ & $50 \%$ & $62 \%$ \\
\hline
\end{tabular}

Source: Note: Multiple answers were possible such that the rows often sum to a value greater than 100). This reflects the complexity of payment arrangements within individual countries. For example in primary care 42 per cent of countries have fee for service as a payment method but 31 per cent of these services is financed through out-of-pocket spending as well. Source: OECD questionnaire on coordination of care $2006, \mathrm{~N}=26$.

50. Replies to the questionnaire provide some hints concerning the links between existing payment arrangements and country replies about care coordination concerns.

$25 \quad$ There was no information as to which system was dominant in each country or the mix of different components of mixed payment systems. 
- Countries with fee-for-service payments in specialist care are also those that are more likely to consider that they have care-coordination problems at this level ${ }^{26}$

- Countries with mixed payment schemes (a combination of fee-for service, capitation and/or salary) at the levels of specialist care and long-term care have a lower risk of having carecoordination problems;

- Countries with out-of-pocket payments are also those that have higher degrees of concern about care coordination. ${ }^{27}$

In addition, out-of-pocket payments in long-term care are also closely linked with perceived problems in acute inpatient care - after controlling for patient entry and referrals (Odds Ratio 170: p-value, 0.029 (see model 9, Table A2.6 in Annex 2). One possible reason for this last result is that higher cost-sharing in these two sectors may encourage patients to rely more heavily on ambulatory care. It may also affect efficiency in hospital care as there is an incentive for patients in need of long-term care to remain in inpatient care as long as possible. 


\section{Box 3. Problems of care coordination and payment incentives}

The box Table below shows the results of tests linking the type of payment schemes in individual countries with perceived problems in care coordination. The results are shown for the entire health-care sector and the three subsectors. For each of these a "+" or "- "indicates the direction of changes - i.e. a positive sign indicates that the presence of a specific type of payment mechanism is associated with a higher perceived degree of concern - as shown in Figure 1.5 --in the sector indicated in the column heading. The second column under each heading indicates the sub-sectors where that particular payment mechanism impacts on perceived problems. ${ }^{28}$

Box Table 1. The impact of payment schemes on the likelihood of reporting problems of care coordination

\begin{tabular}{|c|c|c|c|c|c|c|c|}
\hline \multirow[b]{3}{*}{ Fee for service } & \multicolumn{7}{|c|}{$\begin{array}{l}\text { Impact of payment schemes on the likelihood of problems in care } \\
\text { coordination per sector }\end{array}$} \\
\hline & \multicolumn{2}{|c|}{ HEALTH SYSTEM } & \multicolumn{2}{|c|}{$\begin{array}{l}\text { AMBULATORY } \\
\quad \text { CARE }\end{array}$} & \multicolumn{2}{|c|}{$\begin{array}{l}\text { ACUTE INPATIENT } \\
\text { CARE }\end{array}$} & $\begin{array}{l}\text { LONG TERM } \\
\quad \text { CARE }\end{array}$ \\
\hline & + & $\begin{array}{l}\operatorname{AIC}^{*} \\
\operatorname{LTC}^{*}\end{array}$ & + & $\begin{array}{l}\mathrm{PC}^{*} \\
\mathrm{SOPC}^{*} \\
\mathrm{AIC}^{*}\end{array}$ & & & \\
\hline $\begin{array}{c}\text { Mixed (combination of fee } \\
\text { for service, capitation } \\
\text { and/or salary) }\end{array}$ & - & $\begin{array}{l}\text { SAMBC } \\
\text { SOPC }^{* *} \\
\operatorname{LTC}^{* *}\end{array}$ & - & $\begin{array}{l}\text { AIC }^{*} \\
\text { LTC }^{*}\end{array}$ & - & $\begin{array}{l}\operatorname{AIC}^{* *} \\
\operatorname{LTC}^{*}\end{array}$ & \\
\hline Case rates, e.g. DRG & - & $\begin{array}{l}\operatorname{SAMBC}^{*} \\
\operatorname{LTC}^{*}\end{array}$ & - & $\begin{array}{l}\text { SAMBC }^{*} \\
\text { SOPC }^{* *} \\
\text { AIC }^{* *}\end{array}$ & - & $\begin{array}{l}\text { SAMBC }^{* *} \\
\operatorname{LTC}^{*}\end{array}$ & \\
\hline $\begin{array}{c}\text { Per diem rates, e.g. bed } \\
\text { days }\end{array}$ & - & $\mathrm{LTC}^{\star *}$ & - & LTC $^{*}$ & & & $\operatorname{AIC}^{* *}$ \\
\hline Out-of-pocket payments & + & $\begin{array}{l}\text { PC }^{*} \\
\text { SOPC }^{*} \\
\text { AIC }^{*} \\
\text { LTC }^{*}\end{array}$ & + & $\begin{array}{l}\mathrm{PC}^{* *} \\
\mathrm{AIC}^{*} \\
\mathrm{LTC}^{*}\end{array}$ & + & LTC $^{* *}$ & \\
\hline \multicolumn{8}{|l|}{ * significant at $10 \%$} \\
\hline \multicolumn{8}{|l|}{$\mathrm{PC}=$ primary care } \\
\hline \multicolumn{8}{|c|}{ SAMBC $=$ specialist ambulatory care } \\
\hline \multicolumn{8}{|l|}{$\mathrm{SOPC}=$ specialist outpatient care } \\
\hline \multicolumn{8}{|l|}{$\mathrm{AIC}=$ acute inpatient care } \\
\hline $\mathrm{LTC}=$ long term care & & & & & & & \\
\hline
\end{tabular}

Source: OECD questionnaire on coordination of care $2006, \mathrm{~N}=26$

28 For example, fee-for-service payments in primary care (PC), in specialist outpatient care (SOPC) and in acute inpatient care (AIC) make problems of care coordination in ambulatory care more likely (second cell in the first row). To take another example, mixed payment schemes in specialist ambulatory care (SAMBC, SOPC) and in long-term care (LTC) make system-wide perceived problems of care coordination less likely. 
These results are broadly consistent with what theory and empirical studies suggest about the impact of payment schemes on provider behaviour and on the way they deliver services. For example, fee-for-service payment schemes provide incentives to deliver high quality of care - or at least they have the potential to do so. However, fee-for-service payment can also lead to over-provision of care because providers - based on their information advantage - may induce demand beyond medically-necessary levels and offset efforts to contain cost (Ginsburg and Grossman, 2005).

In contrast to fee-for-service schemes, flat fees (salaries, capitation) do not encourage high levels of supply, and may lead to a low level of provision and waiting lists. Furthermore, it may encourage doctors to refer more patients than medically indicated to specialists or hospitals, leading to provision of care at an inappropriate level. In order to prevent too frequent referrals, medical providers can be asked to share some of the risk (cost) associated with referrals. This was, for example, pursued in the fund-holder initiative launched in the United Kingdom in the early 1990 s and in the current primary-care arrangements. Although the impact of salaries on efficiency and equity seems largely undetermined, payment by salary has been associated with the lowest use of tests and the lowest number of referrals compared with fee-for-service schemes and capitation (Gosden et al., 1999).

In attempts to contain over-provision, countries have gradually moved to mixed payment schemes in various care sectors (Hartmann, et al., 2006). Mixed payment schemes often combine fee-for-service payments with capitation or salary. In sum, mixed payment schemes seem to make problems of care coordination less likely. This is consistent with recent proposals to promote better care coordination in the United States (Davis, 2007). However, it is not easy to design systems with the right balance between flat-rate and fee-for-service components. While quality care delivery may be enhanced with fee-for service components, a relatively large flat-fee element may, at the same time, stimulate high levels of referrals (Iversen and Luras, 2000).

A meta-analysis of studies of referral patterns by and large confirms a priori expectations of payment incentive effects on referral behavior (O'Donnell 2000). However, in that study, incentives explain less than 40 percent of the variation in referral rates even after taking into account patient characteristics (case mix) and only around 10 percent after adjusting for physician and practice characteristics. Thus, intrinsic psychological variables, e.g. risk behavior in the case of uncertainty, are also important factors influencing the referral frequency of individual doctors.

Finally, prospective-case payments such as case rates or DRGs provide incentives to hospitals to increase the through-put of patients (to increase revenues) and to reduce costs per care episode. This should increase technical efficiency. At the same time, it also encourages providers to reduce their costs either by limiting the amount of care provided during the hospital stay or by discharging the patients earlier than clinically desirable (i.e. quicker and sicker). Where hospitals refer patients early to ambulatory care providers or to long-term care arrangements, the demand for care in both sectors will increase. As noted, statistical tests demonstrate that countries indicating high frequencies of referrals from hospitals to primary care are more likely to perceive that there are problems of care coordination. At the same time, frequent referrals from primary care to specialist care are associated with fewer perceived concerns (see Figure A1.8 in Annex 1 and Table A2.5 in Annex 2).

\section{There are few contractual incentives to encourage coordination of care}

51. Relatively few countries encourage care coordination on a contractual basis (see Figures 2.5 and 2.6). Survey results show that the use of financial incentives is infrequent: only 31 per cent "often" have explicit payment for care coordination at the primary-care level and widespread application is apparently found only in Japan, Latvia and in the Slovak Republic. Care coordination objectives or stipulations regarding quality are even less frequent. Thus, there is little financial encouragement for improved care coordination from payment arrangements, even though coordination takes time and needs to be rewarded.

52. In many cases, current arrangements do not appear to encourage the development of skills aimed at chronic-care management, communication with patients, patient support and networking with other providers, particularly in the social- or long-term care sectors. Some studies suggest that time allocated to see patients can differ significantly across countries and between the predominant payment schemes in use. For example, Boerma (2003) finds that home visits are more likely if providers are paid on a fee-for- 
service basis ${ }^{29}$ and that GPs spend less time with patients in countries where they work under a mixed capitation scheme (compared with countries with salary and fee-for-service).

53. Only a small fraction of countries has given their primary-care coordinators budgets to purchase care for their patients and there is little selective contracting with the objective of promoting coordination or their capacity to provide these services (see Figure 2.6).

Figure 2.5 What are the incentives for care coordination?

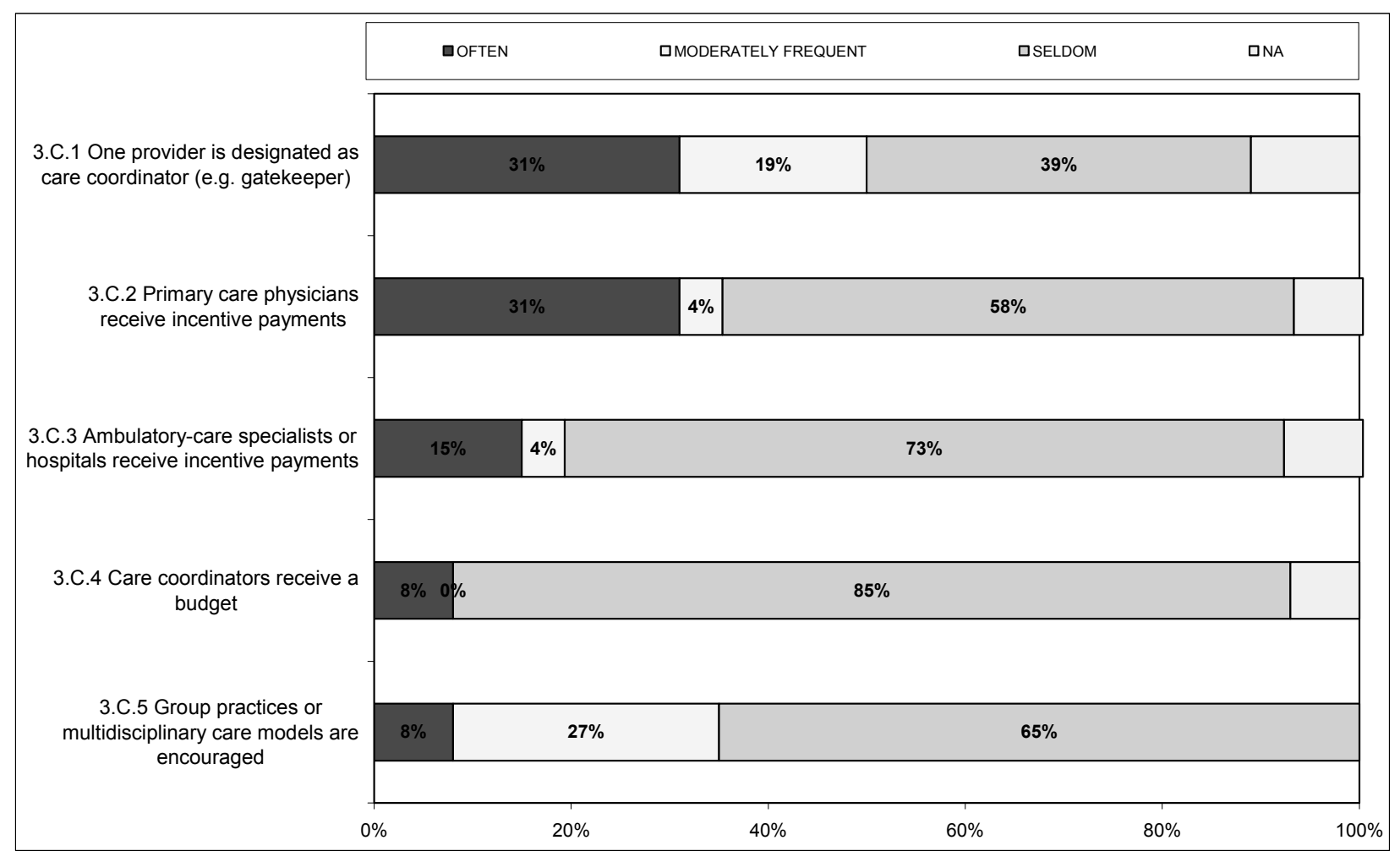

Source: OECD questionnaire on coordination of care 2006, N=26 (Annex 1, Table A1.16). 
Figure 2.6 Arrangements and incentives for care coordination

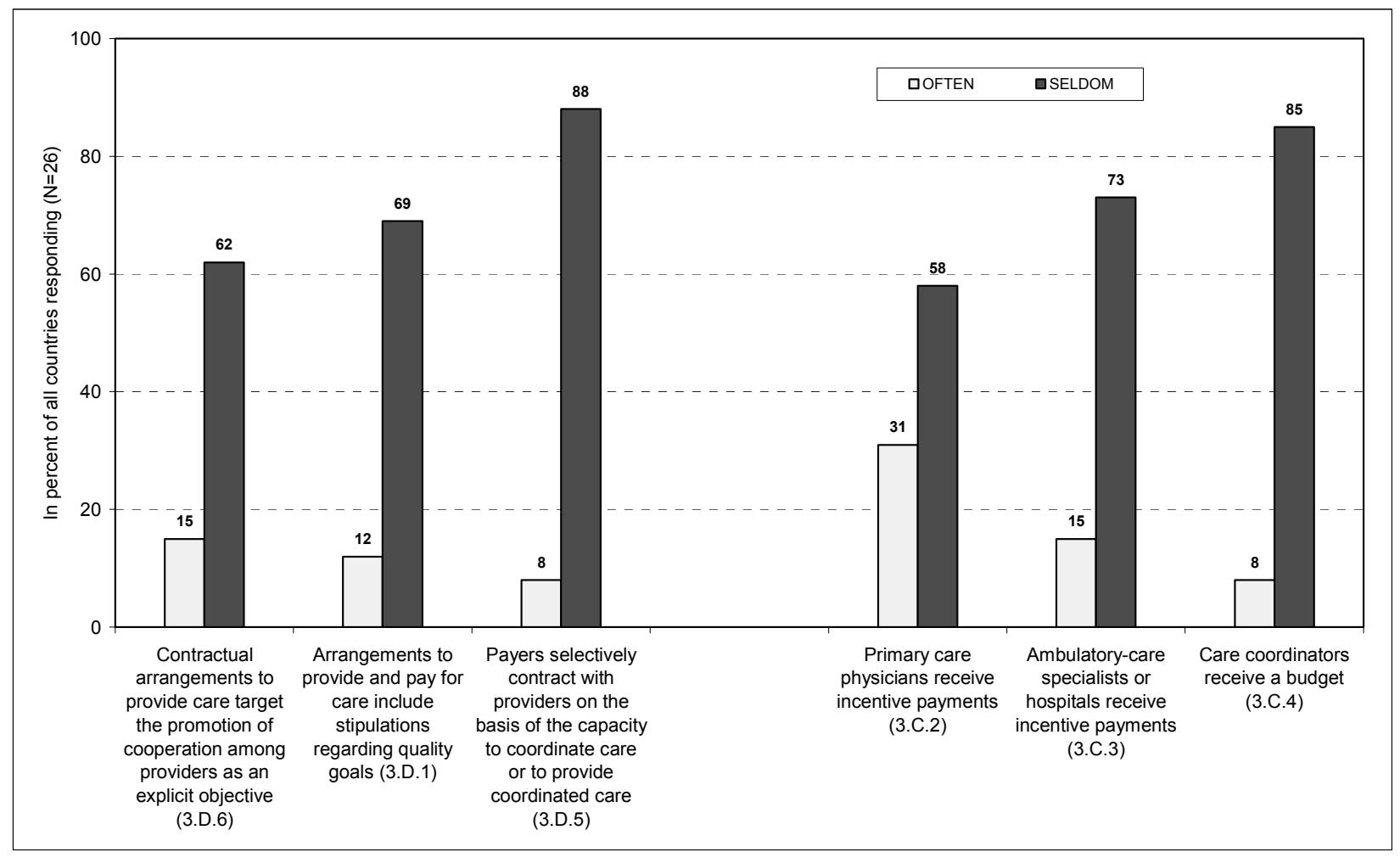

Source: OECD questionnaire on coordination of care $2006, \mathrm{~N}=26$.

\section{Attention needs to be paid to the system-wide impact of payment arrangements}

54. In setting payment schemes, attention needs to be paid to the indirect spill-over effects of payment arrangements in one sector on others (Davis 2007). As noted in Box 3, where hospitals are paid by case rates ${ }^{30}$ they may discharge patients early and refer them either back to ambulatory care or on to long-term care providers. Even though no direct link between discharge practice and case rates in the hospital sector could be established, questionnaire replies indicate a higher level of concern about poor care coordination where referrals from hospitals to other care settings are frequent (see Section 2.2 and Figure A1.8).

55. At the same time payment policies to control demand at the level of ambulatory care can hamper more comprehensive care for people with multiple care needs. For example, recent research shows that gate keeping practices increased the number of elective admissions to hospitals when providers are not confronted with budgets or explicit prices (Dusheiko et al., 2006). In this context, literature also suggests that strict gate-keeping may as well lead to over-use of hospital or specialist services where there is low accuracy in diagnosis at the GP level (Brekke et al., 2007).

56. Within this broader context, payment incentives at the level of primary or ambulatory care are likely to be particularly important in fostering coordinated-care delivery. Efforts to improve care coordination need to ensure that primary-care providers are rewarded for the time taken to oversee the care

$30 \quad$ In 2006 about half of OECD countries have implemented performance-based payment schemes in acute inpatient care, see for details OECD (2007), Box 1. 
needs of chronically-ill patients. A number of statistical results - including those reported in Box 3 provide some evidence that primary-care payment schemes that combine salary or capitation with fee-forservice payments appear to provide better overall incentives for care coordination. However, the impact on care coordination will be more powerful where fee-for-service payments specifically remunerate coordination activities (Davis 2007).

57. Much policy attention is currently being given in the United States to developing more comprehensive payment schemes for primary care that link, for example, a certain fraction of disbursements to providers to the achievement of efficiency and health-outcome targets, including greater patient-centred care (Goroll et al., (2007). Combined payments for providers for care episodes that cross inpatient and outpatient settings are also being debated (De Brantes and J. A. Camillus, 2007). More recent US proposals suggest combining lump-sum payments for a delivery system that includes the fees of both the hospital and the physician in order to promote more team working between providers (Cortese et al 2006). The United Kingdom is currently re-engineering fund-holding and is experimenting with such approaches within the context of primary-care-practice commissioning (see also section 4.3). Recent evidence about the impact of fund-holding practices indicates that doctors holding budgets provided patients with more non-medical support services and better practice organization (Dusheiko et al., 2007). ${ }^{31}$

58. These findings demonstrate the difficulties involved in aligning payment schemes across health sectors and the most appropriate mix of payment arrangements. This is all the more the case as the impact of payment reforms on provider behaviour often remains uncertain (Grytten and Sorensen, 2007). Particular attention needs to be paid to any negative effects on other policy goals such as equity of access and patient choice (Karlson, 2007). Changes to remuneration arrangements will, thus, require experimentation, discussion and debate, in particular with providers. As this is likely to be a slow process, government policy makers may be able to achieve more rapid improvements in care coordination by targeting institutional or regulatory impediments as discussed in the next section.

\subsection{Regulatory and administrative barriers to cooperation across sectors need to be reduced}

\section{Financing of care from diverse sources may make patient-centred care more difficult to achieve}

59. The financing of health-care systems in respondent countries is often characterised by separate budgets for individual segments of care. These can reinforce other regulatory barriers lying between "silos" and contribute to fragmentation of the overall health-care system. These barriers can include:

- Administrative separation between the health-care sector and the long-term-care sector. This is often combined with vertical divisions of responsibility for providing care, with long-term care often the responsibility of lower levels of government in many countries.

- Organisation of care over small geographical areas. This may lead to difficulties in planning and providing efficient and quality care services over wider areas (e.g. Switzerland, OECD, 2006c).

60. In these cases, the various health-care sectors are often financed on different budgets, use different administrative systems and apply different rules and regulations for the attribution of care (Reed et al., 2005, Lloyd and Wait, 2005). This can sometimes lead to cost shifting from one level to another (Joumard and Suyker, 2002). Under these conditions, creating an improved environment for care coordination becomes more difficult.

61. Questionnaire results provide some indications of where problems arise:

31 However, overall patient satisfaction has been higher in non-fund-holding practices. 
- Countries reporting vertical dispersion of responsibility for providing care between different levels of government have a greater risk of care-coordination difficulties in the area of long-term care $^{32}$;

- Countries where different levels of government have responsibility for providing different levels of care are also those that have more intense policy debates about cost-efficiency (see Chapter 1) both in tax-financed and social-security-financed countries ${ }^{33}$;

- Countries where care is organized within narrow geographical areas also debate issues of costefficiency more intensely ${ }^{34}$ and this is particularly the case for countries with social insurance systems. $^{35}$

- Countries where care provision is largely tax financed appear to have less efficiency concerns arising from governance ${ }^{36}$. This could suggest that health systems largely financed from one budget may be structurally more integrated than social insurance countries. However, this finding could also reflect a reporting bias.

- Countries indicating problems of care coordination in ambulatory care also tend to be those where there are care-coordination difficulties in long-term care as well. As already noted, ambulatory care - as it is currently organised in many countries -- may not have adequate resources or be appropriately structured to address emerging chronic care needs.

32 OR 36.40; p-value 0.271, see Annex 2, Table A2.6

33 Correlation between questions 1B4 and 3B2 in Annex 3; correlation 0.519, p-value 0.057 (for the subset of countries largely financed by social health insurance ( $\mathrm{SHI})$ ).

Correlation between questions 1B4 and 3B2 in Annex 3; correlation -0.461, p-value 0.066 (for the subset of countries with largely tax funded systems (TAX_F)).

Correlation between questions 1B4 and 3B4 in Annex 3; correlation 0.510, p-value 0.008. 
Figure 2.7 Do administrative barriers between sectors hamper coordination of care?

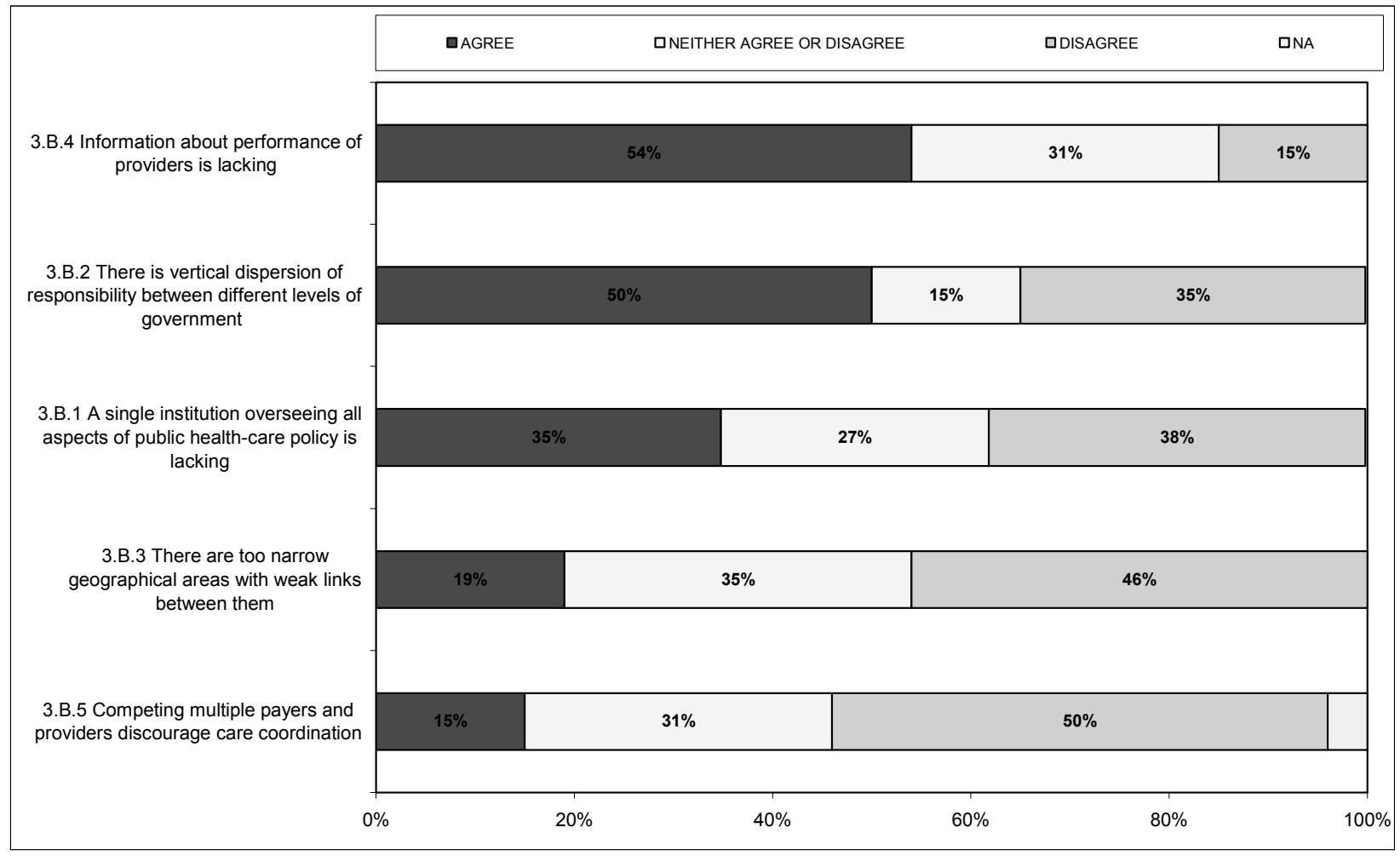

Source: OECD questionnaire on coordination of care 2006, N=26 (Annex 1, Table A1.15).

\section{System integration could help improve care coordination}

62. Integration has taken a wide range of dimensions and can signify anything from the closer coordination of clinical care for individuals to the formation of managed care organizations that either own or contract for a wide range of medical and social support services. Examples of these developments are HMOs and integrated care organisations in the United States and polyclinics and integrated care models in Germany (see Chapter 4) These developments reflect the view that better clinical co-ordination may benefit quality of care, particularly for the chronically ill and experience from the social HMO demonstration in the United States has shown that, for elderly at least, community long-term care can be integrated with acute care, at a manageable cost (Leutz et al., 1994).

63. A similar approach would be to bundle resources from different sources (e.g. cross-institutional pooling of resources) for specific purposes across institutional boundaries. Measures of this kind are under consideration in a number of countries. One possible model currently being introduced in the United Kingdom, concerns primary-care commissioning where the primary-care provider purchases services for individual patients (on the basis of an indicative budget provided by the Primary Care Trust (see section 4.3)). This gives doctors greater oversight of the health budget for their patients, allowing them to control spending on an "episode-of-care" basis. It may also give the primary-care doctor more control over other providers. Similar measures may need to be provided/extended to long-term care facilities. It may intensify collaborative efforts targeted on selected needs, which are of potential benefit to both the care and social sectors - for example, to limit costly acute-care hospital stays for people with chronic diseases through case management (e.g. community matrons in the UK, $(\mathrm{DoH}, 2004)$ ).

64. Alternative approaches concern the recent implementation of "integrated care contracts" in Germany (see section 4.2) or "reform pools" at the state levels in Austria. Both of these policies attempt to 
stimulate cooperation between sickness funds or local governments across sub-sectors of the health-care system in order to promote better coordination of care. Local Area Agreements in the UK have much the same purpose and allow health and long-term care providers to finance collaborative care services on a local basis that benefit both sectors. Alternatively, some countries, like the Netherlands have been successfully experimenting in this area with "transmural" care where, for example, GPs head a unit in general hospitals - for example stroke units - and in which GPs, home care organizations, hospitals and nursing homes participate (Calnan et al., 2006). In all of these cases, the simple fact that diverse payers, (e.g. sickness funds and/or local governments) in collaboration with providers are forced to negotiate programmes needed to enhance care coordination may already create greater awareness of existing problems impeding system-wide coordination.

65. A large body of evidence shows that multidisciplinary-care models have potential for reducing utilization and maintaining health status for the elderly who are chronically ill (Sommers et al., 2000, Shortell et al., 2004). Likewise, team performance within the US programme (the Programme of Allinclusive Care in the United States) was significantly associated with better functional and with better long-term urinary incontinence outcomes. This suggests that, PACE improved patient outcomes by improving the functioning of care teams (Mukamel et.al 2006). Furthermore, improved discharge planning and re-organised post-acute care through better medical oversight and the active involvement of physicians during transitions has been found to prevent costly re-admissions in acute-care settings (Naylor et al., 1999, Wolff et al., 2002).

\section{Broadening the scope of activities and improving mutual professional esteem among providers may encourage care coordination}

66. Questionnaire results suggest that scope-of-practice rules may also limit the capacity of systems to adopt new models of providing care, particularly in the ambulatory sector. They show that regulation of professional profiles of health-care providers impedes care coordination by nurses in at least one quarter of the countries (Figure 2.8). Problems of care coordination in ambulatory care seem more likely when there are regulatory barriers between doctors practising in ambulatory care and in the hospital sector. ${ }^{37}$

67. As described below in Section 4.1, the implementation of the chronic care model in the United States may require practice nurses -- or other health professionals with coordination tasks -- taking on a wider role in the care process under the control of medical doctors (Wagner et al., 2001). While there is a considerable debate over the appropriate scope of activities of, say, nurses (Courtenay and Maynard, 2006, Lankshear et al., 2005), up-skilling of medical staff and the creation of new types of health-care workers versed in coordination techniques may be required (Sibbald et al., 2006).

68. There is also some evidence that coordination of care could be enhanced if there were greater mutual respect among health-care providers. Questionnaire results, for example, confirm weaker professional esteem for primary care and long-term care providers in about half of the countries (see Figure 2.8). Countries that perceive lack of professional esteem for certain professional groups also see themselves as having problems arising from regulations that limit the scope of provider activities. Such results could suggest that countries with a high degree of mutual esteem among providers may be better able to make more flexible use of the potential of all health-care professionals. ${ }^{38}$

37

After controlling for payment schemes and professional respect. Odds Ratio, 15.25: p-value, 0.050 (see model 5, Table A2.6 in Annex 2).

Coordination problems in long-term care - holding the average frequency of referrals constant - tend to be significantly more likely in social health insurance countries than in tax-funded countries (Wilcoxon ranksum test $=-2.0$, p-value $=0.04$ and see Figure 1.3.). 
Figure 2.8 Regulations governing permitted activities on coordination of care

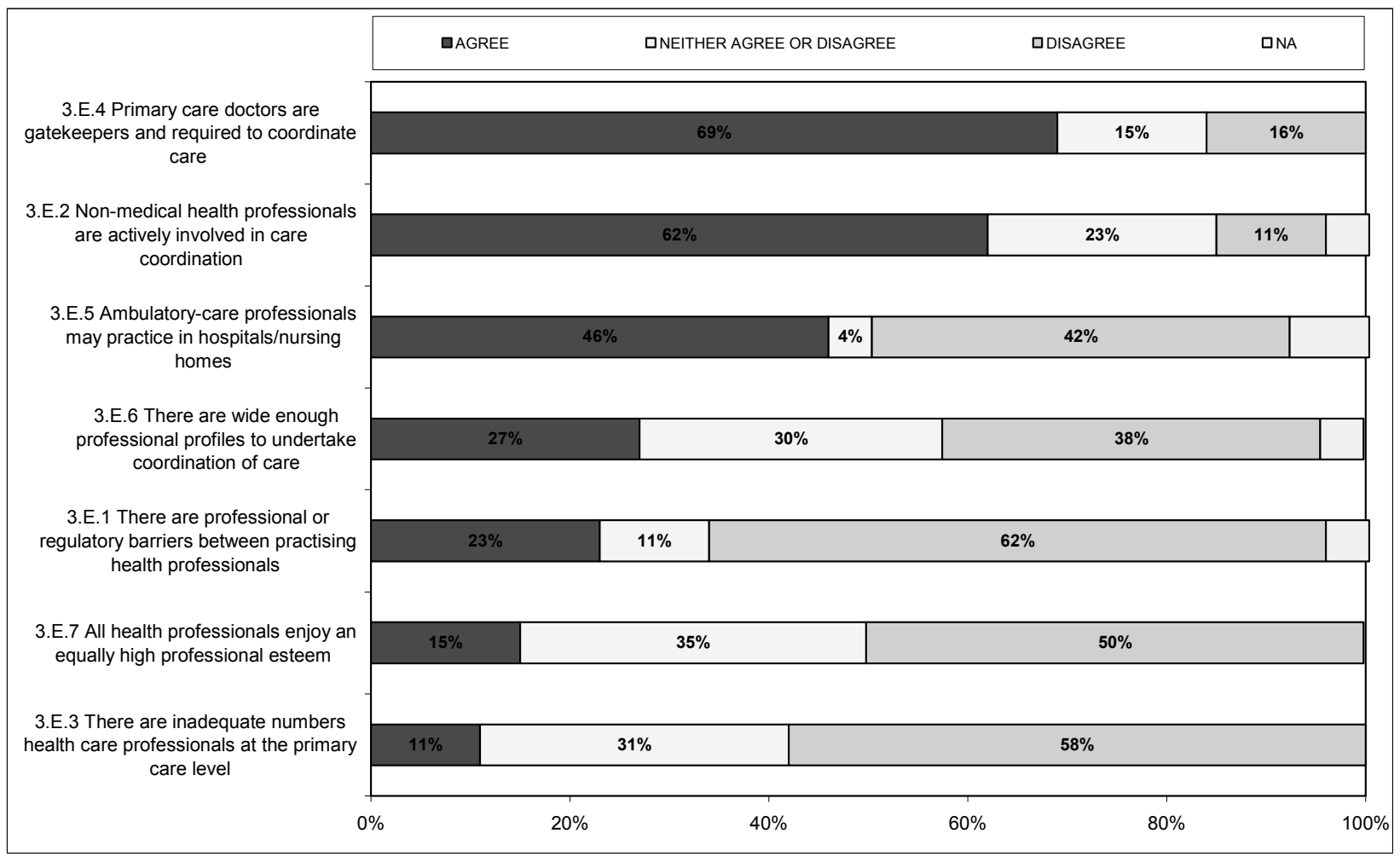

Source: OECD questionnaire on coordination of care 2006, N=26 (Annex 1, Table A1.18).

69. In sum, improved care coordination requires a mix of measures ranging from better organized ambulatory care to patient-centred integration of health and long-term service provision. All of the four key areas under consideration appear important for achieving the much-desired improvements in the performance of health-care systems, although the precise mix of policies will necessarily differ across countries. Enhanced information transfer across providers is key in this context. Furthermore, payment models which encourage cooperation across sectors and reward multidisciplinary care need to be developed to better engage providers at all levels in reorganizing the health-care system. The following chapter looks in greater detail where countries currently are in efforts to stimulate coordination of care, focusing on targeted disease management programmes as these appear to be the area receiving the most policy attention. 


\section{CHAPTER 3. "TARGETED" CARE CO-ORDINATION PROGRAMMES AND POLICIES}

70. This chapter reviews country experiences with policies/programmes that have emerged over the past decade aimed at improving care coordination for the chronically ill (see Box 1). It first summarises country experience as reported in the questionnaire (see Annex 1 and 3). It then reviews evidence from the literature.

71. The various types of care-coordination programmes listed in Box 1 do not fundamentally differ in intent, but do so in terms of emphasis, patient focus and in detail. Because the programmes under consideration are aimed at the chronically ill, they are broadly referred to, in this report, as "targeted programmes". The results of the questionnaire and the literature review both suggest that "disease or case management", programmes are the most widely used approach in OECD and EU countries. These have largely been developed in the United States. As noted in Chapter 1, interest in such arrangements has been driven by two key objectives. First major improvements in the quality of care are needed, particularly for those with chronic conditions (Naylor et al., 1999, Casalino et al., 2003). Second, overall health-care costs need to be contained. In this context, it is hoped that improved quality of care delivery - along with various forms of patient education and follow-up - should reduce the demand for high-cost care, for example in the form of un-planned hospital stays.

\subsection{Experience with targeted programmes: a cross-country overview}

72. Countries were requested to provide information on programmes of the types listed in Box 1 and for five very common chronic disease types: Cancer, Diseases of the circulatory system, Diabetes, Chronic lower respiratory conditions and Dementia (see Questionnaire, Annex 3).

\section{There are few countries with specific care coordination programmes in place}

73. Whatever the precise definition of these programmes, it would appear that there are relatively few countries with targeted care-coordination programmes aimed at the listed disease categories (Table 3.1). ${ }^{39}$ On average, only 6 to 7 countries (around one quarter) report that they have targeted carecoordination programmes in place, taking into account both the programme type and the medical condition under consideration. ${ }^{40}$ Programmes for diabetes - all programme types taken together -- are the most prevalent with dementia the least.

74. Detailed country comments drawn from the questionnaire indicate that there is, nonetheless, considerable experimentation in a number of other countries, although it is not always clear whether these initiatives were limited to pilot-programmes or whether they have been introduced on a widespread basis and actively promoted and used. Some of these developments go beyond "targeted" programmes and concern efforts to improve coordination within existing health-care systems by restructuring care delivery within and across sectors including long-term care.

39 Seven countries had no readily available information on programmes (Canada, Denmark, Estonia, Latvia, Spain, Sweden and Turkey). Spain indicated that there are some selected programmes in a few autonomous regions (see Box 5). Some of these countries have decentralised responsibility for the organisation of care provision (e.g. federal arrangements) which may help explain the difficulty in obtaining more information. In addition, Austria, Japan and the Slovak Republic indicated that there were no programmes of this nature in their countries.

The United States also has such programmes with different insurers but was unable to respond to the questionnaire. 
Table 3.1 Share of countries reporting targeted programmes

(Percent)

\begin{tabular}{|c|c|c|c|c|c|}
\hline & Cancer & $\begin{array}{c}\text { Diseases of the } \\
\text { circulatory } \\
\text { system }\end{array}$ & Diabetes & $\begin{array}{l}\text { Chronic lower } \\
\text { respiratory } \\
\text { diseases }\end{array}$ & \begin{tabular}{||c|} 
Dementia and \\
other \\
degenerative \\
diseases of the \\
nervous \\
system \\
\end{tabular} \\
\hline Care management & $30 \%$ & $22 \%$ & $35 \%$ & $17 \%$ & $17 \%$ \\
\hline Case management & $22 \%$ & $17 \%$ & $30 \%$ & $13 \%$ & $13 \%$ \\
\hline Continuing care & $35 \%$ & $26 \%$ & $30 \%$ & $26 \%$ & $21 \%$ \\
\hline Disease management & $30 \%$ & $30 \%$ & $52 \%$ & $26 \%$ & $17 \%$ \\
\hline Episodes of care & $13 \%$ & $13 \%$ & $21 \%$ & $9 \%$ & $17 \%$ \\
\hline Patient pathways & $17 \%$ & $26 \%$ & $48 \%$ & $17 \%$ & $9 \%$ \\
\hline
\end{tabular}

Source: OECD questionnaire on coordination of care $2006, \mathrm{~N}=26$.

\section{Box 4. Targeted care coordination programmes in OECD countries}

Australia: In the primary-care sector, Medicare --Australia's national insurance system -- supports a range of structured care services for people with chronic conditions. This includes rebates for services such as health assessments, management plans, team care, case conferencing and reviews. Also a range of specific treatments covered by Medicare and other initiatives have recently been introduced to provide better and more coordinated care to the mentally ill. In addition, there are a range of initiatives in place to increase the capacity of health and aged-care sectors to provide good dementia care through various approaches. A number of trials of targeted programmes have taken place but with ambiguous results concerning cost effectiveness.

Austria: Better integration of acute inpatient care and ambulatory care was one important aim of the 2005 Health Reform Act. At the state (Laender) level, Funds have been created to promote coordinated care both within and across regions but resources remain limited. Some of the state authorities have implemented a disease management programme for diabetes while others focus on cancer care or care for cardiovascular diseases. Structural changes in supply are aided by a nationwide framework -- the Austrian Health Plan -- which provides for services on each care level based on regional morbidity information and other indicators. Furthermore, special nursing staff or social workers in hospitals -- who are in charge of coordination with other care settings (outpatient services, rehabilitation) in the context of discharge management -- have been established in recent years. Although considerable experimentation is going on in this area, e.g. in Vienna, the capacity and resources of discharge managers are limited.

Belgium: Disease management programmes mainly concern diabetes, for which an episode-of-care approach and the definition of patient pathways have been established.

Canada: Care-coordination programmes - covering those which are monitored by the Health Council of Canada at a national level - have been introduced gradually and are mainly at the demonstration stage. Most attention has been given to care for the elderly. Some provinces are working towards a more integrated approach to care policy, such as the introduction of Local Health Integration Networks (LHINs) in Ontario and the Reseaux locaux de Services $(\mathrm{RLS})$ in Quebec. Eventually, these may help support more specific care-coordination policies.

The Czech Republic: All types of programmes exist for all five pathologies with the exception of i) programmes of continuing care for dementia; and, ii) care-episode approaches for all groups. Patient pathways have been defined for diabetes.

Denmark: A strategy for the improved care and coordination of care in chronic conditions is being developed.

Hungary: Case management for diabetes has been established along with, continuing care for all 5 disease groups. Patient pathways have been defined for all 5 groups except dementia. This has been introduced within a context of managed-care experiments that allow health-care providers (a group of doctors, a polyclinic or a hospital) to become a "care-coordinator organisation" which then contracts with other providers for care needed by their patients. 
Italy: Legislation provides for the possibility of creating a range of different types of care programmes but has, up to now, limited itself to disease management programmes for several pathologies.

Korea: Case management programmes for diseases of the circulatory system, diabetes and dementia have been set up along with a disease management programme for diabetes. Patient pathways for diseases of the circulatory system and diabetes have been defined.

Mexico: The main social insurance institute (IMSS) has programmes for care and case management for cancer, diseases of the circulatory system and diabetes as well as disease management, episode-of-care programmes and patient pathways for all 5 disease categories.

The Netherlands: has continuing care arrangements for cancer and dementia, disease management for diabetes and has defined patient pathways for diabetes.

New Zealand: A care-management programme for cancer, a disease-management programme for diabetes and patient pathways for chronic lower respiratory diseases have been introduced. In addition, a more general programme, at the primary-care level ("Care Plus"), aims to improve the patterns of provision to make them more responsive to patients. "Dependable Systems for Long-Term Conditions" have been introduced in this context to enhance the capacity of "Care Plus" programmes to deliver simple but highly cost-effective interventions and care coordination for common, uncomplicated long-term conditions. These include intensive secondary prevention; supported selfmanagement and care coordination (all based on best-practice care management).

Portugal: Case management programmes exist for all disease categories except dementia. Continuing care is in place for all five disease groups. Disease management exists for all illness categories except dementia.

Spain: A few of the autonomous regions have small-scale programmes aimed at improving care coordination and contain elements of a case or disease management approach. In practice, these programmes have been more successful in small-sized medical areas (which are generally rural where the relations between the hospital and primary care are tighter than in the larger urban environments).

Switzerland: Case management has been set up by the main Swiss accident insurer (SUVA) for individuals with serious problems following an accident. This programme ensures that the right care is made available and appropriately sequenced. It is claimed that this programme has helped keep down the growth in insurance premia, which have risen significantly less rapidly than for the public health-care system (OECD, 2006c).

\section{Very few countries conduct detailed evaluations of targeted programmes}

75. Largely reflecting the experimental nature of many targeted programmes in responding countries, questionnaire replies indicate little evaluation of direct costs and benefits of these countries among responding countries. As a result, comprehensive cost-effectiveness studies appear to be virtually nonexistent (Figure 3.1). Net economic costs of these programmes were evaluated "moderately frequently" only in the Netherlands. Additional administrative costs are not monitored except in the Netherlands and Turkey. Such instruments to assess whether programmes should be extended further has been used only rarely with only Italy, Sweden and the UK indicated that such policy tools were widely employed. 
Figure 3.1 Are programmes evaluated?

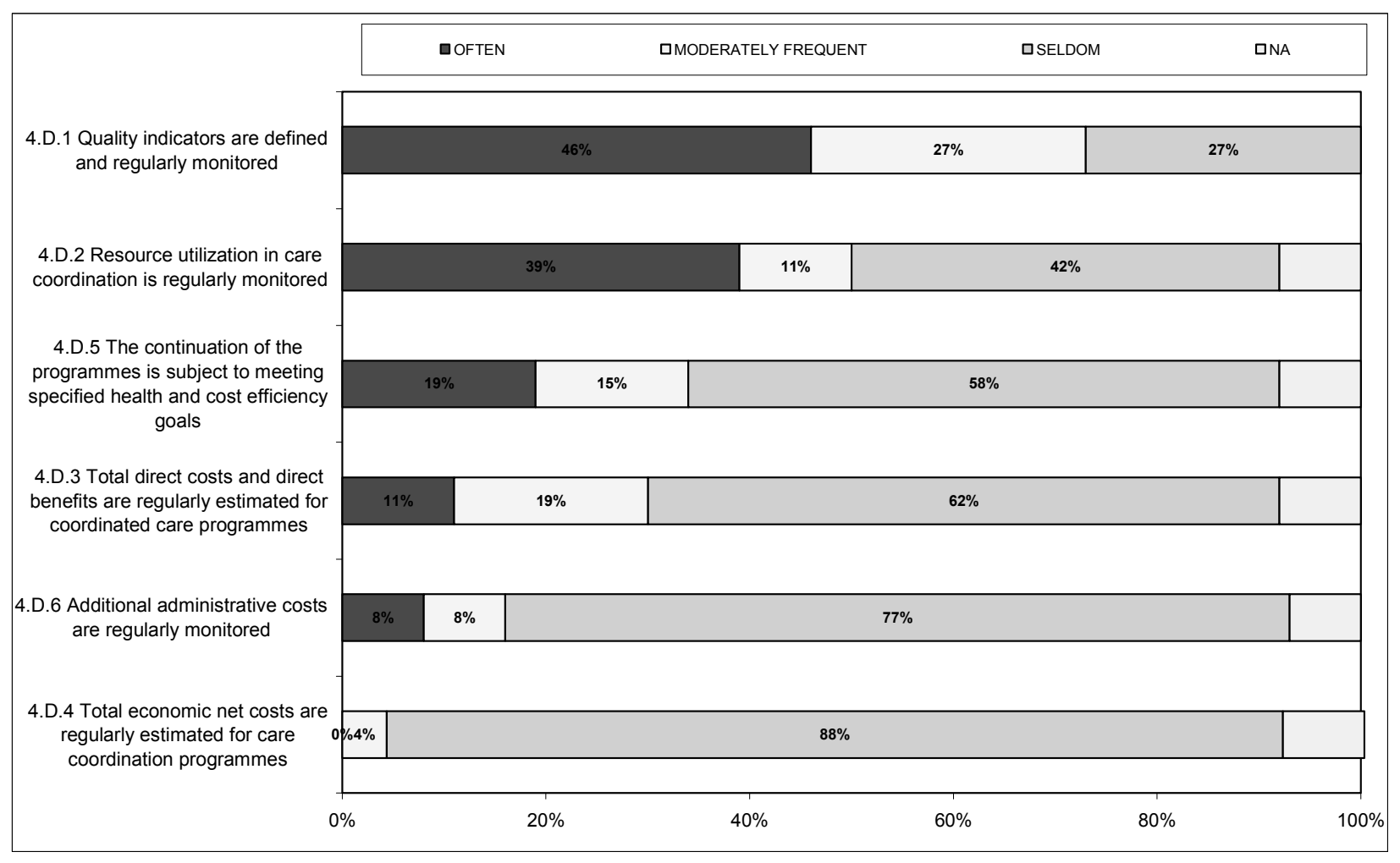

Source: OECD questionnaire on coordination of care 2006, N=26 (Annex 1, Table A1.21).

76. Overall, twelve out of the twenty-six countries reported that quality indicators were regularly reviewed and ten regularly monitored the resource utilisation of care coordination policies. However, the patterns of questionnaire responses suggest that the replies of some countries may have related to more general and system-wide reviews or assessments rather than specific/formal care coordination policies and programmes.

\section{Targeted programmes have potential but knowledge about their impact on quality and cost-efficiency is limited}

77. Consistent with the goal of reducing costs (see Figure 1.2), questionnaire replies suggest that countries see shorter hospital stays and reduced re-hospitalisation, treatment in less costly settings (especially ambulatory care), and better follow-up and self-care as key ways in which targeted programmes can help improve efficiency (Figure 3.2). However, a similar share of countries indicated that they were unable to make conclusive judgements about the impact of care coordination programmes on cost efficiency, possibly reflecting the absence of formal evaluations (see Figure 3.1) and/or the absence of adequate information to make necessary assessments on a comparable basis within and across countries. The results of the OECD questionnaire therefore suggest that countries appear unable, as yet, to reach a considered view about the longer-term effects on performance. As regards quality, about half of the responding countries agreed that better targeted programmes, improved adherence to best practice medicine and allowed speedier access and improved patient satisfaction (Figure 3.3) but with a significant share of countries unable to assess what are the most important channels. 
DELSA/HEA/WD/HWP(2007)6

Figure 3.2 Have targeted programmes increased efficiency?

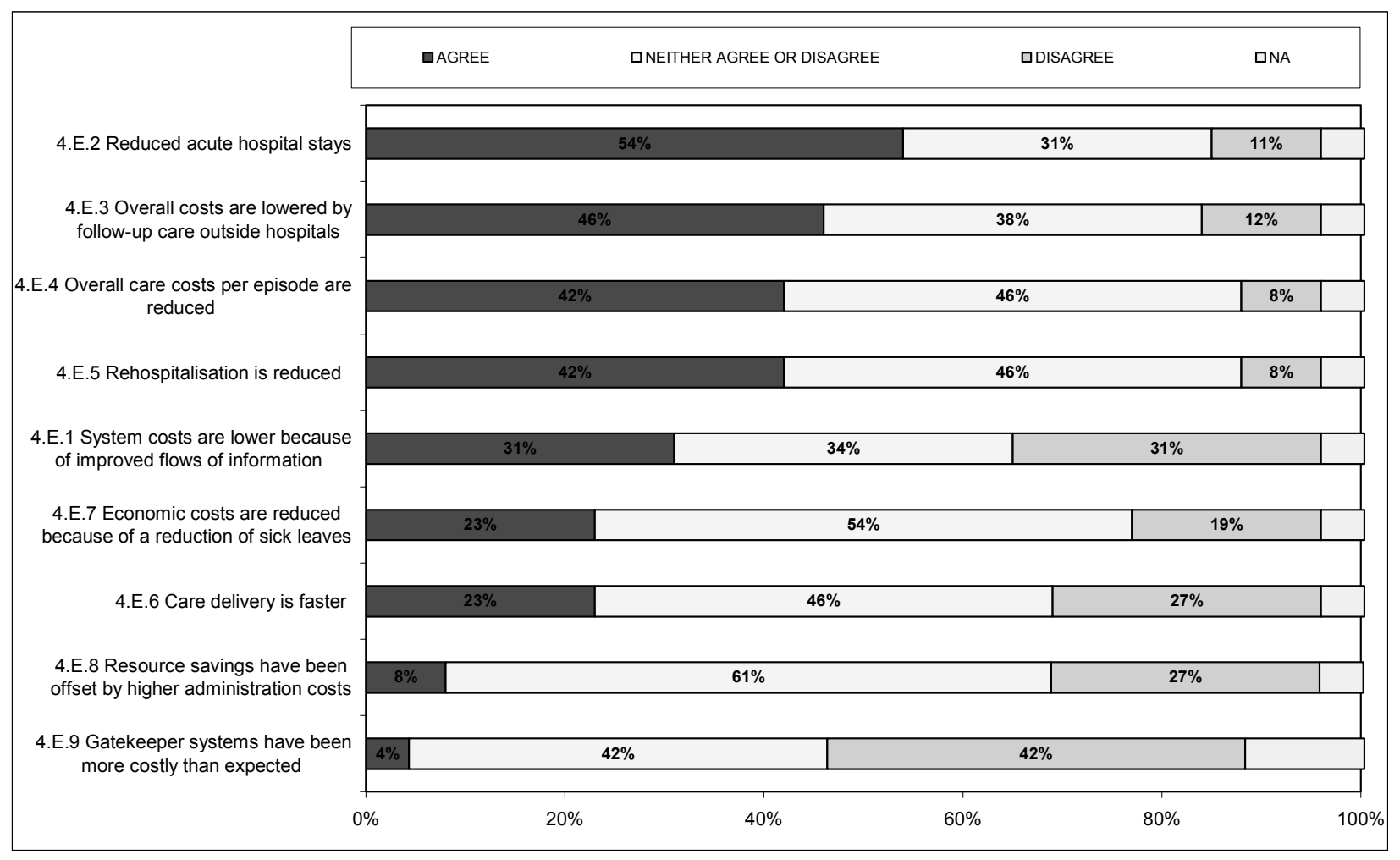

Source: OECD questionnaire on coordination of care 2006, N=26 (Annex 1, Table A1.22). 
Figure 3.3 Have targeted programmes increased quality and patient responsiveness?

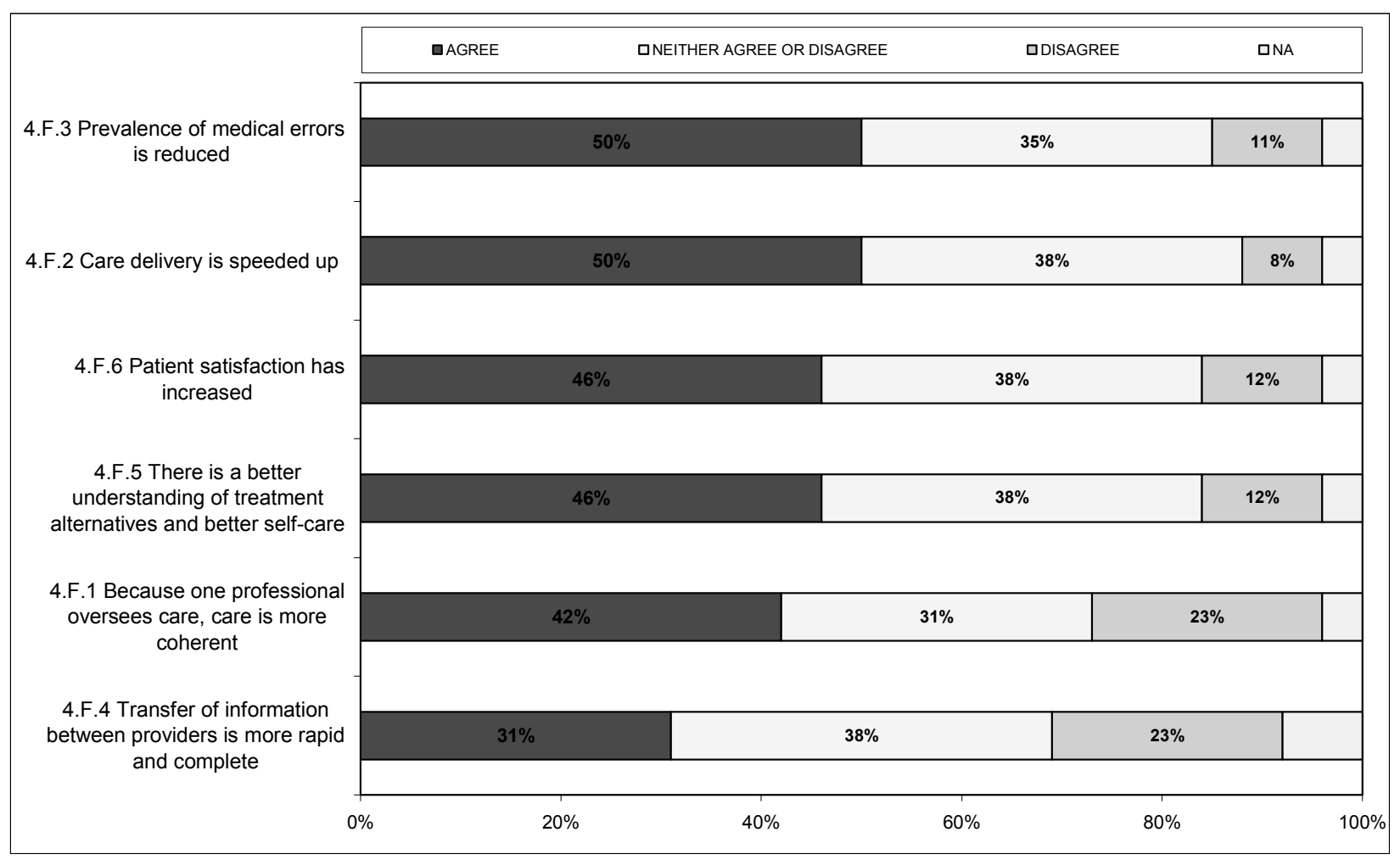

Source: OECD questionnaire on coordination of care 2006, N=26 (Annex 1, Table A1.23).

\subsection{The impact of disease/case management programmes: a review of recent literature}

78. Of the different programme types listed in Box 1, most attention has been focused on disease and case management. The key attraction of these programmes lies in the expectation that they can lead to better quality of care and, thereby, to better quality of life for the chronically ill. At the same time, reduced costs are expected to ensue as better quality of ambulatory care limits the need for high-cost hospital stays or visits to accident and emergency departments. These programmes have two additional advantages. They offer the prospect of cost savings without invoking unpopular restrictions on utilisation or on benefits (Short et al., 2003), something that is particularly important in the United States; and, they tend to operate in parallel with the existing care system and thereby do not require changes to the existing patterns of care provision (Casalino, 2005).

79. In these models, disease management is generally focused on patients with one chronic condition. However many reviews of disease management also include case management which is normally reserved for patients with serious and multiple conditions requiring more intense follow-up. In practice, the definitions between the two are often blurred. ${ }^{41}$ As regards disease management, one private provider of these services identifies three levels of care: supported self-care for those in good health with stabilised conditions; disease management for those with a risk of complications and case management for those with a high risk and who often need hospitalisation (IGAS, 2006). Thus, disease management per se is often defined as focusing on those individuals with a single chronic condition while case management is

$41 \quad$ For example, Ouwens et al. (2005) notes that 20 different definitions of disease/case management had been used in the studies that they reviewed. 
reserved for individuals with multiple pathologies. Box 5 provides further detail on the nature of these programmes.

80. Key expected results of disease or case management on quality can include: better adherence to clinical guidelines; better patient education in how to deal with the chronic conditions; monitoring of the patients' condition; and, coordination of care across different providers. Disease or case management can sometimes focus as, well, on transitions from one care setting to another as these area periods of high risk of re-hospitalisation (Coleman, 2003).

81. Disease management programmes have now been under way since the 1990s in the United States. A few countries have attempted to emulate these models and two of these are discussed in Chapter 4 of the main document. Since questionnaire replies did not address the implementation of these programmes in any depth for other countries, this section largely focuses on the literature in the United States. Given the size and diversity of the literature in this area, attention is focused on literature reviews and meta-studies that compare results after eliminating articles that lacked the necessary analytical rigour. 


\section{Box 5. How disease management works}

Disease and case management in the United States are now largely provided by specialist firms. These companies first attempt to identify at-risk patients, drawing on clinical and other data in the client's files. Once these patients are enrolled, they are followed by case coordinators, case managers and/or disease managers with the level of follow-up depending on the risk of complications. ${ }^{42}$ Contacts are most often via telephone to assess patients' needs and to ensure that best practice medicine is being provided. Thus, these programmes tend to have only limited direct contact with the patient's doctor can often only influence treatment indirectly, even where there where a problem requiring rapid medical intervention has been identified. The disease management programmes can often only recommend that the patient contact her or his physician or emergency department. But there can also be direct contact through home visits (rather rare); various forms of electronic medical checks at distance; coordination of hospital care in the case of admissions or link patients to community resources for transition management.

The following hypothetical numerical example for diabetes illustrates the "mechanics" of disease management and indicates some of the difficulties in achieving a positive return taking diabetes as an example. ${ }^{43} \mathrm{~A}$ disease management service provider would begin by assessing the risks that a patient with diabetes normally faces: for example, a $4 \%$ risk of a heart attack, $2 \%$ for stroke, 0.25 and for kidney failure, and $0.1 \%$ for amputations. In setting up its programme, the disease management organisation would take as a working hypothesis that it can reduce the incidence of these risks by, say, $10 \%, 12 \%, 15 \%$ and $20 \%$ respectively. The associated cost reductions are then compared with the cost of the programme - mailings, telephone calls and home visits and additional care where new needs become apparent. The difference in this ratio represents the return on the investment, which is the most commonly used measure of cost effectiveness. A ratio greater than 1 indicates a cost-effective programme.

To provide an example of the relative costs of the programme, assume that a target population of 1000 persons would normally expect to have 50 hospitalisations per year to treat the risks indicated above ( $5 \%$ risk of hospitalisation) at an average cost of $\$ 30000$ for each episode. If one allows for a programme based on a yearly average of 6 telephone calls of 20 minutes at $\$ 3$ per minute for each person on the programme, the overall programme cost will be $\$ 360000$. $^{44}$ For the programme to be cost effective (i.e. a positive return on investment) hospitalisations will need to be reduced by $24 \%$ (12 hospitalisations). This reduction in hospitalisations would need to be even larger if there were additional medical costs to the insurer as a result of the programme. In practice, the level of monthly charges of individuals on these programmes would appear to require a reduction in hospital admissions of 10-30 per cent. This example suggests 2 key features of disease or case management that are likely to affect cost effectiveness:

-- First, cost effectiveness can be reached more easily if the disease management organization can tightly target those population groups most likely to benefit from these programmes. Tighter focusing of programmes will reduce costs of following patients while increasing the chances of reducing the number of episodes requiring hospitalization or emergency care;

-- Second, the return will be higher if results can be achieved earlier. If the programme has to carry on say for five years before full effects are felt, the costs will be higher than if the same results can be achieved in, say, two years. In this context, it is sometimes argued that the effects may be more important if programmes are allowed to develop over the longer term. However, in this case it will require a larger reduction in care costs to compensate. ${ }^{45}$

Source: Howe, 2005 as cited by IGAS, 2006

The largest of these service providers (American Healthways) finds that 3 to 5 per cent of patients with chronic conditions require case management. Normally, there is 1 case manager (usually a nurse) for a maximum of 100 patients. Disease management programmes cover 20 to 40 per cent of the patients and are followed by 1 nurse for every 700 patients. Remaining individuals are mainly provided with education services to enhance their capacity for self-help and self-care (IGAS, 2006).

IGAS (2006) who have drawn, in turn, on Howe R. (2005) and Linden, A. (2006).

This does not take into account the costs of any additional medical treatment - for example because adequate levels of insulin are not being used).

In the United States market, disease management organisations most often claim to achieve positive results and positive returns on investment after a period of 12 to 18 months. 


\section{Measuring the impact of disease/case management programmes is intrinsically difficult}

82. In practice, there is great difficulty in evaluating the results of many studies because of: unsatisfactory methodology; differences in the criteria for evaluation and lack of homogeneity across the programmes or trials being compared. Further, the disease management industry itself is often reluctant to reveal programme costs for commercial reasons (IGAS, 2006). Finally, disease management has largely developed outside of Medicare which covers the vast majority of the chronically ill in the United States and where the impact of disease management programmes might be expected to be the greatest. A number of experiments are now underway in Medicare which may lead to new policies in this area. ${ }^{46}$

83. A key additional problem in the evaluation of disease management programmes is that there is a wide range of different indicators or measures that are used to justify these programmes. CBO (2004), for example, presents a series of indicators that can be used to proxy how disease management programmes impact on health and on costs. Taken in sequence, disease management programmes for say, diabetes, can be expected to first show up in process outcomes indicators (such as adherence to care protocols), followed by intermediate outcomes indicators(blood sugar levels) or in terms of health outcomes (blindness or heart attacks). While improving health outcomes is the key objective of health-care policy makers, results used to indicate success in most studies are mainly in the form of process or intermediate indicators, partly reflecting the lags that can be expected between the introduction of disease management policies and the effects on morbidity and mortality.

84. In addition and reflecting questionnaire results (see Figure 3.2), very few studies examine the net impact of these programmes on costs. A full accounting of the cost of these programmes would include the following items:

- The administrative costs of targeting the individuals to be included in the programme, their subsequent enrolment and their follow-up;

- All associated medical costs including hospital and accident and emergency department visits, ambulatory care visits (which could well increase) and drugs;

- Unintended effects -- such as including individuals who are not in need of the programme or complications due to additional medical interventions or tests -- should also be included, even though increased costs here may be balanced by improved overall quality of care.

85. Thus, while the overall cost of hospital stays are expected to decrease, other costs may rise as care is shifted into the ambulatory sector (Fireman et al., 2004). Thus, disease management programmes may actually increase costs over longer periods if they prolonged life or make use of better but more costly therapy. (Esterman and Ben-Tovim, 2002).

86. Results for either quality or cost are also affected by the study design. As in most areas of medical research, the "gold standard" is randomised clinical trials where individuals are assigned to either the programme or to a control group on a random basis. Many studies have difficulties in meeting this standard, potentially leading to biased results. ${ }^{47}$ There may be other factors - such as treatment methods -

$46 \quad$ For more specific information, see http://www.cms.hhs.gov/DemoProjectsEvalRpts and Medpac, 2006.

For example, Ofman et al. (2004) examined just under 17000 titles with only 102 that met their criteria for adequate study quality. Possible problems of bias can arise from: i) selection bias in cases where individuals may themselves choose to be on the programmes and where these individuals tend to be informed patients in better health; and ii) before and after comparisons can lead to "regression to the mean" 
that change over the evaluation period, the effects of which should not be attributed to the disease management programme (CBO, 2004, Fireman et al., 2004). Programmes can also differ significantly in what is included and in the intensity of care and patient follow-up. Small sample size or limited geographical scope in many studies can also make results difficult to generalise (Villagra and Ahmed, 2004). A final important issue is the relatively short periods of time over which most programmes have been evaluated. ${ }^{48}$ Stronger effects may become evident if programmes were continued over longer periods of time, although there is no certainty that this will necessarily lead to greater cost effectiveness (see Box 5). All of these factors limit the number of studies that are of adequate quality and make comparisons among them more difficult.

\section{Disease management programmes appear to improve quality of care}

87. As noted, there is a widely held view among policy makers that disease management programmes do have a positive effect on process indicators. ${ }^{49}$ Evidence from the literature indicates that the impact may differ according to the pathology under consideration. For example, studies reviewed by Ofman et al., (2004) find that positive outcomes are most marked for depression where $48 \%$ of studies showed measured improvements, $45 \%$ for excess cholesterol, $39 \%$ for cardiac insufficiency, $37 \%$ for high blood pressure and $36 \%$ for type- 2 diabetes. The numbers of studies with a significant impact on process measures remain much less important for asthma, rheumatism, and coronary insufficiency. Intermediate indicators suggest that the most widespread effects were measured for patient satisfaction, patient and doctor compliance and patient knowledge about their condition. While indicators of patient health outcomes are slightly less positive, just under half show a positive effect on patients' ability to deal with their disease and improved morbidity and mortality for about one quarter. These results have been broadly confirmed by WHO (2003).

88. Several reviews of the literature (IGAS, 2006 and Norris et al., 2002) also find that the positive case for diabetes is much stronger and these views are also supported by a study on programmes of care self-management for older patients (Chodosh et al., 2005). The review of 35 studies by Norris et al. (2002) find that blood sugar declined in all but one of the studies providing information for this indicator and there were significant improvements in process indicators such as retinal and foot checks as well. Villagra and Ahmed (2004) also find positive results for diabetes using a much larger sample of over 50000 patients spread over 10 sites. The latter also suggest that control of blood pressure is also effective in a sizable share of the studies reviewed. ${ }^{50}$

89. Results from German evaluations also suggest improvements in quality even though the methodology used has weaknesses. A regional quality report from 2005 indicated quality improvements in all disease management programmes. For example, seven out of nine quality targets were achieved for diabetes patients with a similar positive result for individuals with breast cancer. As regards the programme for coronary heart disease, blood pressure was reduced substantially even though these patients had participated for a much shorter time in this programme than patients in other programmes (Qualitaetssicherungsbericht 2005, Disease Management Programme in Nordhein). Kirchner (2005)

if the participants are chosen on the basis of their high care costs (a frequently used indicator for inclusion) as their costs are normally lower in the subsequent period.

The short evaluation periods often reflects the fact that the insured in the United States tend to change insurers frequently. The average length of membership with an insurer in the United States is 18 to 24 months. This means that insurers are less likely to be interested in assessing the impact of programmes over longer time periods: where patients leave the insurer they may lose their "investment" with them.

See Figure A.2.2 for an indication of what this includes.

However these results may be prone to publication bias. 
surveyed the impact of disease management programmes on providers, patients and payers and found greater patient satisfaction with the perceived quality of care.

90. Other reviews or meta-studies also provide evidence of positive effects for congestive heart failure (Göhler et al., 2006) both in terms of mortality and intermediate indicators and process outcomes. However, in all cases there is considerable heterogeneity of the results across studies and little evidence of the reasons why this might be the case. In practice, none of the programme characteristics of the studies explain these differences. Nonetheless, IGAS (2006) - on the basis of partial review of the literature -suggest that three broad areas that appear likely to increase the chances of a positive result:

- First, results were positive where providers are more integrated - either in physician group network models, in staff model HMOs such as Kaiser Permanente or in the Veterans Hospital Administration. Better performance was partly attributed to the strong ICT support systems in the last two institutions. In this context, payment-for-performance approaches were also seen as having a positive impact;

- Second, integrating other medical personnel such as nurses or social workers and pharmacists in providing care and follow-up has positive effects;

- Finally, programmes that encourage patients to change their behaviour through patient education and self-help support this process. Indeed, programmes which combine both patient education and a stronger role of other medical personnel than doctors seem to reinforce each other and have a stronger overall impact. ${ }^{51,52}$

91. There have been a number of studies for specific diseases. Göhler et al. (2006) find reductions in both re-hospitalisation and in mortality in meta-study that aggregated data from 36 articles covering 13 different countries for congestive heart failure. They also attempt to explain the heterogeneity in the size of the effects or non-effects across the studies and find that the results depend on: the relative use of betablockers; the duration of the programme; the degree of follow-up; and, the mode of post-discharge contacts. There was also some evidence that the severity of the medical condition is an important factor in success. In other words, programmes that mainly focus on the very ill do better than those that spread efforts equally across the target population, a feature that may be applicable to cost-efficiency as well. A review and meta study by Gonseth et al,. (2004) look at the effect of follow-up measurers subsequent to an acute-care episode for heart problems. They find sharp reduction in hospital re-admissions and mortality from a wide range of patient follow-up measures in programmes of an ambulatory nature but not for hospital outpatient visits. Weinberg et al., (2007) also find that better arrangements for care coordination that are supported by changes in provider incentives led to improved clinical outcomes and satisfaction for patients who have undergone hip-replacement surgery.

92. Ouwens et al., (2005), in a review of systematic reviews, noted that it remains extremely difficult to come to strong conclusions on the impact of these programmes - either for health quality or for cost efficiency - because of the widely different programme definitions that have been drawn together. While the studies included reviews of heart failure, diabetes, arthritis, cardiovascular disease, stroke and chronic

51 This, of course, can depend on the study. For example, Taylor et al. , (2005) examined 9 studies of nurse led case management of patients with chronic obstructive pulmonary disease (COPD) and found that there was little impact either on mortality or on re-hospitalisation even after 9-12 months of follow-up or improvements in patient well being or quality of life.

They also note that in the United States a number of other factors can reduce the impact of such programmes including: lack of insurance coverage; cultural barriers for ethnic minorities; proximity to care; co-morbidities and mental problems. 


\section{DELSA/HEA/WD/HWP(2007)6}

obstructive pulmonary disease (COPD), functional health status was positively affected in only one of two meta-studies reported. Other studies showed some decrease in hospitalisation but there were significant effects in only three. Overall, there was only weak evidence of effects on mortality and there were no significant effects on patient satisfaction and quality of life.

\section{Cost savings through disease management programmes are possible but evidence remains inconclusive}

93. There remains considerable uncertainty over the cost-effectiveness of disease management-type programmes. A number of meta-studies find very mixed evidence across disease types and individual programmes. While specific programmes for congestive heart failure appear to be largely cost-reducing, those for mental health seem to be the least cost-effective. In the former, the involvement of care coordinators seems to support cost-effectiveness and is often associated with improvements in the quality of care. However, poor methodology and small sample size make generalisation to larger population groups difficult.

94. In this context, a critical review of randomised trials for a number of disease categories by the CBO (2004) generally found that care costs fell under disease management programmes for congestive heart disease (coronary heart disease), primarily in the form of reduced re-hospitalisation. But only about half of the studies reviewed provided estimates of programme costs, making assessments of cost efficiency difficult. Those that did suggested that lower care costs were offset or partly offset by the operating costs of the programmes and the need for additional medical treatments revealed as a result of the programme. ${ }^{53}$ Findings for coronary artery disease programmes generally lead to a reduction in risk factors (such as smoking or high cholesterol etc). While these programmes can improve process indicators, reduce hospitalisation and enhance functional status, their impact on subsequent coronary infarctions and patient survival are less clear and their impact on cost efficiency remains uncertain. In addition, and as argued by McAlister (2001), the optimal mix of services to maximise the impact on patients and minimise costs remains uncertain.

95. The CBO concludes that, overall, results of those studies are mixed and do not provide a firm basis for concluding that disease management programmes are cost efficient. A number of additional surveys provide much the same picture. Krause (2005) looked at the cost effectiveness of asthma, heart disease and diabetes using meta-analysis on the basis of 67 studies. While a number of the studies included in this review showed some positive effects on cost efficiency, few took into account total medical or programme costs making it difficult to say whether these led to an overall positive return on investment.

96. Goetzel et al., (2005) reviewed 44 studies providing assessments of the financial impact and return on investment from disease management programmes for asthma, congestive heart failure, diabetes, depression and patients with multiple illnesses. Somewhat in contrast with other studies, Ofman (2004) finds positive returns on investment for congestive heart failure and for patients with multiple diseases. While results are mixed for asthma, programmes for depression appear to cost more than they save in medical expenses. A number of elements contributing to successful programmes included:

- Development of appropriate clinical guidelines with constant updating;

- Good medical information systems;

- Incentives for patients and providers to participate;

53 Some of the studies were for high-risk patients for a high-risk period just after a serious medical event and results may not be applicable to patient groups with different health characteristics. Results were also marked by possible selection error. 
- Repeated evaluations of the programme effectiveness;

- Sharing results with providers and patients;

- Co-promotion with local health-care providers to gain grass roots support;

- Individualised and personalised risk-reduction counselling to those with highest risks;

- Education to improve self management of the medical condition.

97. There is some - but still inadequate - evidence that programmes for diabetes are cost effective but more studies are needed (IGAS, 2006). The CBO (2004) finds disease management programmes do lead to reductions in blood sugar. However, as it may take some time for these effects to feed through into health outcomes, the short-term impact of disease management programmes for diabetes on costs may be small (Beaulieu et al., 2003). In this context, Gertler and Simcoe (2006) find that a three year disease management programme for diabetes in two US managed care organizations results in short-term cost savings. ${ }^{54}$ Siderov et al., (2002) and Villagra and Ahmed (2004) also find that disease management for diabetes is cost effective. ${ }^{55}$

98. Despite these more positive results a number of other studies point to weaker effects. A study in Kaiser Permanente (KP) in northern California (Fireman et al., 2004)) followed patients over a relatively long period for the United States (1996-2002). While there is a reduction in costs for diabetes patients, there was a slower evolution in spending in all areas over the same period such that the change for diabetes patients cannot be solely attributed to the disease management programme. In addition, the care units with the best results with regard to quality within the KP system have had less of a slowdown in spending such that the improvements in care may simply reflect an investment in the overall quality of care and in the health of the patients. Finally, evaluations may fail to take into account the effects of lengthening lifetimes on costs. For example, diabetes management programmes showed cost reductions when evaluated for cost effectiveness over the short run. However once the lifetime costs of improved care and longer life expectancy were taken into account, overall costs were calculated to be higher (Djikstra, 2005). ${ }^{56}$

99. There is some scattered evidence that disease management programmes reduce care costs in Germany. One insurer (TK) has reported marginal savings on the basis of a case management approach. This group has estimated cost differences with a control group not receiving case-management services and finds that hospital spending has been reduced by around 3 per cent with additional savings for pharmaceutical drugs and reduced sick leave (Hecke and Erzberger, 2005). Kottmair et al., (2005) find, on the basis of before and after comparisons, a reduction of 35 per cent in costs in the first year of operation compared with the previous three-year average. This fall is largely the result of reduced hospitalisations. ${ }^{57}$

54 The authors also argue comparisons across 10 different sites and a sample of 42000 patients make these results potentially easier to generalise.

The former finds a return on investment of 2.2 with cost reductions mainly the result of reduced hospitalisation. While the costs of the programme were not revealed, the authors of the latter argued that this still led to a net positive return on investment.

In this context, Dijkstra et al. (2005) test the cost effectiveness of two implementation strategies for diabetics compared with usual hospital outpatient care, including both patient-related and interventionrelated costs. They found improvements in blood sugar control and, on the basis of a model for disease progression, estimated likely effects on average lifetimes. They found that, while the programme costs per patient/practitioner were low per head in the programmes proposed, there was nonetheless a significant increase in lifetime costs due to longer periods of insulin use.

However these results may not have taken into account programme costs. Officially designed disease management evaluations intending to assess medical issues, financial issues and quality-of-life parameters are currently being put out for tender. But the framework for analysis has already been criticised as no 
There has also been some evidence of a reduction in hospitalization in "before and after" comparisons in England. But estimates of cost effectiveness for pilot programmes of case and disease management in selected Primary-care Trusts (PCTs) ${ }^{58}$ have not been able to show positive results, although the conditions under which they took place may not have been optimal.

\subsection{Some tentative conclusions: quality improvements may come at a cost}

100. Taken together, these results point to improvements in the overall quality of care under disease or case management but with the degree differing across pathologies. As regards the impact on cost efficiency, IGAS (2006) suggests that short-term cost efficiency is more likely for heart disease, COPD and kidney failure. These results need to be treated with caution as all costs may not have been taken into account in assessing cost efficiency. The effects on cost efficiency remain less clear for diabetes. Benefits in the form of reduced blood-sugar levels are significant, but the impact on cost efficiency may depend on the longer term development and cost of such programmes. Programmes for asthma, depression and back pain do not appear to be cost effective (although there are positive effects on process indicators). However, these results have essentially concerned individuals under 65 in the United States and it is by no means certain that they can be generalised to the elderly taken as a group or to other countries.

101. Nonetheless, it is also the case that these results are based on a narrow definition of returns on investment. Improvements in quality of care are valuable in their own right while the net overall impact on costs can be more important if they costs were adjusted, for example, the number of working days lost due to illness. Indeed, Liljas and Ladensuo (1997) find much higher rates of return once they take into account the number of days of reduced activity as a result of the disease for Sweden. In addition, programmes that lead to longer lifetimes should include a valuation of these gains (for example, in the form of QALYs). Policy makers may wish to take into account the positive social effects from better health and more complete care for those with chronic illness in assessing whether to embark on such programmes.

102. Finally, several key factors which may help make these programmes more successful are:

- The quality of the underlying programme, in particular as regards the best practice medicine.

- Continued focus on obtaining cost gains;

- Good information systems and, in this context, wider introduction of ICT;

- A focus on patients with the highest risk - i.e. better targeting of patients;

- The presence of high quality and well-trained staff both in terms of medical knowledge and the ability to create good relations with the clients, patients and family;

- More generally, there is need for more information on the impact of these programmes using common definitions, analytical methods and time frames.

103. In sum, disease management programmes have the potential to improve health outcomes and to raise system performance in terms of quality even if the impact on costs remains uncertain. However these models are only one approach to enhancing care coordination. Recent policies in a number of countries are also seeking to provide appropriate and safe care outside of hospitals by strengthening the role of ambulatory care delivery. In this context, more attention may need to be paid to ensuring that capacity, incentives and patterns of provision in the ambulatory sector are adequate to support such changes. The following chapter examines such wider developments in three countries.

randomized prospective trials are foreseen and a number of important elements are not included in estimates of cost-effectiveness (Greiner 2005). 


\section{CHAPTER 4. EXPERIENCE WITH COORDINATION OF CARE IN SELECTED OECD COUNTRIES}

104. This chapter provides greater detail on care coordination policies in three selected countries: Germany, the United States and the United Kingdom (England). These three countries were chosen because:

- All three have gained some early practical experience in the introduction of care-coordination policies both of a targeted and of a broadly-based nature.

- They are representative of three different institutional environments and approaches to reform:

- The United States health-care system is marked by largely private supply of care services financed through a mix of private and public insurers. Improvements to care coordination have been mostly market driven. Approaches aim at mitigating some of the perceived negative effects of managed care on patients and providers by putting stronger emphasis on patient-centeredness and on quality of care delivery;

- Supply of care is private and fragmented in Germany, reflecting, in part, strong regulatory barriers across sectors. System finance is dominated by the social security system. The introduction of policies to improve care coordination have taken place in a context of policies to reduce regulatory barriers and increase competition in insurance and provider markets;

- In the United Kingdom (England), the health-care system is tax financed and, despite reforms (e.g. the introduction of a purchaser-provider split), it has remained more integrated in organisation and operation than the other two. Policies to improve care coordination have focused on a stronger role for the general practitioner and on bridging the gap between health care and long-term or social care.

105. Because of generic challenges arising from emerging care needs, all three countries have introduced policies that are focused on the chronically ill. These have been motivated by the desire to improve the quality of care provided and cost efficiency. Each of the country case reviews begins with a brief description of the context in which care coordination policies have emerged. They then examine the interaction between the institutional environment and the specific care coordination policies. A key aim of this chapter is to highlight the importance of the institutional context in the introduction of such programmes.

\subsection{The United States}

106. Care coordination policies in the US system largely evolved in response to market forces and a changing regulatory environment. During the 1990 s, the private insurance market shifted to managed-care arrangements that restricted patient choice of carer but gave insurers more control over care delivery. These new types of insurance contracts ranged from health maintenance organisations (HMOs) which provide all necessary care from a restricted set of providers for a capitated fee to insurance arrangements providing a greater degree of choice in exchange for a higher premium and increased cost-sharing (such as preferred-provider plans or point-of-service plans). These arrangements appear to have contributed to the slower growth of expenditure during the 1990s. But as the impact of these new arrangements on spending faded, insurers have focused on finding new methods of cost control through policies that are aimed at improving care quality (Robinson and Yeagan, 2004). 
107. On the supply side, there has been a shift away from doctors operating as independent private contractors in solo practice towards increased collaboration and integration between providers (Kletke et al., 1996). Group practices have taken on a variety of forms ranging from individual practice association (IPAs) for networks of doctors to integrated medical groups (IMGs) or integrated delivery networks in which ambulatory practice groups are often linked to a hospital (IDNs). There remain a number of HMOs providing integrated care approaches such as Kaiser Permanente and the Group Health Cooperative of Puget Sound. Furthermore, community health clinics, which are publicly financed, are also providing care to a growing number of Americans (Le Roi et al., 2006). These changes have been partly driven by the need to strengthen the market position of suppliers relative to insurers and this has not always led to better coordination of medical practice (Burns and Pauly, 2002). Care models that are better adapted to treating chronic care (Bodenheimer et al., 2002a, Wolff and Boult, 2005) have failed to penetrate far into the US health-care system, partly because a large majority of the chronically ill are covered by Medicare which continues to act largely as a fee-for-service indemnity insurer.

108. Furthermore, personal care services -- e.g. help with daily activities are not covered (AARP, 2006) and sit at the centre of the divide between health and long-term care (Breslow, 2005), often making it difficult to organise care needs at cross-over points and to substitute nursing home care with home care. In the late 1980s and early 1990s, a series of demonstrations with "social HMOs" were run. They aimed at integrating acute care with long-term care largely at local levels. Social HMOs provided for case management and this was found to improve care for the chronically ill and to strengthen informal care giving. They attempted to "tailor working relationships" among providers and families in a way that supported the autonomy of patients (Leutz et al., 1994). Early successes of those "All-Inclusive Care for the Elderly (PACE)" led to its designation as a permanent Medicare programme in 1997. However, important barriers -- including competition, poor understanding of the programme among referring professionals and a lack of financing -- appear have slowed its expansion (Gross et al., 2004).

\section{Care-coordination policies and programmes}

109. Recent efforts to improve care coordination in the United States largely reflect the search for new tools to control costs that are more acceptable to insurees, patients and providers than simply integrating structures or restricting choice for both patients and providers. A wide range of programmes are being tried. For example, Wolff and Boult, (2005) indicate the following key models: outpatient geriatric evaluation and management; disease management; self management; health enhancement, case management, transitional care (Coleman, 2003) and caregiver support. Each of these programmes can use a number of techniques including: comprehensive or individual care planning, promotion of adherence to practice guidelines; patient empowerment, coordination of care across multiple conditions and across provider settings; caregiver support and education; and, access to community resources. From among the wide range of techniques, three broad approaches have emerged:

- Disease- and case-management programmes for specific pathologies increasingly provided by specialist disease management companies to private insurers (see section 3.2 for further details) ;

- Adapting primary care to provide improved primary care through better coordination or integration of care delivery, e.g. in staff-model HMOs, IMGs or IDNs; and,

- New payment incentives and other experiment aimed at improving care coordination in Medicare. 


\section{Chronic care models to improve care by strengthening coordinated primary-care delivery}

110. The "chronic care model" has been pioneered within staff-model HMOs, such as Care Cooperative of Puget Sound, Kaiser Permanente, and, in the public sector, the Veterans Affairs health system (Bodenheimer, 2002). It concerns changing the way chronic care is handled in the primary-care sector. In this approach, case or disease management forms an integral part of health-care delivery and attempts to improve care by bringing together a system based on six elements: drawing on external support for patients; improved quality of care in line with best practice; better self-care by patients; team working in the provision of care with the doctor called on for acute cases; decision making aids; and a welldeveloped information system permitting reminders, a rapid flow of information between those providing care; and, an electronic medical record (EMR) system to permit the organization and planning of care and patient follow-up (Oliver 2007a).

111. While improvements in care delivery are reported in these models, notably in the quality of care provided and in responsiveness (see section 3.2), this approach is less well adapted to independent practitioners working in a fee-for-service environment and requires a major change in the way health care is delivered and financed (Rittenhouse, et al. 2004). In the light of this, a number of medical associations have proposed an "advanced medical home" which adapts the chronic care model to the "traditional medical system" (American College of Physicians, 2006, American Academy of Pediatrics, 2005). In this approach, patients would have a primary-care doctor leading practice teams with financing arrangements that support such an approach, something that is currently not very widespread. Wider change particularly in the area of remuneration of primary-care providers - needs to be made before significant progress on this front can be expected (Davis, 2007; Pham et al., 2007, Ginsberg and Grossman, 2005).

\section{Medicare pay-for-performance demonstrations aim at improving care for the chronically sick}

112. While much of the experimentation with new health-care models for coordination has taken place in the private-insurance-financed sectors and in integrated care, the bulk of the chronically ill are elderly and, hence, are covered by Medicare. Providers are paid on the basis of Medicare fee schedules, which emphasize curative care and face-to-face contact with patients rather than responding the specific healthcare needs of patients with chronic conditions or in need of improved care coordination. The Centers for Medicare and Medicaid Services (CMS) within the U.S. Department of Health and Human Services have initiated a range of projects. Within this context, they have recently introduced a range of demonstrations or trial programmes, carried out by private plans and providers, and aimed at improving coordination of care in Medicare. ${ }^{59}$ To this end, the CMS selected ten large physician groups (PGPs) in 2005 to participate in the demonstration which runs until 2008. Physician groups that succeed in improving patient outcome and lowering overall health-care costs will share the savings with CMS. Halfway through the allowed time frame for the demonstrations, there is some preliminary evidence that these approaches - which include additional incentives to providers -- permit gains in efficiency while increasing the quality of care provided (Trisolini et al., 2006). The PGP demonstration system retains many of the positive features of FFS reimbursement, such as the patient's free choice of provider and lower incentives for under-treatment than obtained under salary or capitation payment.

113. As noted, information transfer is a key framework feature that will impact on the capacity of health-care systems to coordinate care. In studying US physician organizations, Rundall et al. (2002) found that quality improvement in chronic care delivery is facilitated - amongst other things -- by electronic record or information systems. This was also found to be a crucial success factor for performance improvements in the public sector (Oliver, 2007a). Supportive managerial and medical leadership was also found to facilitate better care management. At the same time, the lack of financial resources and inadequate clinical information systems were seen as important impediments. 
114. There is wide diversity in the use of ICT in the US health-care sector. Some large staff-model HMOs have invested heavily in ICT and are continually upgrading systems. The VHA amongst others in the public sector has followed a similar approach. In these cases, information is easily accessible within house to individual providers. Less progress in introducing ICT has been made in loosely integrated provider arrangements and in individual solo practice. In a recent survey of primary-care physicians in 7 countries, the United States (28\%) vies with Canada (23\%) for the lowest share of doctors using electronic patient records and falls significantly behind most other countries in most uses of ICT (Schoen et al., 2006a).

\subsection{Germany}

115. Key facets of the German health-care system are the sharing of decision-making powers between the federal government and the Länder and the corporatist approach to the organization of sickness funds, physicians and dentists. The German health-care system is largely financed through a social insurance system containing multiple competing insurers and independent providers. Health-care delivery is decentralized and the federal authorities devolve a large share of powers to the states to regulate the system. At the provider level a subsidiarity principle gives primacy to private over public providers. Finally, there is a comparatively wide delegation of powers to self-governing actors in the social health insurance system (Busse and Riesberg 2004).

116. A strong regulatory separation exists between ambulatory and hospital care, severely limiting the capacity of the hospital sector to expand into outpatient care or day surgery. In addition, budgets are not fungible, thereby reducing the scope for finding more efficient and effective configurations of supply. These institutional arrangements have also created conditions leading to weak information flows between the sectors, duplication of services, difficulty in controlling overall expenditure and suboptimal quality of care.

117. The leading reform principles after reunification have been: the reduction of structural differences between the eastern and Western Länder; cost containment through caps on expenditure; the introduction of prospective provider payment arrangements; and, regulated competition among sickness funds. These goals were to be achieved while securing quality and avoiding any adverse effects on equity. Rationalization has been given priority over rationing. While cost-sharing has been increased, few benefit entitlements were excluded until 2004. A separate mandatory long-term-care insurance system was introduced in the early 1990s to meet the changing needs of the population. Recent reform efforts recognized difficulties arising from fragmentation of the insurance system and aim at enhancing cooperation between sickness funds and long-term care insurers.

\section{Care coordination policies and programmes}

118. Efforts have been made to limit fragmentation in the health-care system since the mid-1990s (Hecke and Erzberger, 2005; Pittmann et al., 2006). The most important steps towards better integration and coordination of care were made in the context of the reforms in 2004 and 2007. ${ }^{60}$ These recent German reforms mainly seek to improve coordination of care by promoting the role of health insurance as active agents of patients through increased competition and improved health-care system incentives. The key developments likely to impinge on care coordination are:

- Disease management programmes;

- New models of integrated care;

- The introduction of a non-obligatory gate-keeper arrangement; and, 
- The extension of medical-care centres providing a mix of primary and specialist ambulatory services.

\section{Disease Management Programmes aim at improving chronic care and fostering competition}

119. The primary goal of disease management programmes in Germany is to improve the quality and the efficiency of medical care delivered to chronically ill patients by avoiding complications, comorbidities and, to the degree possible, a worsening of the disease over time. However, this policy is also being used to improve risk-adjustment between health insurance funds, thereby increasing the scope for competition among health insurers on the basis of quality and price. Competition in the German social insurance system was first introduced in 1996 and included a risk-adjustment fund to compensate for differences in risk profiles of the fund members. But the criteria chosen could only partly adjust for these differences. Changes in 2001 introduced outlier risk-adjustment for high-cost patients (Gress et al., 2006, Van de Ven et al., 2003). To improve this mechanism, the health insurer receives - under the new arrangements -- a sum of money for each insuree enrolled in a disease management programme. This is equal to the difference between the average cost at a national level of all patients and the costs of patients with the chronic condition in question. This provides a strong incentive to enlist as many patients as possible, irrespective of their degree of risk of hospitalisation.

120. Entry into a disease management programme is based on a medical certificate usually established by a primary-care physician on the basis of diagnostic criteria. The doctor receives a payment for filing an evaluation and for follow-up, providing further incentives to increase the number of individuals covered. Patients are also encouraged to join a disease management programme as they face reduced cost-sharing and are not required to pay the $10 €$ quarterly contribution. This approach contrasts with that of the United States and, to a lesser degree, England where considerable effort is given to enlisting patients most at risk of unplanned hospitalisation and, thus, of higher health-care costs. Any impact on cost efficiency may, therefore, be limited. On the other hand, early enrolment in these programmes may reduce the frequency -as well as the intensity -- of hospital stays and this could enhance the cost-effectiveness of programmes over the longer haul by ensuring better health outcomes.

121. Disease management programmes exist for six conditions: type 1 and type 2 diabetes; breast cancer; coronary heart disease, and chronic respiratory diseases such as asthma bronchiale and COPD. In 2007, about approximately 2.8 million beneficiaries were enrolled in such programmes. The contents of the programmes are tightly controlled at the national level (and authorised for a three-year period) to improve programme coherence and quality of care. The federal authorities set the general regulatory framework and establish the best-practice protocols in collaboration with the health-care professionals and sickness funds. The main elements of the programmes include: the designation of a gatekeeper doctor to coordinate care; care on the basis of best available evidence and medical guidelines; patient agreement to participate; patient empowerment; transmission of clinical information between providers and between providers and insurers; training for both patients and providers collaborating with the programme; and, an evaluation of results.

122. The insurers can have direct contact with the patients to provide them with information about providers participating in the programme (where disease management and integrated care models have been linked -- see below), personal medical advice to help the patient manage his or her condition and messages to remind patients and providers of the need for follow-up. Patient education preceded the introduction of disease management in Germany and such programmes are well-established and wellorganised. Patient education programmes enable participants to take a more active role in the treatment process and to cope better with their disease. A few insurers have gone beyond this to provide direct telephone contact and follow-up with chronic care patients included in the programme - as is the norm in the United States, particularly for higher risk patients. Others have provided "hot lines" staffed by nurses 
but they receive more calls than they make and there is no attempt to focus on high-risk patients. These latter approaches do not yet appear to be widespread (IGAS, 2006). A key weakness to making progress in this direction is the fact that the insurers have not had the capacity to make use of the medical information gathered from the providers, either in the form of patterns of patient spending or of the medical reports by the providers. Efforts are currently underway to restructure risk-adjustments among insurers. In this context, it is envisaged to develop disease management programmes further by taking into account co- and multi-morbidity.

\section{More integrated health-care delivery aims at broadening disease management and intensifying competition}

123. While disease management programmes target population groups with specific diseases, other important measures have been taken to foster coordination of care for those with multiple chronic conditions. As elsewhere, this reflects increased awareness that greater provider integration is needed to achieve improved quality of care and to make care delivery more patient-centred. To this end, integrated care contracts are responding to challenges that have arisen from the current model of risk-adjustment between sickness funds. Thus, in the German context, case or care management within integrated arrangements aims to help extend competition in provider markets (see below).

\section{A new GP-Model gives patients financial incentives to contract with a gate-keeper}

124. First, patients can choose -- on a voluntary basis -- one doctor as their family doctor in return for the elimination of the $10 €$ quarterly fee. Patients who contract with a GPs agree to always see their GP before they contact any kind of specialist. Currently about 3.5 million patients have signed up for the GPmodel. Sickness funds may also offer premium reductions to patients contracting with a GP. This has been strengthened by the key role that primary-care physicians play in disease-management programmes in identifying and enlisting chronically-ill patients. As with all other models to enhance care coordination, the overarching goal is to reduce hospitalisation and to promote appropriate care by controlling the utilisation of drugs.

\section{Medical Care Centres - "Polyclinics" foster coordination by integrating ambulatory care}

125. Second, the development of polyclinics in the western part of Germany is also helping to break down the institutional barriers in supply. Traditionally, ambulatory primary-care and specialist doctors have tended to operate in solo practice in Western Germany, contributing to fragmentation in care. Currently, two thirds of ambulatory care providers work in solo practice, a higher proportion than in the US and the UK (Schoen et al. 2006b). However, in the eastern part of the country, polyclinics containing both primary and specialist carers were the norm and these institutions remained in operation after reunification. Recent legislation now allows for establishments of this kind in the western Länder as well. Further changes permit doctors to be employees of these polyclinics rather than being self-employed contractors. Moreover, legislation also permits the integration of pharmacies and paramedical services (e.g. physiotherapy, ergo-therapy) into polyclinics. These medical-care centres provide a wider range of services, some of which were only provided previously in a hospital environment. They can also act as conduits for hospital care as a number of the new polyclinics have been established by hospitals and are often built near by, permitting easier referrals and access to hospital services. While they remain few in number, they are growing rapidly.

\section{Integrated care contracts are developing rapidly, encouraged by a new fund}

126. Third, the recent reforms have encouraged greater collaboration among providers in the form of integrated-care contracts. These allow individual providers to contract with insurers to provide care within 
care networks, either separately or with independent "management organisations" (Management Gesellschaften) which can be set up to manage these new arrangements. Potential partners who can cooperate include institutions or individuals that provide care (e.g. physicians, dentists, hospitals, and institutions for inpatient and outpatient rehabilitation and groups of these providers). The type of contracts are varied and can relate to single procedures (e.g. hip replacements); medical conditions (e.g. stroke); a medical discipline (psychiatry) and contracts with a population-based approach (e.g. a management organisation takes responsibility for organising care for a certain region, including taking on financial responsibility through a budget). The first two of these are the most frequent. The latter - which could evolve into a HMO approach - is only at very early stages of development. The current development is highly concentrated with only one or two insurance funds having the majority of contracts.

127. This development is supported by a fund to encourage integrated care pilots financed by 1 per cent of doctor and hospital billing - representing a $€ 280$ million reallocation from the traditional approach. Initially introduced for a three-year period, this has been extended to end-2008. While a relatively short period has elapsed since the reforms, the number of contracts has been rising rapidly (albeit unequally) across the country to reach almost 3000 by the third quarter of 2006, covering 3.5 million insurees (Bundesgeschäftsstelle fuer Qualitätssicherung 2006). The first results suggest that hospitals are making greatest use of the new arrangements and are involved in around 70 per cent of the contracts.

128. This reform has opened the door to greater provider competition by allowing new contractual relationships to be created between providers and the insurance funds. While at an early stage, it also provides scope for greater development of new supply arrangements that may be better adapted to patient needs. It will also permit greater selective contracting by funds with providers and, as such, greater provider competition.

129. The 2007 health reform also made preliminary proposals to promote cooperation of long-term care insurers with sickness funds. Incentives for acute-care providers and providers of rehabilitation services to compete for contracts are strong and this may help create conditions for more powerful linkages between long-term care insurance and sickness funds in the future.

\subsection{United Kingdom (England)}

130. As a tax-funded system, the National Health Service in England has always been administratively more centralised than many other countries. Given the more integrated organisation of health-care and the key role played by the general practitioner (GP) gatekeeper, there has probably been a considerable degree of care coordination handled by primary-care practices. However, this has taken place in a context of limited supply and uneasy relationships between GPs and hospital specialists, limited patient choice over providers and administrative and budgetary separation between social care (responsibility of the local authorities) and the NHS (the central government). This has contributed to difficulties in coordination and in transitions to the social sector and caused concerns over cost-shifting from one sector to another. (Godfrey et al., 2003).

131. The development of care coordination policies is part of wider reforms that have decentralised decision-making for supply. Key elements of recent changes include (Klein, 2006; Ham, 2006, DoH, 2006a, DoH, 2006b):

- Increased capacity: The number of doctors and nurses has been increased and new contracts with private sector providers have been established, particularly in the area of elective care;

- Greater decentralisation in decision making: Primary care trusts (PCTs) take responsibility for providing both GPs and other ambulatory services and for purchasing hospital care for their local populations; 
- Greater patient choice over provider: Choice will progressively increase such that by 2008 patients will be able to choose any provider that they wish, and this is to be accompanied by greater patient information on provider performance (although choice will often remain limited in areas where supply is low);

- Payment by results: Money follows the patient through a progressive introduction of a national schedule of payments for hospitals such that hospital revenues will become largely activitybased;

- Better integration of health and social care: Most recently, a shift in provision away from inpatient care to the ambulatory sector and better integration of health and social care is being pursued. The aim is to bring care closer to the patient and to encourage "seamless" care across health and long-term care settings (DoH, 2006a and DoH, 2006b).

\section{Coordination of care policies in England}

132. The English Department of Health $(\mathrm{DoH})$ have put in place a number of policies aimed at improving care coordination and care for chronic conditions. These rely heavily on GPs and on the incentives to meet clinical goals built into the primary-care practitioner contract ("quality and outcomes frameworks"). In terms of quality performance, about half of the clinical goals concern the care provided to 11 very frequent and often chronic conditions. Primary-care practices can also obtain additional revenues - negotiated with the PCT -- for better quality provision (e.g. flu vaccinations for the elderly) or services that are normally provided by the hospital sector. ${ }^{61}$

\section{Care coordination policies seek to reduce the frequency of hospitalization}

133. Greater emphasis is now being given to persons with long-term conditions and a model has been developed based on the three-levels-of-risk approach used in the United States: case management; disease management; and, patient self-care (see above). As in the United States, a key objective is to stabilize health conditions of chronically-ill patients for as long as possible, thereby reducing the need for costly care from emergency services or hospitalization. These policies are to be put in place by individual PCTs in collaboration with social care that is currently organized at the local level (DoH, 2005, DoH, 2006b). Key features of the DoH model are:

- Case management: Individuals with highly complex conditions are to be followed by "community matrons" who have clinical expertise and have been specially trained in care coordination and patient communication support and advocacy. They identify patients needing care coordination, build individual care plans (including medication, provision of clinical care and order tests), coordinate care from all agencies and take on the role of the central contact point for these individuals. They are also expected to bridge both the clinical aspects and the social needs of the patient, including housing, transport and other long-term care services. The goal of case management is a reduction of hospital admissions of the target group (estimated to be around 200000 persons) by 5 per cent by 2008 .

- Disease management: Patients with less complex needs but with single or multiple conditions requiring a number of consultations from specialist services will be followed by disease management. Support for these patients will be provided by multi-disciplinary teams based in primary or community care with support from of specialist advice or liaison workers such as a

$61 \quad$ The treatment of chronic conditions has also been enhanced by the "National Service Agreements" (NSAs) which were progressively introduced starting in the late-1990s to provide national standards for care and identify key interventions for a defined service or care group. 
diabetes nurse (DoH, 2004, DoH, 2005). Key elements include: ensuring that agreed clinical standards and protocols are followed; the establishment of multidisciplinary teams and networks; and, follow-up and recall.

- Self-care: The bulk of patients who can, with support, largely manage their care themselves (selfcare) are to receive training concerning the disease and on how to prevent complications. The "Expert Patient Programme" includes health promotion, support sessions animated by patients with the illness, opportunistic counseling and practical help with pharmaceutical drug use to improve compliance.

134. Within this approach, the GPs - and their practice teams - take on a key role in coordination of care. They will be charged with arranging who takes charge of the patient after secondary care and the necessary transfer to social support.

\section{Improved primary-care commissioning aims at intensifying efforts to reduce hospitalization}

135. Since April 2005, GP practices in England have been allowed to hold a practice-based 'indicative' commissioning budget from their primary care trust (PCT). ${ }^{62}$ The GP practices can use this budget to manage directly the delivery of care for their patients, and are allowed to keep at least $70 \%$ of any savings they make. The GPs are required to invest these savings into their premises or in capital equipment to broaden the range of primary care services they offer. Savings by practices adopting practice-based commissioning are reportedly being used to invest in a variety of new services, including new communitybased dermatology, diabetes, orthopaedics and chronic-disease management (Oliver, 2006a). The Government expects that by holding their own budgets, GPs will be less likely to make unnecessary referrals to hospital. On the basis of limited evidence, the authorities have claimed that "unnecessary" hospital referrals had been reduced by $25 \%$ to $33 \%$ in some parts of the country by early 2007 (Oliver, 2007b).

136. As with fundholding, the current approach aims to increase provider-market competition through practice-based purchasing, and this should be facilitated by an increase in the number of providers. In principal, practice-based purchasing could counter-balance the dominant market position of hospitals. However, this could reinforce competition between sectors, thereby potentially reducing the willingness of providers to collaborate as has been recently observed in the US context (Berenson et al., 2006). In addition, joint administrative management across doctors within institutions for both hospital and ambulatory care has been found to foster performance in Kaiser Permanente and in the Veterans Health Administration in the US (Borges da Silva and Borges da Silva, 2005). In the UK context, this could mean that commissioning on a more "collaborative" basis across primary care, hospitals and social services might promote cost efficiency (Light and Dixon. 2004).

\section{Integrating community health and social care}

137. Recent policies (DoH, 2006a and DoH, 2006b) also aim at: shifting care into the ambulatory sectors to bring them closer to the client; better use of technology to improve the quality of care; and, more prevention. The following proposed elements appear particularly germane to care coordination in England (King's Fund, 2006):

- Enhanced access to primary-care and community services, particularly in inner city areas; 
- Better support for long-term conditions through an enlargement of the "Expert Patient Programme", more information to patients with chronic conditions, integrated personal health and social-care plans and more support for informal carers;

- Integration of health and social care. Local Area Agreements (LAAs) between local authorities, the NHS and other local bodies are to be used to structure collaboration between the health and social care sectors to align the planning and support services of the NHS and the local authorities. In this context, PCTs would be required to provide Local Development Plans (LDPs) to indicate how they intend to shift services to community settings;

- All PCTs and local authorities are to establish joint health and social care networks and/or teams to support people with complex needs. Services should be located in a community setting. They should also be financed on a collective basis from the two services.

138. To help finance these changes, the government intends to shift $5 \%$ of the resources currently spent on secondary care to primary care over the next ten years. The focus on primary and community care is seen as necessary in order to meet emerging health-care needs. Nonetheless, it may well be difficult to stimulate cooperation between health and social care sectors as they have traditionally operated within their own silos, and are very protective of their own territories (Oliver 2006b).

\subsection{Lessons learned from country cases}

139. This chapter has presented brief highlights of individual country approaches to improved coordination, either of a targeted or of a broader nature. While the sample is small, the aim of this section has been to show how policies with similar objectives are being adapted to the specific institutional environment in each. A review of these countries suggests that:

- The main objective in all countries was to reduce costly hospitalization by promoting better coordinated care outside hospitals, e.g. ambulatory care and long-term care.

- Programmes and policies in place to foster coordination are, in most cases, relatively new and clear evidence on cost savings is unavailable in all three countries. In an effort to make care delivery more patient-centred, countries have begun to restructure incentives for ambulatory care providers -- e.g. payment by result in the UK, pay-for-performance in the US -- or developed other incentives -- e.g. creating a more flexible contracting environment in Germany.

- Regulatory changes have commenced in all countries to break down barriers between sectors and to stimulate cooperation across providers, e.g. incentives for sickness funds and long-term care insurers in Germany to cooperate or local development plans in England with the aim to shift services to community settings. 
DELSA/HEA/WD/HWP(2007)6

\section{CHAPTER 5. SOME AREAS FOR POLICY CONSIDERATION}

140. This report has provided an overview of whether -- and to what degree -- better care coordination is able to improve health system performance through higher quality of care and improved cost-efficiency. To this end, it has drawn on the analysis of replies to a questionnaire from 26 OECD and non-OECD European Union members. The report also examines a number of approaches that are being employed to address these issues through a deeper examination of the situation in Germany, the United States and the United Kingdom (England) where policies appear to be evolving more rapidly. The results suggest that, while coordination exists in some form in most countries, there is need for improvement and ample scope to do so using a range of different instruments or policies. However, policy assessment in this area is hampered by the limited amount of evidence regarding the impact of existing programmes.

\section{Demand-side issues}

141. Demands placed on health-care systems have been evolving. An epidemiological shift from communicable disease towards chronic conditions is underway and is likely to accelerate over coming decades as populations age. As it stands, patients with chronic disease, most of whom are older, absorb a large and growing share of total health-care resources. At the same time, they may not always be receiving health care in line with best practices, leading to greater risks of, for example, un-planned hospital episodes. As a result, there is a presumption that quality can be improved while limiting costs by improving the architecture of health-care systems and the way that the chronically-ill population is cared for. As lifetimes lengthen, patients may need to be followed over longer time periods but, hopefully, this will be at lower levels of intensity.

142. Within this context of evolving patient needs, almost all countries highlighted particular coordination difficulties at the interfaces between the various parts of the health-care system on the one hand and the long-term care sector on the other. These difficulties tend to affect individuals who are very ill or severely incapacitated and who need social as well as medical care and follow-up. The widespread difficulties at this interface may also reflect the fact that long-term care often belongs to a different ministry or level of responsibility in many countries, making it more difficult to develop and organize more patient-centred care.

\section{The supply-side response to emerging needs}

143. Analysis of the questionnaire results suggested that both the type of coordination problems in individual countries and the policies needed to strengthen performance in this area will depend on the institutional framework of the country in question. For example, distinguishing between countries with largely tax-based financing and countries that are mainly social-insurance financed suggests that problems of inadequate capacity may be more important in the former while problems of system fragmentation may be more prevalent in the latter. However, all policy approaches in the area of targeted programmes aim at improving the quality of care in an ambulatory environment with the expectation that this will lead to lower costs because the need for high-cost hospitalisation has been reduced.

144. Questionnaire replies (see Annexes) and the discussion of the three country cases have revealed a range of policy (and sometimes market-driven) responses to the need for greater care coordination. The 
introduction of "targeted" programmes directed towards certain population groups and cutting across disease and health-care sectors provides one approach (e.g. disease and case management). For example, the United States and, to a lesser extent, Germany have focused on such programmes with these largely operating in parallel with the existing provider arrangements. While UK reforms are in the process of being set up, disease and care management programmes appear more tightly bound into the existing GP arrangements, as has been the case in larger HMOs in the United States. Thus, there are a range of potential approaches to providing more focused attention for the chronically ill via targeted approaches. Some additional countries have begun to establish programmes of this kind and others are experimenting with such arrangements.

145. Assessing whether such programmes have the desired impact on performance is not straightforward. There are large differences between the programmes in terms of structure and intent. Evaluations differ due to the length of time of the trials and in the methodology used for evaluation. The bulk of the information comes from the United States, where the institutional environment for finance and provision of health care differs from most other countries. While it is probably too early to take a definitive view of their effects, it would appear, nonetheless, that these programmes have an impact on the quality of care although the impact can depend on the illness in question.

146. However, there is less evidence that these programmes always lead to significant and observable cost savings. Although positive results have been identified for some individual studies and appear stronger for some pathologies than for others, the results are not consistently positive. There are several possible reasons for this outcome: high costs of setting up programmes and running them; the fact that these programmes may reveal unmet needs; and inadequate matching of care and follow-up with the degree of need. The latter can be technically difficult, particularly where there is only limited clinical or other information - such as the degree of family support -- available for this purpose.

147. Furthermore, the questionnaire reveals that comprehensive evaluations of targeted programmes -including economic net costs and benefits -- are virtually non-existent for the countries covered. While this reflects generic difficulties in conducting comprehensive evaluations of the cost-effectiveness of care delivery programmes (see section 3.2), policy makers may need to intensify their efforts of evaluation by looking at the impact of existing policies and regulations that prevent more patient-centred care delivery from spreading. This should involve efforts to re-structure care delivery by ensuring better targeting of chronically ill and by creating a "user-friendly" environment for providers and patients to build on any positive impacts of targeted programmes such as disease and case management. This in turn requires broader, system-wide approaches to improve care coordination.

\section{System-wide approaches to improving care coordination}

148. In this context, the report highlights four key areas for policy consideration;

- A first involves the need for better patient information and systems permitting its transfer between providers and across institutional boundaries;

- A second concern is whether ambulatory care - and primary care in particular - has the capacity to respond to emerging patient needs. Key elements in this context are whether scope-of-practice rules for health professionals are flexible enough and whether overall resources in the ambulatory and long-term care sector are adequate.

- A third set of issues involves how coordination can best be organised and whether payment arrangements for providers can help encourage the desired coordination and cooperation among providers; 
- A final area concerns breaking down barriers between care "silos" through increased integration of care.

149. Questionnaire results suggest that all of these four key areas are critical for achieving improvements care coordination and in overall health-care system performance. But the wide variation in the starting positions of individual countries implies that the precise mix of policies will necessarily differ across countries.

\section{Better collection and transmission of information is needed}

150. Information dissemination and transfer is a key and pervasive issue in most survey countries. It concerns both the availability of medical records of individual patients and information on provider performance. The collation and dissemination of information is a cornerstone to building better care coordination policies and ICT systems appear to hold enormous promise as a vehicle for helping to improve health system performance: the organisation of referrals would be facilitated and the appropriateness of care received enhanced if patient information is accurate and available on a timely basis. In addition, dissemination of information on care is needed to ensure better system-wide governance - e.g. by ministries or insurers -- over quality and efficiency.

151. Questionnaire replies suggest that the need for better information flows is the most widely debated care-coordination issue. At the same time, information on medical records and patient needs is "often" shared among providers in only half of the countries. The penetration of ICT to date appears to have been relatively modest, despite increased government efforts in this area and significantly improved technology. On the basis of the OECD questionnaire, scarcely 15 percent of countries consider that providers are "often" equipped with IT and only about one third "often" have patient files in electronic format. Doctors may have also resisted ICT to avoid being "micro-managed" by payers or governments, who, as well, are likely to harvest a good part of any potential efficiency gains. Transmission of information on quality of care is infrequent (12 percent of countries), very likely reflecting the fact that many countries do not yet collect information on quality at the practitioner level.

152. Despite this increased interest from policy makers and reduced resistance from patient and consumer groups (who remain concerned about confidentiality issues), ITC systems can be expensive, requiring heavy up-front investment and non-negligible operating and maintenance costs. Governments and insurers are often reluctant to fund such programmes in a context of already large health budgets, the more so as the benefits are likely to accrue only in the medium- to long-term. Thus, those responsible for health policy will need to identify areas where the marginal benefits from increased information transfer are highest and where benefits are likely to balance the costs.

\section{Build adequate capacity in care settings outside acute hospital care.}

153. Most countries have experienced a shift in the supply of care from an inpatient to an outpatient environment as technology has allowed more individuals to be cared for in ambulatory environments. Indeed, the case for disease or case management and other such programmes is that they offer to transfer the focus of care from, high-cost hospitalisation to lower-cost ambulatory settings. However, to achieve this without a fall in quality and effectiveness requires adequate resourcing of ambulatory care providers and for information systems which will satisfactorily substitute for the better information flows that hospitals (in principle) can provide. Data from a limited number of countries suggest that the share of total health-care spending absorbed by ambulatory care providers has not substantially increased over the last decade. Thus, policy-makers may need to reassess whether the balance of financial resources going to the various care sectors is appropriate to meet the change in relative demands in each sector. Such assessments would need, of course, to be taken in conjunction with an analysis of the appropriateness of existing models of ambulatory-care provision and the payment of ambulatory-care providers. 
154. Despite significant variation in the number of doctors per capita, the questionnaire suggests that, in general, coordination of care is not limited by the supply of health-care professionals. However, a majority of countries noted that restrictions on the scope of professional activities of non-medical care providers (e.g. nurses) limit their capacity to undertake care-coordination activities. Cost-effectiveness may be enhanced if new classifications of medical workers were proposed whose job it is to undertake such tasks. This is particularly necessary for elderly or chronically ill patients, those in long-term care environments and those in transitions from one segment of care to another. A European study found that the management of patients at transitions to long-term care was facilitated if the care models had included a clear statement that coordination/integration is a task on its own, with respective skills and methods, i.e. "coordination as a profession" (Leichsenring et al. 2004). In this context, the promotion of a "shared culture" in teams has been found to mitigate some of the resistance of medical providers towards multidisciplinary work (Coxon et al., 2004). Thus, profiles of health-care professionals and, in particular, of medical professionals involved in coordinating care need to be adapted to the multifaceted challenge of "curing" and "caring" for chronically ill patients.

\section{Better ambulatory-care models for better care coordination are needed}

155. In practice, referral patterns show that most countries appear to channel, in one way or another, the entry of patients into the health-care system via the primary care provider. Questionnaire replies of most countries indicate that access to specialist care - either in an ambulatory or inpatient environment - is normally associated with a primary-care referral. Thus, there is some presumption that the primary carer is possibly best placed to undertake this coordinating task, even though the questionnaire replies also suggest that the role of the primary care provider weakens as patients move - as their illness dictates -- to progressively "higher" levels of care. This, in turn, may require encouraging multidisciplinary teams to be involved and, in this context, attention needs to be paid to whether GPs have the capacity or willingness to take on this task.

156. A first set of issues in this context concerns the nomination of care coordinators and the incentives to encourage greater coordination. For countries wishing to follow the path of building on existing care structures, a care coordinator with an appropriate professional profile would need to be identified. The questionnaire results suggest that this is often not done. For most countries, the primary care provider is the person usually presumed to provide coordination. But there is no necessary reason why coordination of care should always be at the primary care level. Indeed, the recent French reforms permit specialists to be named as family doctors who will act as care coordinators. One potential concern in this area is whether primary-care doctors have the necessary skills to operate as care coordinator, especially in countries where there has been no tradition for treating general medicine as a specialisation in its own right.

157. In addition, there are a wide range of primary care models to choose from among respondent countries, some of which may be better able to provide more coordinated and integrated services than others. In general, institutional arrangements where primary care providers operate in solo practices and are paid for on a fee-for service basis may be the least conducive to meeting new chronic-care needs. This partly reflects the fact that in many systems doctors are not be remunerated for services of counselling, education and guidance. This contrasts with, for example, the approach in England where there is a progressive move to multi-doctor practices running practice teams, providing scope for a wider range of services that are better adapted to meeting patient needs on a coordinated basis. Similarly, the "Chronic Care Model" or the "Advanced Medical Home" concept (Bodenheimer et al., 2002, Wagner et al., 2001, American College of Physicians, 2006), are widely discussed approaches in the United States. These approaches are specifically focused on reorganising and reorienting physician practice towards systematic efforts to improve quality of care for the chronically ill. 
158. The performance of these models will strongly depend on contractual relations between the providers and payers. Contracts need to be widened to specifically include services that enhance care coordination and, in this context, payment arrangements should be adjusted to align incentives appropriately. In particular, "soft skills" relating to counselling and guidance need to be acquired and remunerated. The analysis of questionnaire replies in Chapter 2 suggests that perceived problems of care coordination are possibly less marked in countries that use mixed payment systems suggesting that countries may need to modify the contractual terms of current remuneration schemes to encourage the willingness and capacity of professionals to provide coordinated service delivery.

159. Selective contracting by the primary carer with other providers is another way to enhance care coordination through alternative remuneration arrangements. The extension of the purchasing role of primary-care physicians to a wide range of services in the United Kingdom provides the primary-care doctor with greater capacity to ensure access to care and oversee care episodes. It also ensures that the practice reaps a large part of the financial benefits from good oversight of patients - for example, they benefit directly from lower unplanned hospital stays. However, for this to work the number of available providers must be large enough to make the health-care market contestable. Such systems will also need to guard against under-spending or ignoring patients needs and preferences by physicians (Dusheiko et al., 2007).

\section{Make care more patient-centred through greater integration of provision}

160. As stressed earlier in this report, health-care systems in responding countries are often characterised by strong administrative separation of care provision into "silos" operating on different budgets. Such problems are compounded by governance arrangements which place the responsibility for different sectors of care at different levels of government - for example, long-term care is often the responsibility of local governments in many countries. This can lead to a focus on maximising budgets for individual sectors or institutions therein rather than evaluating how overall health-care systems can provide care most efficiently and effectively. Attempts to shift costs from one sector to another can also result. From the patient's perspective, such situations make it more difficult to achieve patient-centred care and better clinical integration.

161. Integrated models of care - which bring together specialities and services under one roof or within one institution or organisation -- are also becoming more frequent. Integration has the potential to transform complex and fragmented systems of health and social care so that they are more "patientfriendly". However, full integration may not always be appropriate and can be resisted by professionals fearful of losing their professional autonomy (Leutz,1999) In practice, countries have many different approaches to achieving greater integration involving many other health-care professionals than doctors (Leichsenring, et al., 2004).

162. In the United States, some of the large HMOs appear to be successful in providing bettercoordinated care for the chronically ill, something that is probably facilitated by the provision of integrated care within a single organisation. A wide range of collaborative - but less integrated -- arrangements between providers are also emerging, but they are only partly aimed at better clinical integration (e.g. ICOs) (Mechanic, 2004). The introduction of integrated care contracts in Germany is increasing incentives to improve active purchasing across health-care settings. Primary-care clinics - for example in Spain and some of the Nordic countries - are also better adapted to providing coordinated-care services, while the reemergence of polyclinics in Germany and the networking models in France ("reseaux et filières") provide examples of other alternatives.

163. Efforts to improve performance and to maintain quality of care outside hospitals probably require policies leading to better integration in the area of long-term care, where medical and social care are often 
intimately linked. Demands for long-term care are set to rise. Lengthening lifetimes combined with increased prevalence of chronic conditions may place greater pressure on capacity both in institutional and in ambulatory care.

164. In this context, creating the conditions for better clinical integration is particularly important and requires careful attention. Reform programmes need to ensure that care integration is not blocked by professional resistance that may be linked - for example - to lack of mutual esteem and recognition between providers at the primary and long-term care levels. Attention also needs to be given to the effects of possible interactions between payment arrangements across different sectors - e.g. where prospective case-based payments lead to increased (unnecessary) hospital activity even if there is capacity to provide this service more cost effectively in the ambulatory care sector. Such problems could be tackled by giving the ambulatory care providers a stronger role of oversight in the system, for example by giving them a stronger purchasing function for care from outside the practice (e.g. primary-care practice commissioning in England). More importantly, improved care for the chronically ill may result from the pooling of resources between the health and social sectors for specific tasks - for example for staff, such as care coordinators, case mangers or transition managers (Coleman, 2003) who can help coordinate care and act as a bridge between sectors.

165. In sum, this report has pointed to a number of reform areas which may increase the capacity of health-care systems to respond to new needs and these will require more detailed examination in the future. Concern over care coordination is likely to intensify as the importance of chronic disease increases. Countries have already begun to respond. The form of these policies has often reflected the particular difficulties and institutions specific to individual countries. As noted, disease or case management programmes are one approach to improving care coordination. These policies appear to provide scope for improving quality of care, although their capacity to achieve cost savings remains unclear. This may reflect the fact that, in many cases, programmes have not been followed over long enough periods. Better evaluation is needed about which policies appear to work best and in which set of circumstances.

166. More comprehensive efforts to improve care coordination require a mix of policies that go beyond disease management. Care management at transitions to long-term care or better integration of care within individual provider institutions are two of the many possible examples. These approaches need to address the continuing issue of fragmentation of health-care delivery and require payers and providers across care sectors to engage in making care more patient-centred with a focus on multi-disciplinary care. For this to happen, new care delivery models and payment schemes need to be developed and evaluated. Progress in assessing the impact of policies also requires better oversight by payers backed up by information systems and regular reporting of measures of performance. 


\section{BIBLIOGRAPHY}

AARP (2006), European Leadership Study: Long-Term Care 2006, European experience with long-term care, October.

American Academy of Pediatrics (2005), "Care coordination in the medical home: Integrating health and related systems of care for children with special health-care needs", Pediatrics, Vol. 116/5

American College of Physicians (2006), The Advanced Medical Home: A Patient-Centered, Physician Guided Model for Health Care, Policy monograph http://www.acponline.org/hpp/adv med.pdf

Amhof, R. (2006), "Die elektronische Gesundheitskarte": Bekanntheit, Einstellungen und Akzeptanz, gesundheitsmonitor 4/2006, Ein Newsletter der Bertelsmann Stiftung, Guetersloh.

Anderson, G. et al. (2006), "Health care spending and use of information technology in OECD Countries", Health Affairs, Vol. 25:3.

Andreyeva T., et al. (2007), "Obesity and health in Europeans aged 50 years and older", Public Health, doi:10.1016/j.puhe.2006.11.016

Arrow, K. (1963), "Uncertainty and the welfare economics of medical care", American Economic Review, Vol. 53, pp. 941-973.

Asch, S.M. et al. (2006), "Who is at greatest risk for receiving poor-quality health care?", New England Journal of Medicine, Vol. 354(11), pp. 1147-1156.

Audet, M-M. et al. (2004), "Information technologies: when will they make it into physicians' black bags?", Medscape General Medicine, 7 December.

Beaulieu, N.D. et al. (2003), The business case for Diabetes Disease Management at two Managed Care Organizations: A case study of HealthPartners and Independent Health Associations. The Commonwealth Fund, New York, April.

Berenson. R.A. et al. (2006), "Hospital-Physician Relations: Cooperation, Competition, or separation?" Health Affairs, Web Exclusive, 5. December.

Bodenheimer, T. et al. (2002), "Improving primary care for patients with chronic illness", Journal of the American Medical Association, Vol. 288(15), pp. 1775-1779.

Boerma, Wienke G.W., (2003), "Profiles of General Practice in Europe, An international study of variation in the tasks of general practitioners", NIVEL, The Netherlands.

Boerma, Wienke G.W. (2006), "Coordination and integration in European primary care", in Saltman, Richard B., Ana Rico and Wienke G.W. Boerma (eds.) Primary Care in the Driver's Seat? Organizational Reform in European Primary Care. Open University Press, England. 
Borges Da Silva, G. and Borges Da Silva, R. (2005), «La gestion integrée des soins: l'experience de Kaiser permanente et de Veterans health administration, aux USA », Revue Medicale de l'Assurance Maladie, Vol. 36 No. 4, pp. 23-335

Brantes, F. de and J.A. Camillus (2007), "Evidence-informed case rates: a new health care payment model", The Commonwealth Fund, April.

Brekke, K.R. et al. (2007), "Gatekeeping in heath care”, Journal of Health Economics, Vol. 26, pp. 149170.

Breslow, L. (2005), "The organization of personal health services", The Milbank Quarterly, Vol. 83, No. 4. pp. 759-77.

Broemeling, A.M. et al. (2005), "Chronic conditions and co morbidity among residents of British Columbia", Centre for Health Services and Policy Research, Vancouver, UBC.

Burns, L.R. and M.V. Pauly (2002), "Integrated delivery networks: a detour on the road to integrated health care?", Health Affairs, Vol. 21(4), pp. 128-143.

Busse, R. and A. Riesberg (2004), Health Care Systems in Transition: Germany, Copenhagen, WHO Regional Office for Europe on behalf of the European Observatory on Health Systems and Policies.

Calnan, M. et al. (2006), "The challenge of coordination: the role primary care professionals in promoting integration across the interface" in Saltman, Richard B., Ana Rico and Wienke G. W. Boerma (eds.), Primary Care in the Driver's Seat? Organizational Reform in European Primary Care, Open University Press, Bristol.

Casalino, L. (2005), "Disease management and the organisation of physician practice", Journal of the American Medical Association, Vol. 293:4.

Casalino, L. et al. (2003), "External incentives, Information technology, and organized Processes to Improve Health Care Quality for Patients with chronic diseases", Journal of the American Medical Association, 22-29 January, Vol. 289, No. 4.

Chodosh, J. et al. (2005), "Meta analysis: chronic disease self-management programmes for older adults", Annals of Internal Medicine, 143:6.

Coleman, E.A. (2003), "Falling through the cracks: challenges and opportunities for improving transitional care for persons with continuous complex care needs", Journal of the American Geriatric Society, Vol. 51(4), pp. 549-555.

Congressional Budget Office (CBO) (2005), High-Cost Medicare Beneficiaries, Washington DC, http://www.cbo.gov/showdoc.cfm?index $=6332 \&$ sequence $=0$

Cortese, D. and R. Smoldt (2006), "Taking steps toward integration”, Health Affairs, Web Exclusive, 5. December 2005.

Courtenay, M. and A. Maynard (2006), "Debate: nurse prescribing", Eurohealth, 12:1. 
Coxon, K. et al. (2004), "Inter-professional working and integrated care organizations" in Billings, J. and K. Leichsenring (eds.) Long-Term Care in Integrating Health and Social Care Services for Older Persons, Evidence from Nine European Countries, European Centre, Vienna. Ashgate.

Davis, K. (2007), "Paying for Care Episodes and Care Coordination", New England Journal of Medicine, 15 ,

Department of Health (DoH) (2004), Improving Chronic Disease Management, HMSO http://www.dh.gov.uk/en/Publicationsandstatistics/Publications/PublicationsPolicyAndGuidance/D H_4075214

Department of Health (DoH) (2005), Supporting People with Long-term conditions, HMSO, London.

Department of Health (DoH) (2006a), Our health, our Care, our Say: Making it Happen, HMSO, London.

Department of Health (DOH) (2006b), Our health, our Care, our Say: New Direction for Community Services, HMSO London.

Dijkstra, R. et al. (2005), "Patient-centred and professional-directed implementation strategies for diabetes guidelines: a cluster randomised trial-based cost-effectiveness analysis", Diabetic Medicine, 23.

Docteur, E. and H. Oxley (2003), "Health Care Systems: Lessons from the Reform Experience", OECD Health Working Papers, No. 9.

Dusheiko, M. et al. (2006) "The effect of financial incentives on gate-keeping doctors: evidence from a natural experiment", Journal of Health Economics, Vol. 25, pp. 449-478.

Dusheiko, M. et al. (2007) "The impact of budgets for gatekeeping physicians on patient satisfaction: Evidence from fundholding", Journal of Health Economics, Vol. 26, pp. 742-762.

Esterman, A. and D. Ben-Tovim (2002), "The Australian coordinated care trials: success or failure?", Medical Journal of Australia, 177:9

Feachem, R. et al. (2002), "Getting more for their dollar: a comparison of the NHS with California's Kaiser Permanente", British Medical Journal, 2002; 324.

Fireman, B. et al. (2004), "Can disease management reduce health-care costs by improving quality", Health Affairs, Vol. 23: 6.

Gauthier, A. et al. (2006), "Towards High Performing Health Systems", Commonwealth Fund: http://www.cmwf.org/usr_doc/Gauthier_highperformance_909.pdf

Gertler, P. and T. Simcoe (2006), "Disease Management", Mimeo

Ginsburg, P.B. and J.M. Grossman (2005), "When the price isn't right: How inadvertent payment incentives drive medical care", Health Affairs Web Exclusive W5- 376-384, 9 August.

Godfrey, M. et al. (2003), "The situation in England" in A. van Raak et al., Integrated care in Europe: Description and Comparison of Integrated Care in Six EU Countries. Maarssen: Elsevier Gezondheidszorg. 
Goetzel, R.Z. et al. (2005), "Return on Investment in Disease Management: A Review, Health Care Financing Review, Summer Vol”. 26(4), pp. 1-19.

Göhler. A. et al. (2006), "A systematic meta-analysis of the efficacy and heterogeneity of disease management programmes in congestive heart failure", Journal of Cardiac Failure, Vol. 12:7.

Goldman, D. et al. (2005), "The value of elderly disease prevention", Forum for Health Economics and Policy.

Gonseth, J. et al. (2004), "The effectiveness of disease management programmes in reducing hospital readmission in older patients with heart failure: a systematic review and meta-analysis of published reports", European Heart journal, Vol. 25.

Goroll, A.H. et al. (2007), "Fundamental reform of payment for adult primary care: comprehensive payment for comprehensive care", Journal of General Internal Medicine, Vol. 22: 3, pp. 410-15.

Gosden, T. et al. (1999), "How should we pay doctors? A systematic review of salary payments and their effect on doctor behavior", Quarterly Journal of Medicine, Vol. 92, pp. 47-55.

Greiner, W. (2005), "Health economic evaluation of disease management programmes, The German Example", European Journal of Health Economics; Vol: 50, pp. 191-196.

Gress, S. et al. (2006), "Financial incentives for disease management programmes and integrated care in German social health insurance." Health Policy. Vol. 78, pp. 295-305.

Gross, D.L. et al. (2004), "The Growing Pains of Integrated Health Care for the Elderly: Lessons from the Expansion of PACE". The Milbank Quarterly, Vol. 82, No.2, pp. 257-2.

Gruen, J. (1999), "The physician and the Internet: observer or participant", MDCompute, Vol. 16:6.

Grytten, J. and R. Sorensen (2007), "Primary physician services - List size and primary physicians' service production". Journal of Health Economics Vol. 26: 721-741.

Ham, C. (2006), "Creative destruction in the NHS", British Medical Journal, Vol. 332, pp. 984-985, April.

Hartmann, L. et al. (2006), "Access to regular health care in Europe in Reforms and regulations of health care systems", Revue française des affairs sociales, Paris, avril-september.

Hecke, T. and M. Erzberger (2005), "Continuous case management of a Germany statutory health insurance", Health Care Financing Review, 27:1.

Howe, R. (2005), The Disease Manager's Handbook, Jones and Bartlett Publishers.

Hutt, R. et al. (2004), "Case managing long-term conditions: what impact does it have in the treatment of older people" King's Fund.

IGAS (2006), "Améliorer la prise en charge des malades chronique: les enseignements des experiences étrangères de "disease management", Paris (rapport presenté par Pierre Louis Bras, Gilles Duhamel et Etienne Grass.)

International Diabetes Federation (2006), Diabetes Atlas, Third Edition, International Diabetes Federation. 
Iversen, T. and H. Luras (2000), "The effect of capitation on GP's referral decisions", Health Economics Vol. 9, pp. 199-210.

Joumard, I. and W. Suyker (2002),"Enhancing the effectiveness of public expenditure in Norway", Economics Department Working Papers No. 343.

Joyce, G.F., et al. (2005), "The lifetime burden of chronic disease among the elderly", Health Affairs, Vol. 24 Suppl. 2, pp. W5R 18-29.

Karlson, M. (2007) "Quality incentives for GPs in a regulated market”, Journal of Health Economics, Vol. 26, pp. 699-720.

King's Fund (2006), "Our health our care, our say. A new direction for community services: briefing", www.kingsfund.org.uk/publications/briefings/our_health_our.html

Kirchner, H. (2005), "Moderne Versorgungskonzepte - Was wurde bei den Disease-ManagementProgrammen erreicht?" Z Kardiol 94: Suppl 4 IV-IV/11.

Klein, R. (2006), “The Troubled Transformation of Britain's National Health Service”, New England Journal of Medicine, Vol. 355; 4: pp. 409-415.

Kletke, P. et al. (1996), "Current trends in physicians' practice arrangements. From owners to employees", Journal of the American Medical Association, Vol:276(7), pp. 555-60.

Kohn, L.T. et al. (2000), To Err is Human: Building a Safer Health System", Washington DC, National Academy Press.

Kottkair, S. et al. (2005), "Germany's disease management program: Improving outcomes in congestive heart failure", Health Care Financing Review, 27:1.

Krause, D. (2005), "Economic effectiveness of disease management programs: a meta analysis", Disease Management, 8:2.

Lafortune, G. and G. Balestat (2007), "Trends in Severe disability among elderly people: Assessing the evidence in 12 OECD countries", OECD Health Working Papers, No. 26.

Lankshear, A. et al. (2005), "Nursing challenges: are changes in the nursing role and skill mix improving patient care?", Heath Policy Matters, 10.

Le Roi, S. et al. (2006), "The quality of chronic disease care in US community centers", Health Affairs, Vol: 25:6.

Leichsenring, K. et al. (2004), "Moments of Truth. An Overview of Pathways to Integration and Better Quality" in Billings, J. and K. Leichsenring Long-Term Care in Integrating Health and Social Care Services for Older Persons, Evidence from Nine European Countries, European Centre, Vienna. Ashgate.

Leutz, W.M. (1999), "Five Laws for Integrating Medical and Social Services: Lessons form the United States and the United Kingdom”, The Milbank Quarterly, Vol. 77, No. 1999.

Leutz, W.N. et al. (1994), "Integrating Acute and Long-Term Care”, Health Affairs, pp. 58-74. 
Light, D. and M. Dixon, (2004), "Making the NHS more like Kaiser Permanente", British Medical Journal, Vol. 328: 763-765.

Liljas, B. and A. Lahdensuo (1997), "Is Asthma self-management cost effective?", Patient Education and Counseling, 32: S97-104.

Lloyd, J. and S. Wait (2005), "Integrated care: a guide to policy makers", Paper based on presentations to the 2005 European Social Network Conference, Edinborough.

Mackenbach, J. (2005), "Health and Health Care" in Börsch-Supan, A., A. Brugiavini, H. Jürges, J Mackenbach, J. Siegrist and G. Weber (eds.), Health, Ageing and Retirement in Europe - First Results from the Survey of Health, Ageing and Retirement in Europe. Mannheim: MEA, 2005.

Mcinnes, K. et al. (2006), "General practitioners' use of computers for prescribing and electronic health records: results from a national survey", Medical Journal of Australia. Vol. 185: pp. 88-91.

Mechanic, D. (2004), "The rise and fall of managed care", Journal of Health and Social Behavior, Vol. 45 (Suppl), pp. 76-86.

MEDPAC (2006), Report to Congress: Increasing the Value of Medicare, June.

Mukamel D. B. et al. (2006), " Team Performance and Risk-Adjusted Health Outcomes in the Program of All-Inclusive Care for the Elderly (PACE)", The Gerontologist Vol. 46, No.2, 227-237

National Public Health Service for Wales (2005), "A profile of long-term and chronic conditions in Wales", National Assembly for Wales.

Naylor, M.D. et al. (1999), "Comprehensive discharge planning and home follow-up of hospitalized elders: a randomized clinical trial". JAMA, Vol. 281: 613-620

Norris, S. et al. (2002), "The effectiveness of disease and case Management for people with diabetes: a systematic review", American Journal of Preventive Medicine, 22(4S):15-38.

O’Donnell, C.A. (2000), "Variation in GP referral rates: what can we learn from the literature?" Family Practice 17:6, pp. 462-471.

Ofman, J. et al. (2004), "Does disease management improve clinical and economic outcomes in patients with chronic disease? A systematic review", American Journal of Medicine, Vol. 117.

Oliveira Martens, M. J. and C. De La Maisonneuve (2006), "The Drivers of Public Expenditure on Health and Long-Term Care: an Integrated Approach", OECD Economic Studies, No. 42.

Oliver, A. (2006a) "Developing Practice-Based Commissioning". Health Policy Monitor, October 2006. Available at http://www.hpm.org/survey/uk/a8/2

Oliver, A. (2006b) "Integrating community health and social care". Health Policy Monitor, April 2006. Available at http://www.hpm.org/survey/uk/a7/3

Oliver, A. (2007a) "The Veterans Health Administration: An American Success Story?" The Milbank Quarterly, Vo. 85, No.1, 2007 pp.5-35 
Oliver, A. (2007b), "Developments in practice-based commissioning". Health Policy Monitor, April 2007. Available at http://www.hpm.org/survey/uk/a9/1.

Organisation for Economic Cooperation and Development (2007), "Improving the efficiency of health care spending: selected disaggregated analyses", ECO/CPE/WP1(2007)3.

Organisation for Economic Cooperation and Development (OECD) (2006a), Draft work plan in the area of information and communication technologies in the health sector", DELSA/HEA/ICT(2007)1

Organisation for Economic Cooperation and Development (OECD) (2006b), "Incentives for implementation of information, communication technologies in the health sector", DEELSA/HEA(2006)8.

Organisation for Economic Cooperation and Development (OECD) (2006c), OECD Reviews of Health Care Systems: Switzerland. Paris: OECD;

Organisation for Economic Cooperation and Development(OECD) (2005a), Health at a Glance, Paris

Organisation for Economic Cooperation and Development, (2005b) Long-Term Care of Older People, Paris

Ouwens, M. et al. (2005), Integrated care programmes for chronically ill patients: a review of systematic reviews," Journal for Quality in Health Care, 17:2.

Perrin J.M. et. al (2007) The Increase of Childhood Chronic Conditions in the United States, JAMA, Vol. 297, No. 24, pp 2755-2759.

Pham, H., D. et al. (2007), "Care patterns in Medicare and their implications for pay for performance", New England Journal of Medicine, Vol. 356; pp 1130-9, 11, 15 March.

Pittman, P.M. et al. (2006), "Care management in Germany and the US: an expanded laboratory." Health Care Financing Review, Vol. 27(1): pp. 9-19.

Protti, D. (2007), “Canada's EHR journey: pragmatic progress and promising potential”, Powerpoint presentation to OECD Expert Meeting on ICT in the Health Sector, Paris, 13 April.

Qualitaetssicherungsbericht (2005), Disease Management Programme in Nordhein

Reed, et al. (2005), "A literature search to explore integrated care for older people" International Journal of Integrated Care, Vol. 5.

Rittenhouse, D. et al. (2004), "Physician organization and care management in California: from cottage to Kaiser", Health Affaires. Vol. 23:6.

Robinson, J. and J. Yeagan, "Medical Management After Managed Care", Health Affairs Web Exclusive, May 19, 2004.

Rostenthal, M.B. et al. (2005), "Early experience with pay-for-performance", Journal of the American Medical Association Vol. 294 No. 14, 12 October 12.

Rundall, T.G. et al. (2002), "As good as it gets? Chronic care management in nine leading US physician organisations", British Medical Journal, Vol. 325(7370), pp. 958-961. 
Schmidt, U. (2006), Health policy and health economics in Germany, Speech on the occasion of the visit of the German Minister for Health to the United States of America, Minneapolis, June 5, 2006.

Available at http://www.cges.umn.edu/outreach/ullaschmidt.htm.

Schoen, C. et al. (2005), "Taking The Pulse Of Health Care Systems: Experiences Of Patients With Health Problems In Six Countries", Health Affairs, Web Exclusive, November 3.

Schoen, C. et al. (2006a), "On The Front Lines of Care: Primary Care Doctors' Office Systems, Experiences, and Views in Seven Countries", Health Affairs Web Exclusive :w555-w571, 2 November.

Schoen, C. et al. (2006b), "The 2006 international health policy survey of primary care physicians in seven countries", Commonwealth Fund, November.

Shekelle, P.G. et al. (2006) "Costs and Benefits of Health Information Technology. Evidence Report/Technology Assessment No. 132. Southern California Evidence-based Practice Center Agency for Healthcare Research and Quality, AHRQ Publication No. 06-E006.

Short, A. et al. (2003), "Disease management: a leap of faith to lower-cost, higher quality health care", Center for Studying Health System Change, Washington, D.C.

Shortell, St.M. et al. (2004), "The Role of Perceived Team Effectivness in Improving Chronic Illness Care", Medical Care, Vol. 42, No. 11, pp: 1040-1047).

Sibbald, B. et al. (2006) "Changing Task Profils", in Saltman, Richard, B., Ana Rico and Wienke G. W. Boerma (Eds.) Primary care in the driver's seat? Organizational reform in European primary care. Open University Press, England.

Siciliani, L. and Jeremy Hurst (2004),"Tackling excessive waiting times for elective surgery", in OECD, Towards High Performing Health Systems: Policy Studies, Paris

Siderov, J. et al. (2002), "Does Diabetes Disease Management Save Money and Improve Outcomes?", Diabetes Care, 25: 4 APRIL.

Sommers, L.S. et al. (2000) "Physician, Nurse, and Social Worker Collaboration in Primary Care for Chronically Ill Seniors". Archives of Internal Medicine, Vol. 160, pp 1825-1832

Statistics Canada (1999), Towards a Healthy Future: Second Report on the Health of Canadians, Ottawa.

Stroetmann, K. et al. (2006), Study on Economic Impact of E-health: Developing an Evidence-based Context-adaptive Method of Evaluation for E-Health, E-Health Impact ; WWW.Ehealth-Impact.org

Thorpe, K.E. and D.H. Howard (2006), "The rise in spending among medicare beneficiaries: the role of chronic disease prevalence and changes in treatment intensity", Health Affairs, 22 August.

Trisolini, M. et al. (2006), "Medicare physician group practices: innovations in quality and efficiency", The Commonweath Fund.

Van de Ven, W.P.M.M. et al. (2003), "Risk adjustment and risk selection in on the sickness fund insurance market for five European countries" Health Policy, 65: pp. 75-98. 
Villagra, V. and T. Ahmed (2004), "Effectiveness of a disease management program for patients with diabetes", Health Affairs, 23:4.

Wagner, E.H. et al. (2001), "Improving chronic illness care: translating evidence into action", Health Affairs (Millwood), Vol. 20(6), pp. 64-78.

Weinberg, D.B. et al. (2007), Beyond our walls: impact of Patient and Provider Coordination across the Continuum on Outcomes for Surgical Patients, HSR: Health Services Research 42:1, Part I, February .

Wolff, J.L. et.al. (2002), "Prevalence, expenditure and complications of multiple chronic conditions in the elderly", Archives of Internal Medicine, Vol. 162, pp 2269-2276.

Wolff, J.L. and C. Boult (2005), "Moving beyond round pegs and square holes: restructuring Medicare to improve chronic care", Annals of Internal Medicine, Vol. 143(6), pp. 439-445.

World Health Organisation, Europe (WHO) (2003), "Are disease management programmes (DMPs) effective in improving quality of care for people with chronic conditions?", Copenhagen. Available at http://www.euro.who.int/document/e82974.pdf 


\section{OECD HEALTH WORKING PAPERS}

Papers in this series can be found on the OECD website: www.oecd.org/els/health/workingpapers

No. 29 HEALTH CARE QUALITY INDICATORS PROJECT 2006 DATA COLLECTION UPDATE REPORT (2007) Sandra Garcia-Armesto, Maria Luisa Gil Lapetra, Lihan Wei, Edward Kelley and the Members of the HCQI Expert Group

No. 28 PHARMACEUTICAL PRICING AND REIMBURSEMENT POLICIES IN SWEDEN (2007) Pierre Moïse and Elizabeth Docteur

No. 27 PHARMACEUTICAL PRICING AND REIMBURSEMENT POLICIES IN SWITZERLAND (2007) Valérie Paris and Elizabeth Docteur

No. 26 TRENDS IN SEVERE DISABILITY AMONG ELDERLY PEOPLE: ASSESSING THE EVIDENCE IN 12 OECD COUNTRIES AND THE FUTURE IMPLICATIONS (2007) Gaétan Lafortune, Gaëlle Balestat, and the Disability Study Expert Group Members

No. 25 PHARMACEUTICAL PRICING AND REIMBURSEMENT POLICIES IN MEXICO (2007) Pierre Moïse and Elizabeth Docteur

No. 24 PHARMACEUTICAL PRICING AND REIMBURSEMENT POLICIES IN CANADA (2006) Valérie Paris and Elizabeth Docteur

No. 23 HEALTH CARE QUALITY INDICATORS PROJECT, CONCEPTUAL FRAMEWORK PAPER (2006) Edward Kelley and Jeremy Hurst

No. 22 HEALTH CARE QUALITY INDICATORS PROJECT, INITIAL INDICATORS REPORT (2006) Soeren Mattke, Edward Kelley, Peter Scherer, Jeremy Hurst, Maria Luisa Gil Lapetra and the HCQI Expert Group Members

No. 21 THE SUPPLY OF PHYSICIANS IN OECD COUNTRIES (2006) Steven Simeons and Jeremy Hurst

No. 20 CONSUMER DIRECTION AND CHOICE IN LONG-TERM CARE FOR OLDER PERSONS, INCLUDING PAYMENTS FOR INFORMAL CARE: HOW CAN IT HELP IMPROVE CARE OUTCOMES, EMPLOYMENT AND FISCAL SUSTAINABILITY? (2005) Jens Lundsgaard

No. 19 TACKLING NURSE SHORTAGES IN OECD COUNTRIES (2004) Steven Simoens, Mike Villeneuve and Jeremy Hurst

No. 18 PRIVATE HEALTH INSURANCE IN THE NETHERLANDS. A CASE STUDY (2004) Nicole Tapay and Francesca Colombo

No. 17 SKILL-MIX AND POLICY CHANGE IN THE HEALTH WORKFORCE: NURSES IN ADVANCED ROLES (2004) James Buchan and Lynn Calman

No. 16 SHA-BASED NATIONAL HEALTH ACCOUNTS IN THIRTEEN OECD COUNTRIES: A COMPARATIVE ANALYSIS (2004) Eva Orosz and David Morgan

No. 15 PRIVATE HEALTH INSURANCE IN OECD COUNTRIES: THE BENEFITS AND COSTS FOR INDIVIDUALS AND HEALTH SYSTEMS (2004) Francesca Colombo and Nicole Tapay

No. 14 INCOME-RELATED INEQUALITY IN THE USE OF MEDICAL CARE IN 21 OECD COUNTRIES (2004) Eddy van Doorslaer, Cristina Masseria and the OECD Health Equity Research Group

No. 13 DEMENTIA CARE IN 9 OECD COUNTRIES: A COMPARATIVE ANALYSIS (2004) Pierre Moise, Michael Schwarzinger, Myung-Yong Um and the Dementia Experts' Group

No. 12 PRIVATE HEALTH INSURANCE IN FRANCE (2004) Thomas C. Buchmueller and Agnes Couffinhal

No. 11 THE SLOVAK HEALTH INSURANCE SYSTEM AND THE POTENTIAL ROLE FOR PRIVATE HEALTH INSURANCE: POLICY CHALLENGES (2004) Francesca Colombo and Nicole Tapay 
No. 10 PRIVATE HEALTH INSURANCE IN IRELAND. A CASE STUDY (2004) Francesca Colombo and Nicole Tapay

No. 9 HEALTH CARE SYSTEMS: LESSONS FROM THE REFORM EXPERIENCE (2003) Elizabeth Docteur and Howard Oxley

No. 8 PRIVATE HEALTH INSURANCE IN AUSTRALIA. A CASE STUDY (2003) Francesca Colombo and Nicole Tapay

No. 7 EXPLAINING WAITING-TIMES VARIATIONS FOR ELECTIVE SURGERY ACROSS OECD COUNTRIES (2003) Luigi Siciliani and Jeremy Hurst

No. 6 TACKLING EXCESSIVE WAITING TIMES FOR ELECTIVE SURGERY: A COMPARISON OF POLICIES IN 12 OECD COUNTRIES (2003) Jeremy Hurst and Luigi Siciliani

No. 5 STROKE CARE IN OECD COUNTRIES: A COMPARISON OF TREATMENT, COSTS AND OUTCOMES IN 17 COUNTRIES (2003) Lynelle Moon, Pierre Moïse, Stéphane Jacobzone and the ARD-Stroke Experts Group

No. 4 SURVEY OF PHARMACOECONOMIC ASSESSMENT ACTIVITY IN ELEVEN COUNTRIES (2003) Michael Dickson, Jeremy Hurst and Stéphane Jacobzone

No. 3 OECD STUDY OF CROSS-NATIONAL DIFFERENCES IN THE TREATMENT, COSTS AND OUTCOMES OF ISCHAEMIC HEART DISEASE (2003) Pierre Moise, Stéphane Jacobzone and the ARD-IHD Experts Group

No. 2 INVESTMENT IN POPULATION HEALTH IN FIVE OECD COUNTRIES (2003) Jan Bennett

No. 1 PHARMACEUTICAL USE AND EXPENDITURE FOR CARDIOVASCULAR DISEASE AND STROKE: A STUDY OF 12 OECD COUNTRIES (2003) Michael Dickson and Stéphane Jacobzone

\section{RECENT RELATED OECD PUBLICATIONS:}

OECD HEALTH DATA 2006 (2006), available in English, French, German, Italian, Russian and Spanish on CDROM (Windows 98/2000/NT/Me/XP); online version features these languages, plus Japanese

OECD REVIEWS OF HEALTH SYSTEMS - SWITZERLAND (2006)

OECD REVIEWS OF HEALTH SYSTEMS - FINLAND (2005)

HEALTH AT A GLANCE - OECD INDICATORS 2005 (2005), published biennially

LONG-TERM CARE FOR OLDER PEOPLE (2005), OECD Health Project series

HEALTH TECHNOLOGIES AND DECISION MAKING (2005), OECD Health Project series

OECD REVIEWS OF HEALTH SYSTEMS - MEXICO (2005)

TOWARDS HIGH-PERFORMING HEALTH SYSTEMS (2004), OECD Health Project series

TOWARDS HIGH-PERFORMING HEALTH SYSTEMS: POLICY STUDIES (2004), OECD Health Project series

PRIVATE HEALTH INSURANCE IN OECD COUNTRIES (2004), OECD Health Project series A DISEASE-BASED COMPARISON OF HEALTH SYSTEMS: What is Best and at What Cost? (2003)

For a full list, consult the OECD On-Line Bookstore at www.oecd.org, or write for a free written catalogue to the following address:

OECD Publications Service

2, rue André-Pascal, 75775 PARIS CEDEX 16

or to the OECD Distributor in your country 